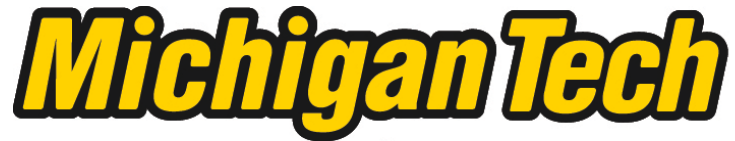 \\ Michigan Technological University Create the Future Digital Commons @ Michigan Tech
}

Dissertations, Master's Theses and Master's Reports - Open

Dissertations, Master's Theses and Master's

Reports

2009

Water and sanitation accessibility and the health of rural

Ugandans

Jonathan E. Mellor

Michigan Technological University

Follow this and additional works at: https://digitalcommons.mtu.edu/etds

Part of the Civil and Environmental Engineering Commons

Copyright 2009 Jonathan E. Mellor

\section{Recommended Citation}

Mellor, Jonathan E., "Water and sanitation accessibility and the health of rural Ugandans", Master's Thesis, Michigan Technological University, 2009.

https://doi.org/10.37099/mtu.dc.etds/259

Follow this and additional works at: https://digitalcommons.mtu.edu/etds

3 Part of the Civil and Environmental Engineering Commons 


\title{
Water and Sanitation Accessibility and the Health of Rural Ugandans
}

\author{
by \\ Jonathan E. Mellor
}

\begin{abstract}
A Thesis
Submitted in Partial Fulfillment of the Requirements

For the Degree of

Master of Science in Environmental Engineering
\end{abstract}

Michigan Technological University 2009

Copyright (c) Jonathan E. Mellor 2009 
This thesis, "Water and Sanitation Accessibility and the Health of Rural Ugandans," is hereby approved in partial fulfillment of the requirements for the degree of MASTER OF SCIENCE in the field of Environmental Engineering.

\section{DEPARTMENT:}

Civil and Environmental Engineering Master's International Program

Signatures:

Thesis Advisor

Dr. David Watkins

Department Chair

Dr. William M. Bulleit

Date 


\section{Contents}

1 Background 1

1.1 Introduction . . . . . . . . . . . . . . . . . . . 1

1.2 Geography and Natural Resources . . . . . . . . . . . . . . 2

1.3 Cultural and Linguistics . . . . . . . . . . . . . . . 4

1.4 Rakai District and Kalisizo Town Council . . . . . . . . . . . . . . 4

1.5 NGO Information . . . . . . . . . . . . . . . . . 6

1.6 Water Usage Survey NGO and Regional Information . . . . . . . 7

2 Literature Review $\quad 8$

2.1 Water Accessibility and Usage . . . . . . . . . . . . . . 8

2.2 Causes and Prevention Strategies of Diarrheal Disease . . . . . . . . 12

3 Research Methods $\quad 20$

3.1 Water Usage Survey Methodology . . . . . . . . . . . . . . . . 21

3.1.1 Survey Questions ... . . . . . . . . . . . . . . . 21

3.1.2 Limitations and Possible Sources of Error of Survey . . . . . . 23

3.1 .3 Statistical Analysis . . . . . . . . . . . . . . 25

3.2 What Works Best in Diarrheal Disease Prevention Methods . . . . . . 26

3.2.1 Project Goals and Objectives . . . . . . . . . . . . 27

3.2 .2 Community Selection Criteria . . . . . . . . . . . . 28

3.2 .3 Survey . . . . . . . . . . . . . . . . . . . . . . 30

3.2 .4 Health Survey Questions in Detail . . . . . . . . . . . . 32

3.2.5 Water and Sanitation Questions in Detail . . . . . . . . . . 34

4 Implementation of WWB Improvements $\quad 37$

4.1 Initial Community Selection . . . . . . . . . . . . . . . 38

4.2 Needs Assessment . . . . . . . . . . . . . . . . . . . . . . . . . . 38

4.3 Intervention Selection . . . . . . . . . . . . . . . . . 40

4.4 Community Planning Meetings . . . . . . . . . . . . . . . 42

4.5 Shallow Wells . . . . . . . . . . . . . . . . . . . 43

4.6 Latrines Improvement Campaign $\ldots \ldots \ldots \ldots$ 
CONTENTS

4.7 Water Filters . . . . . . . . . . . . . . . . 51

4.8 Hand-Washing Stations . . . . . . . . . . . . . . . . 55

4.9 Health Education . . . . . . . . . . . . . . . . . 58

4.10 Playing Catch Model of Development . . . . . . . . . . . . . 60

4.11 Sustainability Plan . . . . . . . . . . . . . . . . . 62

5 Water Accessibility Verses Usage Results 63

5.1 Water Usage Trends . . . . . . . . . . . . . . . . . . 63

5.1.1 Average and Variation of Household Usage . . . . . . . . . . . 64

5.1.2 Water Protection Status . . . . . . . . . . . . . . . 66

5.1.3 Distance and Time to Source and Seasonal Variation . . . . . 70

5.1.4 Time vs Distance Measurements . . . . . . . . . . . . . . . 73

5.2 Collection Effort and Usage Correlation . . . . . . . . . . . . 75

5.2.1 Simple Correlations and Histograms . . . . . . . . . . . . . . 75

5.2 .2 Regional Variation . . . . . . . . . . . . . . . . . 79

5.2.3 Pearson's Coefficient of Correlation . . . . . . . . . . . . . . 80

5.2 .4 Analysis of Variance . . . . . . . . . . . . . . . . . . . 82

5.2.5 Synthesis and Conclusions of Usage and Effort Correlations . . 82

5.3 Socioeconomic Indicators . . . . . . . . . . . . . . . . . . 85

5.3.1 Household Size . . . . . . . . . . . . . . . . 85

5.3.2 Housing Type and Educational Level . . . . . . . . . . . . . 87

6 WWB Results 93

6.1 Diarrhea Rates for Varying Water and Sanitation Practices from Baseline Data . . . . . . . . . . . . . . . . . . . . . . . . . 94

6.1.1 Baseline Survey Analysis . . . . . . . . . . . . . . . . . . 97

6.2 Measures of Program Effectiveness . . . . . . . . . . . . . . . . 98

6.2.1 Water Filters . . . . . . . . . . . . . . . . . . . 99

6.2.2 Water Source . . . . . . . . . . . . . . . . 99

6.2.3 Control ........................ 101

6.2.4 Latrines . . . . . . . . . . . . . . . . . . . . . . . . 102

6.2.5 Hand-Washing . . . . . . . . . . . . . . . . . . 103

6.2.6 All Interventions . . . . . . . . . . . . . . . . . . . . . 104

6.3 Prevalence of Diarrheal Disease . . . . . . . . . . . . . . . . 105

6.4 ANOVA Analysis of Results . . . . . . . . . . . . . . . . . . 108

6.5 Synthesis and Conclusion of WWB . . . . . . . . . . . . . 110

$\begin{array}{lll}7 \text { Conclusion } & 113\end{array}$

A Rainwater-Harvesting Baseline Survey $\quad 121$

$\begin{array}{ll}\text { B What Works Best Survey } & 127\end{array}$ 
C Community Contract $\quad 130$

D Copyright 133 


\section{List of Figures}

1.1 A map of Uganda. Rakai District, where the What Works Best project was carried out and was the location of the author's residence is located in south central Uganda bordering both Tanzania and Lake Victoria. The water usage survey was also carried out in Bugiri District in the far east and Kamwenge District in the west. Map reproduced from USAID publication $[26] . \ldots \ldots \ldots \ldots . \ldots . \ldots$

2.1 The F-diagram showing the basic mechanisms by which feces from one individual, passes through the environment, and into the mouth of another. Barriers that inhibit this process can be classified as primary and secondary barriers. . . . . . . . . . . . . . . .

2.2 Relative risk of the various intervention strategies as compiled by Fewtrell et al.[11]. It is clear from this diagram that there is a significant amount of variability in the data, but, overall water hygiene and sanitation interventions are more effective than other interventions. Figure reprinted from Lancet Infectious Diseases. Volume 5. Edition 1. By Fewtrell, L., R. B. Kaufmann, D. Kay, W. Enanoria, L. Haller, and J. M. Colford. Water, Sanitation, and Hygiene Interventions to Reduce Diarrhoea in Less Developed Countries: A Systematic Review and Meta-Analysis. Page 48. (2005). with permission from Elsevier. Copyright permission reprinted in Appendix D. Available online at: http://www.sciencedirect.com/science/journal/14733099. . . . . . 
2.3 A comparison of the Fewtrell study [11] with previous studies by Esrey et al. [9] and Curtis and Cairncross [4]. (a) All studies and (b) rigorous studies. Shows some consistency, but large overall error bars make absolute comparisons difficult. Figure reprinted from Lancet Infectious Diseases. Volume 5. Edition 1. By Fewtrell, L., R. B. Kaufmann, D. Kay, W. Enanoria, L. Haller, and J. M. Colford. Water, Sanitation, and Hygiene Interventions to Reduce Diarrhoea in Less Developed Countries: A Systematic Review and Meta-Analysis. Page 50. (2005). with permission from Elsevier. Copyright permission reprinted in Appendix D. Available online at: http://www.sciencedirect.com/ science/journal/14733099. . . . . . . . . . . . . . . .

4.1 (a) Digging was easy at first, (b) but became increasingly difficult when once we reached the water table. A gas-power water pump made it much easier. . . . . . . . . . . . . . . . . . . . . .

4.2 Lowering the extremely heavy culverts was a tricky task. To accomplish it we attached three ropes to each culvert and lowered them down slowly with the help of about 20 community members. . . . . . . . .

4.3 (a) Reinforcement bars being cast into the pump-top along with water inlet and outlet pipes, a maintenance hatch and bolts to secure the pump itself. (b) The finished pump-top. . . . . . . . . . . . . .

4.4 (a) Washers that are tied to the rope and act to push the water up the PVC piping. (b) The pump base that is lowered down to the bottom of the well. As the operator turns the crank, the rope with washers tied to it enters the widened PVC pipe on the right. The washers then collect water in the open section of this block (not visible) before returning up through the PVC pipe on the left. . . . . . . . . . .

4.5 (a) The water is pushed up by washers tied to the rope up the grey PVC pipe to the right. It then returns down to the left. (b) The pump is operated by turning the crank as seen here. The flow was so good that we added a second outlet. . . . . . . . . . . . . . . . . . 48

4.6 (a) The pump is enclosed in its housing. (b) A finished pump! . . . . 49

4.7 Local handyman trained by COWESER staff members repairing the shallow well at Nsambya. . . . . . . . . . . . . . . . .

4.8 My brother David operating the finished well at Manyama after the outlets had been encased in brick, lowered to a suitable height and split into two doubling the rate at which jerrycans can be filled. . . . . . . 50

4.9 The latrine mould with two pieces of rebar tied to the wire mesh. . . 51

4.10 (a) The wire mesh being placed on the top of half the concrete mixture. (b) Two finished slabs. . . . . . . . . . . . . . . . . . 52

4.11 Daniel from CAWST describing filter operation and maintenance to the community. . . . . . . . . . . . . . . . . 
4.12 (a) Making sure the sand is of the correct depth. (b) Measuring the flow rate of the filters. . . . . . . . . . . . . . . . . .

4.13 (a) Conducting a tippy-tap training at Kikungwe Village. (b) The LC1 from Kalagala showing the hand-washing committee how to make the holes. . . . . . . . . . . . . . . . . .

4.14 The music dance and drama in Kikungwe Village focusing on handwashing also highlighted improved hygiene and sanitation. A total of 150 people attended shows in both Manyama and Kikungwe. . . . .

4.15 A calendar promoting hand-washing with soap. The title at the top says "Wash Your Hand with Soap For better Health." The four pictures depict the four times we want people to washing their hands with soap: after using the toilet, before eating, before breast-feeding and after cleaning a baby's bottom. . . . . . . . . . . . . . . . .

4.16 The water committee at Manyama Village played an integral part in the "play catch' model used there. . . . . . . . . . . . . . . . . .

5.1 A histogram of per capita usage in liters per person per day. It is clear from this plot that the vast majority of people are getting less that their requisite 20 liters per person per day.

$5.2 \mathrm{~A}$ box and whisker plot showing the Per Capita Waster Usage in all three districts. The lower quartile is represented by the bottom of the box while the upper quartile the top. The mean and median values are also shown. The whiskers represent the minimum and maximum valid values. This plot shows that there is a wide variation in values that are skewed towards the upper end. . . . . . . . . . . . .

5.3 A pie chart of water sources used by the population. Most people, $82 \%$ $(\mathrm{n}=1,267)$ get their water from unprotected sources, while minorities get their water from springs $8 \%(n=123)$, boreholes $6 \%(n=91)$ or shallow wells $3 \%(\mathrm{n}=45) . \ldots \ldots \ldots$

5.4 A histogram comparing the wet versus dry seasons travel distances to water sources. The data indicates that only $52.4 \%(n=814)$ of households are located within 1 kilometer of a water source during the wet season while only $29.2 \%(\mathrm{n}=456)$ are as close during the dry season.

5.5 A box and whisker plot showing the distance to water sources in all three districts. The lower quartile is represented by the bottom of the box while the upper quartile the top. The mean and median values are also shown. The whiskers represent the minimum and maximum valid values. These plots show a definite increase in the distance the research participants had to travel to get water during the dry season. Both also indicate a large spread in the data and are both weighted towards the lower values. . . . . . . . . . . . . . . . . . 
5.6 A box and whisker plot showing the time to water sources in all three districts. The lower quartile is represented by the bottom of the box while the upper quartile the top. The mean and median values are also shown. The whiskers represent the minimum and maximum valid values. These plots show a definite increase in the distance the research participants had to travel to get water during the dry season. The dry season values also indicate a larger spread in the data as some, but not all, families have to travel farther during the drier parts of year. Both skewed towards the lower values as indicated by the median values.

5.7 A box and whisker plot giving the range of the collection time for the three service levels during the wet season. The lower quartile is represented by the bottom of the box while the upper quartile the top. The mean and median values are also shown. The whiskers represent the minimum and maximum valid values. Although there is a significant amount of variability in the data, the trend of increasing collection times with increasing distances indicates that the distance and time measurements are highly correlated. . . . . . . . . . . . . . . .

5.8 Per capita usage as a function of water source distance for both wet (red points) and dry seasons (blue points) in all districts surveyed. The red and blue lines are the best-fit lines whose slopes indicate that usage is not correlated with collection distances or times. . . . . . . . . . .

5.9 Per capita usage as a function of collection time for both wet (red points) and dry seasons (blue points) in all districts surveyed. The red and blue lines are the best-fit lines whose slope and small $R^{2}$ value indicates a very weak correlation. . . . . . . . . . . .

5.10 A histogram of per capita usage and distance to source. It is clear from this data that the water used per capita does not change significantly for any of the service levels. It is also relevant to note that the quantities of water typical for different service levels defined by [15] and shown in yellow are not consistent with this data. [Note that the Accepted Literature value for distances less than $0.1 \mathrm{~km}$ is far off the chart.] Error bars indicate the $95 \%$ confidence intervals. . . . . . . . .

5.11 Per capita usage across the three districts is remarkably consistent. The large error bars for those with 'Intermediate Access' are due to the low number of respondents in that category. The other levels of access are statistically equal across all districts. . . . . . . . . .

5.12 This graph indicates a relatively strong $\left(R^{2}=.09\right)$ correlation between per capita usage and household size. As indicated by the best-fit line, larger households use significantly less water per capita. . . . . . . 
5.13 This plot seems to indicate that those with great socioeconomic status, i.e. with a higher education or better dwelling tend to use more water per capita. However, large errors bars make it difficult to draw any definitive conclusions. . . . . . . . . . . . . . .

5.14 A comparison of housing types for different levels of schooling. The percentage of those having a permanent house clearly rises with educational levels, while the percentage of those having a semi-permanent house clearly decreases. Those having a hut decrease slightly, but the trend is not as well-defined. . . . . . . . . . . . . . . . .

5.15 A comparison of per capita usage as a function of school and housing type. When the level of schooling is held constant the per capita usage does increase from those living in a hut to those living in a permanent house, but the data for those living in a semi-permanent does not as clearly follow that trend. However, the large error bars make this correlation weak. . . . . . . . . . . . . . . .

6.1 Diarrhea rates for poor and satisfactory performers for seven different water and sanitation practices. Most of the improvements show no statistically significant differences in rates. However, those who reported treating their water and those who reported to use a clean water container have reduced diarrhea rates. . . . . . . . . . . . .

6.23 -Month average diarrheal rate displayed before and after interventions in all six communities. The lower quartile is represented by the bottom of the box while the upper quartile the top. The mean and median values are also shown. The whiskers represent the minimum and maximum valid values. The post-intervention mean and medians values were lower in all six cases. The plot highlights the high variability in the data. . . . . . . . . . . . . . . . . .

6.3 Adjusted absolute risk reduction for the five different communities. Household water filters showed the greatest reduction in diarrheal disease followed by the introduction of a water source and all interventions. Both hand-washing and latrine improvement had lower reductions. 109 


\section{List of Tables}

2.1 Service levels as defined by Howard and Bartram[15]. . . . . . . . . .

2.2 Percent reduction for different water and sanitation interventions as reported from Esrey in two different meta-analyses [7, 9]. The earlier data indicated that water quality and availability was the most effective while later studies indicated that sanitation interventions were more effective. . . . . . . . . . . . . . . . . .

2.3 Definitions of a,b,c and d used in relative risk calculations. Where each represents the number of survey subjects in each category. . . . . .

3.1 Interviewer bias was a significant source of error in the baseline survey. Although the surveyors did not all survey the same villages, the large spread is higher than one would expect given the random nature of their assigned survey area. . . . . . . . . . . . . . . . . .

4.1 Latrine coverage and total community size for each of the five communities. This data indicates that all communities had nearly the same latrine initial latrine coverage. Note that this is the total community size and each includes many households that were not included in the interventions or surveys since they did not have children under five. .

4.2 Water source used by respondents in the five communities before intervention. Lusaka, Nsambya and Manyama all had similar safe water coverages while Kikungwe and Kalagala had lower initial coverages. All numbers indicate the percentage of respondents who indicated that they use a particular type of source. . . . . . . . . . . . .

4.3 Percentage of households in each community with a given household type. This data indicates that all of the communities have an approximately equal socioeconomic status. . . . . . . . . . . . . . . 41

4.4 The interventions planned for each community. . . . . . . . . . . . . . 42 
5.1 Pearson's Coefficients, Coefficients of Determination and the test statistic $t$ calculated for the wet and dry season distance and time measurements. The universally small Pearson's Coefficients, Coefficients of Determination and $t$ values all indicate essentially no correlation within the three service levels or the range as a whole. This was true not only for the data as it was divided here, but also with all other divisions investigated by the author, but not included in this report. . . . . .

5.2 ANOVA analyses for both distance and time to source measurements during both seasons. In each case the data was divided into three different service categories and the variance was calculated both between and within the sample ranges. . . . . . . . . . . . . .

5.3 Summary Table of ANOVA F Values for all seasons. $F$ as calculated from tables is more than $F$ calculated from the data in all cases implying that there is no significant difference (95\% confidence levels) in the data means. . . . . . . . . . . . . . . . . . . .

5.4 Howard and Bartram service levels in terms of distance and time. The data indicates that, contrary to Howard and Bartram's assumptions, that the amount of water used per capita is not strongly correlated with the service levels they define. In addition, there is no obvious drop off for very long collection times as predicted by those authors. .

6.1 Diarrheal Disease Rates compared across source protection status and reported treatment techniques. It is clear from this data that treatment practices are far more important than water source protection status.

6.2 Pre and post-intervention reported data for reported cases of diarrhea

6.3 Absolute risk reduction, adjusted rate reduction, sample size, relative risk and adjusted relative risk for all six communities. As the adjusted risk reduction indicates, those households that received water filters experienced the greatest risk reduction, while the latrine intervention turned out to be the least effective intervention strategy. Likewise the latrines also had the lowest relative risk reduction associated with their use. . . . . . . . . . . . . . . . . .

6.4 A reprinting of Table 2.2 with the adjusted absolute risk reduction values from this survey compared to the older work or Esrey. Multiple interventions and water availability interventions are both consistent with the current results. However data for the other interventions is not.111 


\begin{abstract}
The lack of access to sufficient water and sanitation facilities is one of the largest hindrances towards the sustainable development of the poorest 2.2 billion people in the world. Rural Uganda is one of the areas where such inaccessibility is seriously hampering their efforts at development. Many rural Ugandans must travel several kilometers to fetch adequate water and many still do not have adequate sanitation facilities. Such poor access to clean water forces Ugandans to spend an inordinate amount of time and energy collecting water - time and energy that could be used for more useful endeavors. Furthermore, the difficulty in getting water means that people use less water than they need to for optimal health and well-being. Access to other sanitation facilities can also have a large impact, particularly on the health of young children and the elderly whose immune systems are less than optimal. Hand-washing, presence of a sanitary latrine, general household cleanliness, maintenance of the safe water chain and the households' knowledge about and adherence to sound sanitation practices may be as important as access to clean water sources.

This report investigates these problems using the results from two different studies. It first looks into how access to water affects peoples' use of it. In particular it investigates how much water households use as a function of perceived effort to fetch it. Operationally, this was accomplished by surveying nearly 1,500 residents in three different districts around Uganda about their water usage and the time and distance they must travel to fetch it. The study found that there is no statistically significant correlation between a family's water usage and the perceived effort they must put forth to have to fetch it. On average, people use around 15 liters per person per day. Rural Ugandan residents apparently require a certain amount of water and will travel as far or as long as necessary to collect it.

Secondly, a study entitled "What Works Best in Diarrheal Disease Prevention?" was carried out to study the effectiveness of five different water and sanitation facilities in reducing diarrheal disease incidences amongst children under five. It did this by surveying five different communities before and after the implementation of improvements to find changes in diarrheal disease incidences amongst children under five years of age. It found that household water treatment devices provide the best means of preventing diarrheal diseases. This is likely because water often becomes contaminated before it is consumed even if it was collected from a protected source.
\end{abstract}




\section{Acknowledgements}

First of all I would like to thank Anna whose steadfast love and support through my two years abroad put an undue burden on her during her first two years of surgical residency. Secondly, I would like to thank all those people who donated generously to the What Works Best project whose support was essential to making that project a success.

Next, the prodigious work ethic of Mr. Ssenyonga Max, my Ugandan counterpart, who made the What Works Best project such a resounding success, deserves special commendation. He single-handedly navigated the political players to support our project, mobilized six different communities, kept them actively involved in the project for more than 10 months, managed the daily activities of the project, acted as both a cultural and linguistic translator between myself and the communities as well as being an invaluable support to me as we struggled to improve the lives of rural Ugandans. My Ugandan supervisor Mr. Mubiru Joseph and his organization Open Palm COWESER also supported me and my work to an utmost degree both by providing me with physical resources for my work, but also by introducing me to numerous entities that helped me be productive throughout my tenure in Kalisizo.

I would like to thank my advisor, David Watkins for his personal commitment to all the international programs at MTU and his continuous support for and interest in my work.

Lastly, my family also deserves a special thank you for giving me the fortitude to live and work so far away and their implacable encouragement for me to live my dream. 


\section{Chapter 1}

\section{Background}

\section{$1.1 \quad$ Introduction}

Access to sustainable water and sanitation facilities is one of the biggest challenges the developing world faces, as an increasing number of people inhabit those areas. In fact, the United Nations estimates that there are nearly one billion people who lack access to water facilities and nearly 2.2 billion who do not have basic sanitation worldwide. The situation in rural Uganda follows this pattern since the vast majority of the population are subsistence farmers living in rural areas far from commercial centers.

This report investigates the relationship between access to water and sanitation facilities and health improvements in rural Uganda. As such, the following sections will introduce the reader to the geographical, cultural and social factors that are necessary for understanding the context in which this research was undertaken. The primary residence of the author was in the town of Kalisizo, which is located in Rakai District 
Uganda. This was the location of the What Works Best project as well as one third of the water usage survey. Households were also surveyed in both Kamwenge and Bugiri districts in western and eastern Uganda respectively.

\subsection{Geography and Natural Resources}

Uganda is a land-locked medium-sized country of more than 32 million people located in East Africa. Although the country lacks direct access to the sea it contains four large and important lakes including Lake Victoria, Lake Albert, Lake Edward and Lake Kyoga. The location where the Nile River pours out of Lake Victoria on its 6,695 kilometer journey to Egypt is also in Uganda, near the city of Jinja. The country straddles the equator and so has a distinctly mild, tropical climate. Since much of the country lies at around 1,200 meters in altitude, daily temperatures typically vary between 15 and $30^{\circ}$ Celsius. Much of the country receives around 1.2 meters of yearly rainfall although precipitation is usually higher during the two rainy seasons [24], which typically last from October until December and March until May. Mount Elgon in the east at 4,321 meters and the snow-capped Rwenzori Mountains at 5,109 meters in the west are the highest mountains in the country. Much of the rest of the country is comprised of flat grassland or sparse woodland with some remaining tropical rain-forest patches in national parks. The country is poorly drained with numerous papyrus wetlands providing ample wildlife habitats throughout the country.

The country is an important wildlife habitat for a diverse number of different species. The national parks in western Uganda are particularly interesting as they harbor healthy populations of lions, leopards, elephants, hippopotamuses, zebras, numerous 


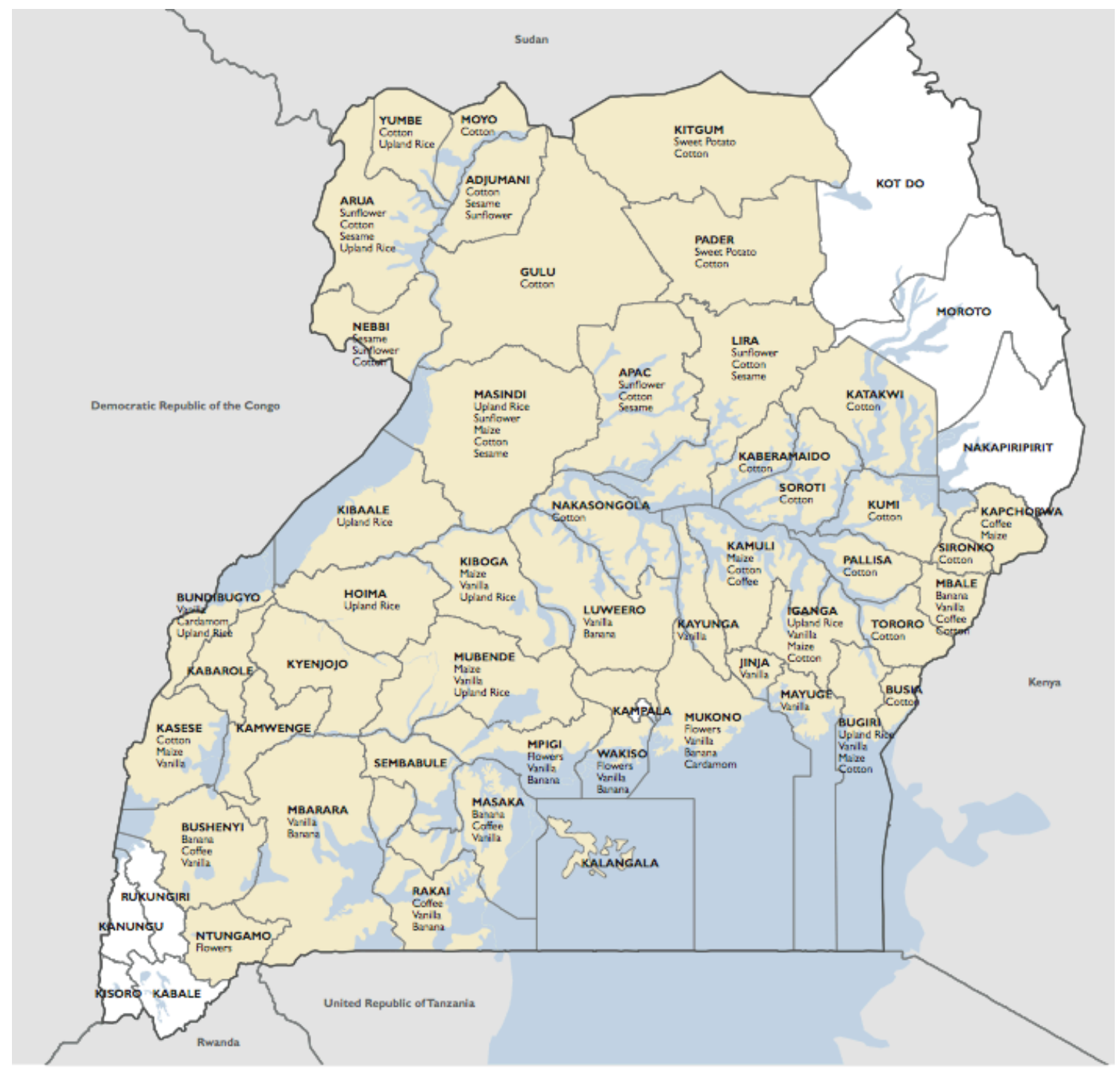

Figure 1.1: A map of Uganda. Rakai District, where the What Works Best project was carried out and was the location of the author's residence is located in south central Uganda bordering both Tanzania and Lake Victoria. The water usage survey was also carried out in Bugiri District in the far east and Kamwenge District in the west. Map reproduced from USAID publication [26]. 
antelope species, buffalo etc. They are also home to primate species including several different species of monkeys as well as baboons, chimpanzees and about half of the world's remaining mountain gorillas.

\subsection{Cultural and Linguistics}

Uganda has more than 30 different indigenous languages with an equal number of ethnic groups and two major language groups: Nilotic and Bantu. The Nilotic people mostly occupy the area north of Lake Kyoga, while the Bantu people live in the southern half. Each ethnic group has its own language and distinct culture. The traditional kingdoms which represent several of the major ethnic groups of Uganda have been restored, which, although they have no political power, constitute an important link to the cultural heritage of Uganda [22].

The largest ethnic group, the Buganda, live throughout central Uganda, comprise approximately $15 \%$ of the population and inhabit Rakai District where the author lived. In fact, their language, Luganda, is the de facto lingua franca of the southern half of the country.

\subsection{Rakai District and Kalisizo Town Council}

The work presented in this report was mostly completed around Kalisizo Town Council located in Rakai District, about $160 \mathrm{~km}$ south of Kampala along a paved road. The district, which abuts the Tanzanian border to the south and Lake Victoria to the east is 4,989 square kilometers and is comprised of over 500,000 people [23]. With an 
annual growth rate of around $3.2 \%$, overpopulation is perpetual problem [25]. The district, like much of Uganda, receives ample rainfall and is comprised of green rolling hills interspersed with numerous wetlands and little remaining forest.

About $70 \%$ of the population is subsistence farmers [26] growing staple crops such as bananas, maize, sweet potatoes and cassava. This diet is supplemented with locally grown fresh fruits like pineapples, jackfruit, mangoes and avocados as well as tomatoes and greens. Beef, chicken, beans and fish from Lake Victoria are all important sources of protein. Most families live in simple houses with either mud and waddle or brick walls.

There are also a number of lakeside fishing communities that are mostly comprised of migrant workers and larger towns that serve as important trading and commercial centers.

The district has had a troubled history. First, the Tanzanian army overran the district in the late 1970s. Later, it became one of the first regions of Africa to suffer from the AIDS pandemic. Known locally as 'slim' because of its slimming effect on the victim, AIDS was first reported in Kasensero, a fishing village near the Tanzanian border from where it quickly spread to other parts of Uganda. AIDS had a devastating effect on the district since it hits those in their 20's and 30's hardest leaving behind countless orphans and divided families.

Most of the district has a relatively high safe-water coverage (around 50\%) [14], however some of the sub-counties surveyed for this report have a very low safe water coverage (some areas have a coverage of less than 5\% [16]) and are climatically and geographically distinct from the rest of the district. Sanitation facilities vary tremendously throughout the district. Although many houses have simple pit la- 
trines, they are often poorly cared for and are therefore an obvious vector for diarrheal disease.

There are a variety of health centers, hospitals and private clinics located throughout the district, which, along with a number of NGOs, provide health services to the population. However, the number and quality of health services is far below what is necessary to maintain a healthy population.

Daily life in Uganda revolves around the large families. The fertility rate is 6.5 children per woman [25] making economic betterment difficult. Families typically live in multigenerational compounds. Education is important to Ugandans, who have free primary education and a primary school enrollment rate of $82 \%$ [25]. Secondary school is only for the elite since school fees are very expensive.

\subsection{NGO Information}

While in Uganda, the author primarily worked for Open Palm COmmunity WElfare SERvices (COWESER), an indigenous NGO based out of Kalisizo Town Council formed in 1996. The 'What Works Best in Diarrheal Disease Prevention' project was implemented primarily by that organization as well as the survey for the rainwaterharvesting project that forms the basis for the water usage survey also highlighted in this report. Its primary work is to improve the health and quality of life for those living in rural Rakai District. It has done this through a variety of different water and sanitation projects as well as anti-malaria interventions and orphan welfare projects. 


\subsection{Water Usage Survey NGO and Regional Infor- mation}

The African Development Bank, through the NETwork for Water and Sanitation in Uganda (NETWAS), funded the water usage survey analyzed for this report. In

late 2008 NETWAS identified three NGOs operating in three water-stressed areas of Uganda to be the implementing agencies. The NGOs included Uganda MUslim Rural Development Association (UMURDA) operating in the far eastern district of Bugiri, Open Palm COWESER operating in the central district of Rakai and Joint Effort to Save the Environment (JESE) operating in the western district of Kamwenge. These three districts represent three different regions of Uganda with varying languages, tribes and cultural practices. Bugiri District is in far eastern Uganda close to the Kenyan border. It is a relatively low-lying district that borders Lake Victoria to its south and contains the main highway running towards Kenya. Kamwenge District is in western Uganda in the shadow of the Rwenzori Mountains. This area is exceedingly beautiful and has a large forest national park and contains countless crater lakes.

All three districts have a similar climate with daily maximum temperatures in the low to mid 20's Celsius and two distinct rainy seasons per year lasting about three months each. 


\section{Chapter 2}

\section{Literature Review}

This report investigates the domestic use of water in rural Uganda as wells as attempting to discover the causes and solutions to the diarrheal disease rampant in much of the country. As a preliminary step in this investigation, a literature review is presented that summarizes the existing literature on these two important subjects.

\subsection{Water Accessibility and Usage}

A basic question in development work is how much water people need to sustain themselves and how does that amount of water change as access becomes easier and less time consuming. The definitive work on this subject is the paper by Howard and Bartram[15]. This document, written for the World Health Organization, discusses basic human water requirements by means of a literature review of the links between water and sanitation practices and improved health. The authors argue that although 
there are increased health benefits from increased availability of water, there is not a direct linear relationship with water quantity used. They define four service levels and argue that it is these service levels that determine the benefit and not the actual quantity of water used.

The authors go on to argue that, ideally, people need about $20 \mathrm{l} / \mathrm{p} / \mathrm{d}$, which they consider to be basic access to water and should be the baseline amount of water that development workers strive to provide. Below this level, there can be serious concerns about health and well-being. Beyond this amount communities should focus on water source protection, establishing good hygiene and sanitation as well as household treatment. Furthermore, the amount of water used for washing and bathing is very sensitive to service levels. Those who have to travel more than $1 \mathrm{~km}$ to fetch water do not use much for bathing or laundering.

The main thrust of their work is to describe water accessibility in terms of water service categories rather than an actual volume in liters. These categories are summarized in Table 2.1. In that table, they divide service levels in terms of 'No Access,' 'Basic Access,' 'Intermediate Access' and 'Optimal Access' in which people respectively use, on average 5, 20, 50 and $100 \mathrm{l} / \mathrm{p} / \mathrm{d}$ (liters per person per day). Those with 'No Access' have to travel more than $1 \mathrm{~km}$ or 30 minutes to fetch water, while those with 'Basic Access' need 5 to 30 minutes to travel $100 \mathrm{~m}$ to $1 \mathrm{~km}$. Finally, those with 'Intermediate Access' have water in or near their compound and take less than 5 minutes to collect it, while those with 'Optimal Access' have multiple taps in their homes.

Later, the authors state that major public health gains can occur in two increments. The first is to overcome lack of basic access when households barely have enough water 
for consumption much less personal hygiene. Secondly, when homes have access at the household level, their health gains are more limited, but they now have more time for activities like child-care, school or other socioeconomic activities. Finally, they state that equal attention should be paid to both water supply and sanitation and that easing access to improved sources outside the home will have limited health returns.

Another important work includes Cairncross [2] who found that, in rural Mozambique, when the length of water collection time dropped from 5 hours to 10 minutes usage increased from 4.1 to $11.1 \mathrm{l} / \mathrm{p} / \mathrm{d}$, with $70 \%$ of that additional water being used for bathing and washing clothes. More than half the time saved was spent on other, more productive household tasks.

Cairncross and Feachem [3] argue that once water collection times exceeds a few minutes the quantities of water used decrease dramatically and level out at a plateau. This plateau lasts from collection times of 5 to 30 minutes and distances of 100 meters to $1 \mathrm{~km}$. Beyond this, collection times decrease further.

A study was completed in Jinja, Uganda [27] about water usage levels for different service levels. It backs up the other works stating that households using communal water sources like springs or hand-pumps use around $15.8 \mathrm{l} / \mathrm{p} / \mathrm{d}$, while those who use communal stand-posts use around $15.5 \mathrm{l} / \mathrm{p} / \mathrm{d}$, while consumption levels increase dramatically for those who have a tap in their yard $(50 \mathrm{l} / \mathrm{p} / \mathrm{d})$ and those who have multiple connections within their home $(155 \mathrm{l} / \mathrm{p} / \mathrm{d})$.

However, Kennedy [19] contradicts the accepted literature with his study of rural Kenya where the average household uses $16.7 \mathrm{l} / \mathrm{p} / \mathrm{d}$ and that water quantity does not depend on collection times or distances, but rather users collect water to fulfill 


\begin{tabular}{|c|c|c|c|}
\hline Service Level & Access Level & Needs Met & $\begin{array}{c}\text { Level of } \\
\text { Health } \\
\text { Concern }\end{array}$ \\
\hline $\begin{array}{c}\text { No access } \\
(\text { less than } 5 \mathrm{l} / \mathrm{p} / \mathrm{d})\end{array}$ & $\begin{array}{l}\text { More than } 1 \mathrm{~km} \text { or } \\
30 \text { minutes } \\
\text { collection time }\end{array}$ & $\begin{array}{l}\text { Consumption: Not assured } \\
\text { Hygiene: Not possible } \\
\text { (unless at source) }\end{array}$ & "Very High \\
\hline $\begin{array}{c}\text { Basic access } \\
\text { (unlikely to exceed } \\
20 \mathrm{l} / \mathrm{p} / \mathrm{d} \text { ) }\end{array}$ & $\begin{array}{l}\text { Between } 100 \mathrm{~m} \\
\text { and } 1,000 \mathrm{~m} \text { or } \\
5 \text {-30 minutes } \\
\text { collection time }\end{array}$ & $\begin{array}{l}\text { Consumption: Should } \\
\text { be assured } \\
\text { Hygiene: hand-washing } \\
\text { and basic food hygiene } \\
\text { possible; laundry/bathing } \\
\text { difficult to assure unless } \\
\text { carried out at source }\end{array}$ & High \\
\hline $\begin{array}{l}\text { Intermediate access } \\
\text { (average quantity } \\
50 \mathrm{l} / \mathrm{p} / \mathrm{d} \text { ) }\end{array}$ & $\begin{array}{l}\text { Water delivered on } \\
\text { site via tap on plot } \\
\text { or within } 100 \mathrm{~m} \text { or } \\
5 \text { minutes collection } \\
\text { time }\end{array}$ & $\begin{array}{l}\text { Consumption: Assured } \\
\text { Hygiene: All basic personal } \\
\text { and food hygiene assured; } \\
\text { laundry and bathing } \\
\text { should be assured }\end{array}$ & Low \\
\hline $\begin{array}{c}\text { Optimal access } \\
\text { (average quantity } \\
100 \mathrm{l} / \mathrm{p} / \mathrm{d} \text { and above) }\end{array}$ & $\begin{array}{l}\text { Water supplied } \\
\text { through multiple } \\
\text { taps } \\
\text { continuously }\end{array}$ & $\begin{array}{l}\text { Consumption: All needs met } \\
\frac{\text { Hygiene: All needs should }}{\text { be met }}\end{array}$ & Very Low \\
\hline
\end{tabular}

Table 2.1: Service levels as defined by Howard and Bartram[15].

their needs. This data was collected via household surveys of collection times and distances. The data was verified by measuring the time it took for the author of that report to walk the same distances. He found that the respondents' estimated collection times were typically 2-5 times longer than was measured. He argues that this is likely due to fact that his measurements do not take into account the time most community members spend socializing, waiting in line and the extra effort necessary when carrying the water. 


\subsection{Causes and Prevention Strategies of Diarrheal Disease}

The causes of, and many of the prevention strategies for, diarrheal diseases in the developing world can be summarized by the F-diagram [15], reproduced in Figure 2.1. This diagram shows the different transmission routes for fecal ingestion, which is the primary cause of such disease. Halting transmission can be done via a variety of different intervention strategies, which cut off transmission at the points indicated by the short lines perpendicular to the connecting arrows. This diagram can be

divided into 'primary' prevention strategies like the use of latrines that prevent feces from getting into the environment and 'secondary' strategies like boiling water, which eliminate bacteria from already-contaminated fluids [15].

There is an abundance of current literature regarding the topics of health and sanitation interventions in the developing world and their health impacts. Most use surveys or child growth curves to determine that relationship. The literature, reviewed below, is incomplete when it comes particularly to the health benefits of communal safe water points. Some papers emphatically state that there is little impact, while others state the opposite. It is clear that there is a lot of room for future research.

Zwane et al [28] discuss what works in fighting diarrheal disease in developing countries using a variety of different sources. They found that child health intervention strategies like the provisioning of oral rehydration therapy, piped water, sanitation projects and point-of-use water treatment systems can reduce diarrheal disease by a significant amount. However, they state that older papers suggesting that communal water supplies can improve health by similar margins had methodological shortcom- 


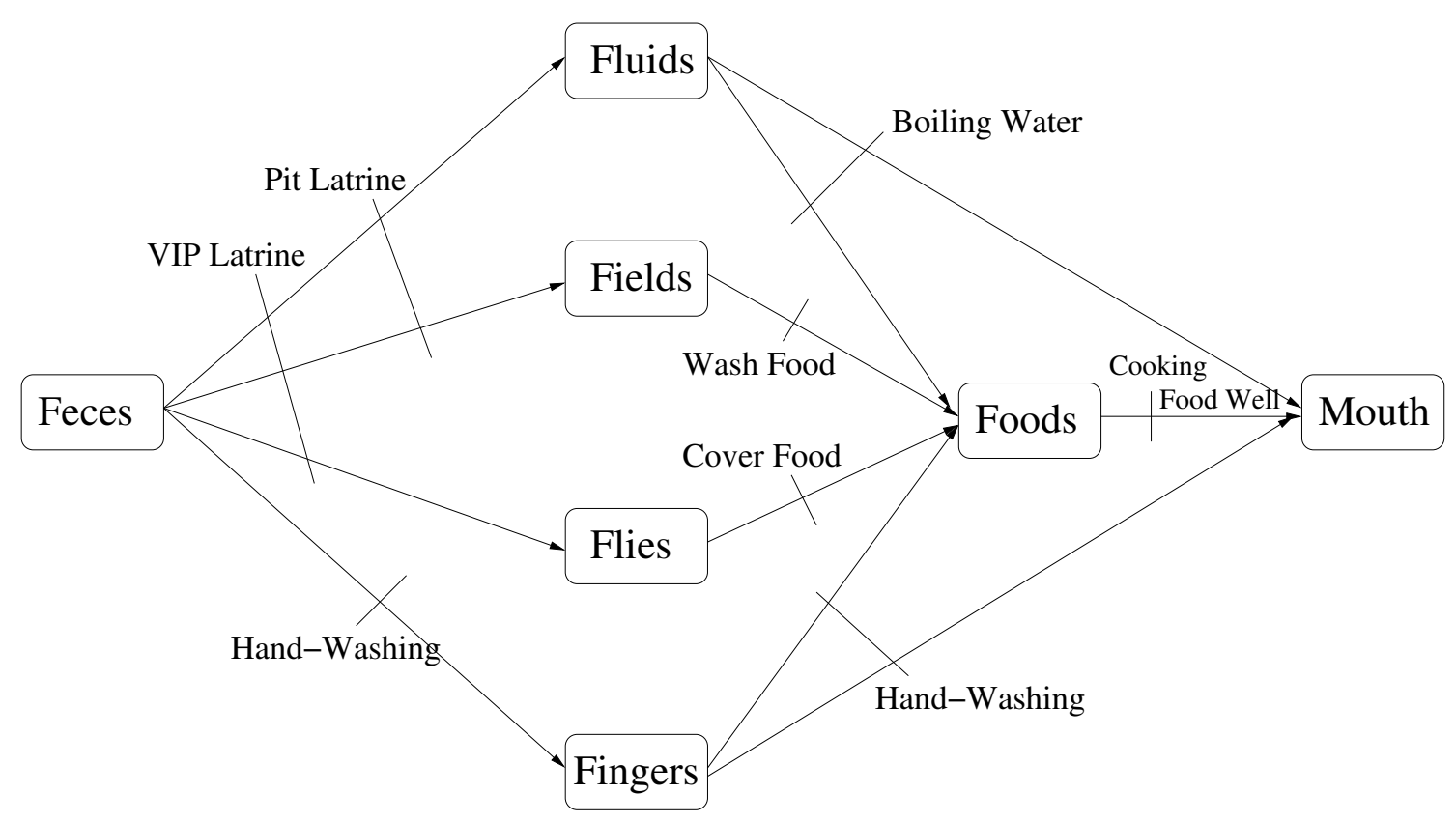

Primary Barriers

Secondary Barriers

Figure 2.1: The F-diagram showing the basic mechanisms by which feces from one individual, passes through the environment, and into the mouth of another. Barriers that inhibit this process can be classified as primary and secondary barriers. 
ings. This is particularly true when programs do not include improved sanitation or hygiene.

Curtis and Miller [6] use the example of $20^{t h}$ century America to show that large-scale improvements in water and sanitation investments can have massive impacts on child mortality. However, this sort of survey has limited relevance to the rural community water sources in the developing world.

Curtis and Cairncross [4] conduct a meta-analysis of hand-washing surveys to find that rigorous hand-washing campaigns can reduce diarrheal disease by $42-47 \%$.

Esrey and others studied the health impacts of various water and sanitation interventions. A summary of these findings is found in Table 2.2. In their earlier paper [7] they reviewed 67 studies to find that interventions focusing on water availability decreased diarrhea by more than interventions that focused on water quality improvements. Combined approaches that included water quality and availability decreased rates even further. Focusing on sanitation interventions or on interventions combining many different strategies were not as effective.

In a later paper, Esray et al [9] used 144 papers in a meta-analysis of the impacts of different water supply, sanitation and hygiene education interventions. They found that sanitation supply and hygiene education results in nearly twice the median reduction in diarrheal incidences as water quality or quantity projects. They said that interventions to improve excreta disposal and water quality produce greater impacts than improvements in water quality alone. In fact, benefits from improved water occurred only when sanitation was also improved and water was optimally provided.

Curtis [5] took a different approach and used biological reasoning to suggest that primary barriers such as safe stool disposal are more important than secondary barriers 
Table 2.2: Percent reduction for different water and sanitation interventions as reported from Esrey in two different meta-analyses [7, 9]. The earlier data indicated that water quality and availability was the most effective while later studies indicated that sanitation interventions were more effective.

\begin{tabular}{ccc}
\hline Type of Intervention & $\begin{array}{c}\text { Percent } \\
\text { Esrey et al., 1985 }\end{array}$ & $\begin{array}{c}\text { Reduction } \\
\text { Esrey et al., 1991 }\end{array}$ \\
\hline Multiple Interventions & 22 & 30 \\
Water Quality & 16 & 15 \\
Water Availability & 25 & 20 \\
Water Quality and Availability & 37 & 17 \\
Sanitation & 22 & 36 \\
Hygiene & $\mathrm{n} / \mathrm{a}$ & 33 \\
\hline
\end{tabular}

like hand-washing. Furthermore, he states that too many messages confuse people and wastes public health resources. They believe that excreta disposal should be given the highest priority.

The work of Kremer et al [20] was to conduct a large-scale spring protection program in Kenya where they protected 184 springs providing water to 1,354 households. They found that household water quality improved by $23 \%$ thereby reducing childhood diarrhea by $25 \%$. In their study they found that hygiene knowledge and latrine coverage did not further improve home water quality gains.

In 1996, Esrey [10] conducted a multi-country study to find that sanitation improvements reduce diarrhea regardless of water supply, although, water improvements do not improve health if sanitation is unimproved. Improving water and sanitation together produced the greatest gains. Water improvements had to be optimal (i.e., piped water supply) to have an effect on health and smaller improvements had no benefit. They also surmised that organisms in traditional water supplies provide protection against pathogens and that water from a protected source is often recontaminated before consumption. Finally, they state that recall data can underes- 
timate health benefits and that height and weight measurements of children provide better estimates of improved health.

The most comprehensive meta-analysis of literature was completed by Fewtrell et al. [11]. Their meta-analysis of 46 studies divided up interventions into categories such as hygiene (i.e., health education), sanitation (i.e., latrines), water supply, water quality and multiple interventions.

Their results, are summarized in Figures 2.2 and 2.3 and are reported in terms of relative risk. Relative risk is an epidemiological term used to describe the risk of a disease and how it varies with exposure to a risk factor. For the purposes of this report it is the ratio of the probability of an event occurring when an intervention is in place versus when an intervention is not in place.

$$
R R=\frac{p_{\text {intervention }}}{p_{\text {no-intervention }}}
$$

Where $p_{\text {intervention }}$ and $p_{n o-i n t e r v e n t i o n}$ represent the incidence rate of the two populations and are defined according to Table 2.3 and the following equations:

$$
p_{\text {exposed }}=\frac{a}{a+b}
$$

and

$$
p_{\text {non-exposed }}=\frac{c}{c+d}
$$

These results are highly relevant to the research carried out in this report and will be 
Table 2.3: Definitions of $a, b, c$ and $d$ used in relative risk calculations. Where each represents the number of survey subjects in each category.

\begin{tabular}{ccc}
\hline & Diarrhea Present & Diarrhea Absent \\
\hline Interventions Present & $\mathrm{a}$ & $\mathrm{b}$ \\
Interventions Absent & $\mathrm{c}$ & $\mathrm{d}$ \\
\hline
\end{tabular}

compared thoroughly in Chapter 6.

The two graphs adapted from Fewtrell [11] are shown in Figures 2.2 and 2.3. The first graph is a meta-analysis of different water and sanitation interventions in terms of relative risk. Hygiene interventions such as hand-washing and educational outreaches proved to be the more effective than water supply interventions. However, the large uncertainties make it difficult to draw any definitive conclusions. The second graph compares multiple meta-analyses including the studies of Fewtrell [11], Esrey et al. [9] and Curtis and Cairncross [4]. Likewise it indicates that interventions aimed at improving hygiene work better than water supply interventions.

Taken in totality, the relevant literature is clear that what works best is an open question; therefore this report aims to further this body of knowledge through the "What Works Best in Diarrhea Prevention" project. 


\begin{tabular}{|c|c|c|}
\hline & $\begin{array}{l}\text { Number } \\
\text { of studies }\end{array}$ & $\begin{array}{l}\text { Relative risk } \\
(95 \% \mathrm{Cl})\end{array}$ \\
\hline Hygiene & 11 & $0.63(0.52-0.77)$ \\
\hline Excluding poor quality studies & 8 & $0.55(0.40-0.75)$ \\
\hline Handwashing & 5 & $0.56(0.33-0.93)$ \\
\hline Education & 6 & $0.72(0.63-0.83)$ \\
\hline Sanitation & 2 & $0.68(0.53-0.87)$ \\
\hline Water supply & 6 & $0.75(0.62-0.91)$ \\
\hline Diarrhoea only & 4 & $1.03(0.73-1.46)$ \\
\hline Household connection & 2 & $0.90(0.43-1.93)$ \\
\hline Standpipe or community connection & 3 & $0.94(0.65-1.35)$ \\
\hline Water quality & 15 & $0.69(0.53-0.89)$ \\
\hline Source treatment only & 3 & $0.89(0.42-1.90)$ \\
\hline Household treatment only & 12 & $0.65(0.48-0.88)$ \\
\hline \multicolumn{3}{|l|}{ Household treatment } \\
\hline - excluding poor quality studies & 8 & $0.61(0.46-0.81)$ \\
\hline - rural location & 6 & $0.61(0.39-0.94)$ \\
\hline - urban/periurban locations & 5 & $0.86(0.57-1.28)$ \\
\hline - urban/periurban excluding Sathe ${ }^{35}$ & 4 & $0.74(0.65-0.85)$ \\
\hline Multiple & 5 & $0.67(0.59-0.76)$ \\
\hline
\end{tabular}

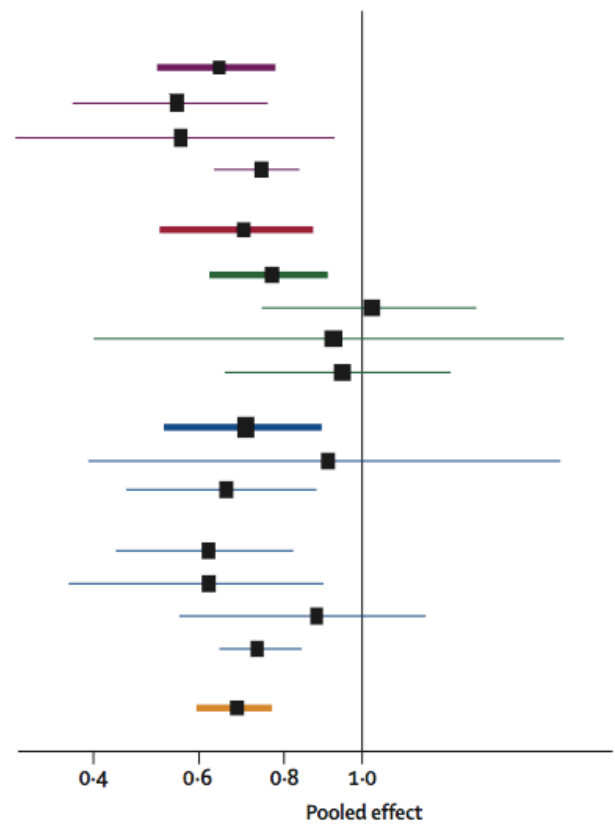

Figure 2.2: Relative risk of the various intervention strategies as compiled by Fewtrell et al.[11]. It is clear from this diagram that there is a significant amount of variability in the data, but, overall water hygiene and sanitation interventions are more effective than other interventions. Figure reprinted from Lancet Infectious Diseases. Volume 5. Edition 1. By Fewtrell, L., R. B. Kaufmann, D. Kay, W. Enanoria, L. Haller, and J. M. Colford. Water, Sanitation, and Hygiene Interventions to Reduce Diarrhoea in Less Developed Countries: A Systematic Review and Meta-Analysis. Page 48. (2005). with permission from Elsevier. Copyright permission reprinted in Appendix D. Available online at: http://www.sciencedirect.com/science/journal/14733099. 


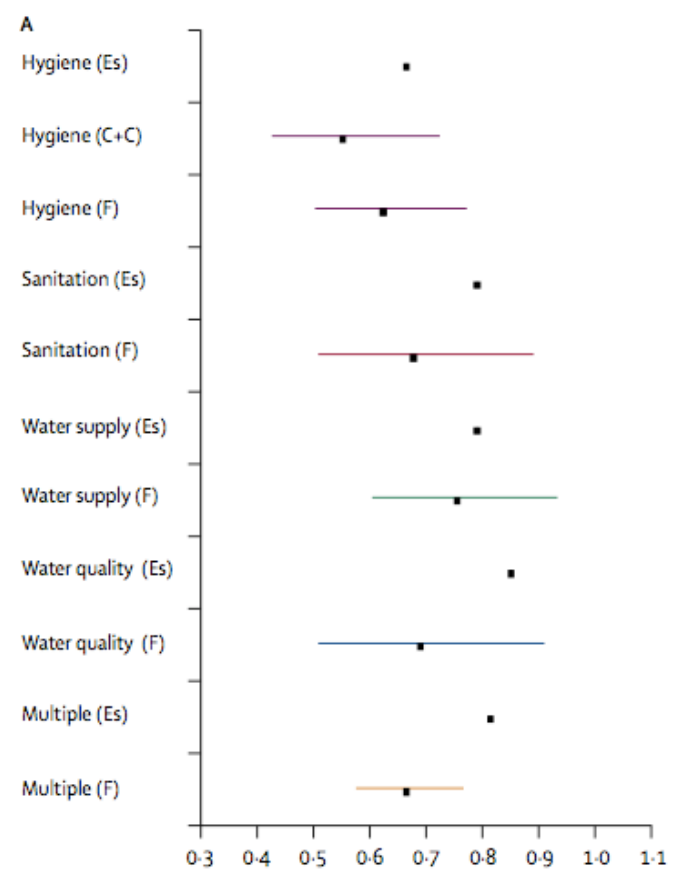

(a)

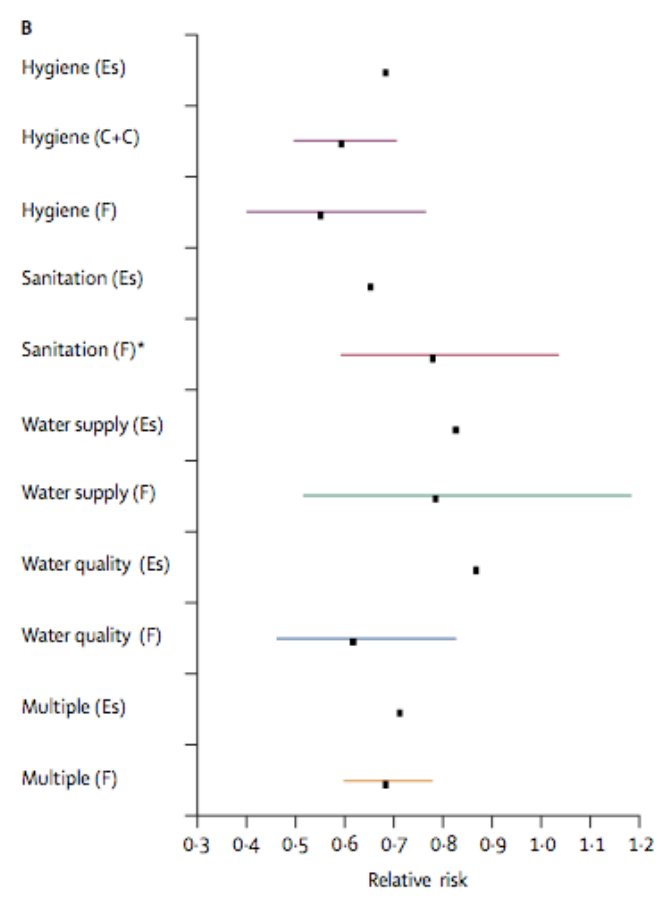

(b)

Figure 2.3: A comparison of the Fewtrell study [11] with previous studies by Esrey et al. [9] and Curtis and Cairncross [4]. (a) All studies and (b) rigorous studies. Shows some consistency, but large overall error bars make absolute comparisons difficult. Figure reprinted from Lancet Infectious Diseases. Volume 5. Edition 1. By Fewtrell, L., R. B. Kaufmann, D. Kay, W. Enanoria, L. Haller, and J. M. Colford. Water, Sanitation, and Hygiene Interventions to Reduce Diarrhoea in Less Developed Countries: A Systematic Review and Meta-Analysis. Page 50. (2005). with permission from Elsevier. Copyright permission reprinted in Appendix D. Available online at: http://www.sciencedirect.com/ science/journal/14733099. 


\section{Chapter 3}

\section{Research Methods}

The data for this report was gathered with two surveys of rural Ugandans to ascertain data regarding the correlation between water accessibility and its use as well as the causes and prevention strategies of diarrheal diseases. In the first case, the data was harvested from a survey conducted by three Ugandan NGOs as part of a rainwaterharvesting project being funded by the African Development Bank in collaboration with the Network for Water and Sanitation (NETWAS) in Uganda.

In the second instance, a research collaboration was formed between Open Palm COWESER, the Rakai Health Sciences Program and Michigan Technological University to implement five different water and sanitation improvements in five different communities around Kalisizo, Uganda. A baseline and follow-up survey of childhood diarrheal incidences was performed before and after intervention to find out how those interventions decreased incidences of diarrheal diseases. 


\subsection{Water Usage Survey Methodology}

Data for the water usage survey was harvested from a survey done by three different NGOs working in three different regions of Uganda as a baseline for a rainwaterharvesting project. The project and the baseline survey were funded by the African Development Bank in collaboration with NETWAS Uganda, the coordinating NGO. The three NGOs who carried out the survey include the Joint Effort to Save the Environment (JESE), which operates in the western Ugandan district of Kamwenge, Open Palm Community Welfare Services (COWESER) operating in the central district of Rakai and the Uganda Muslim Rural Development Association (UMURDA) operating in the eastern district of Bugiri.

\subsubsection{Survey Questions}

The survey itself, reproduced in Appendix A, was created by a NETWAS consultant in limited consultation with representative staff from the three implementing NGOs. Each of the three NGOs was tasked to conduct a baseline survey in the areas where the project was to occur. This report summarizes a total of 1,563 surveys of which 375 were done in Rakai District, 611 in Kamwenge and 577 in Bugiri. The surveys were done with door-to-door informal interviews carried out in the local language by survey assistants with the head of household or whoever was present. The data was recorded and transferred to the NETWAS office in Kampala.

For this report, information about the type of household, the number of men, women, girls, boys and disabled persons living in the home was extracted. Information on the water source used for domestic uses and drinking purposes, the distance and time to 
reach that source in both the rainy and dry seasons, the number of jerrycans collected per day and who fetches the water was also collected.

In addition, those surveyed were asked a number of questions indicative of their socioeconomic status. They were asked for their "Level of Education" (question 1.4), to which they could respond 'Primary', 'Secondary', 'Post-Secondary' or 'Never went to school'. The surveyors also observed the "Type of main dwelling house" (question 1.8) with the following possible options 'Hut', 'Semi-permanent', 'Permanent' or 'Other'. For the purposes of this survey 'Huts' are considered houses with simple thatched roofs and mud and waddle walls. 'Semi-permanent' houses have mud walls, but iron roofs. Finally, 'Permanent' houses have brick walls and an iron roof and are considered the ideal to which rural Ugandans strive for.

Primary school in Uganda is, in theory, universal and is roughly equivalent to elementary school in the United States and many Ugandans attend primary school for several years. Secondary school is akin to intermediate and high school in the US and indicates a certain level of economic fortitude since it is not yet universal and schools fees can be very high. Post-secondary school is achieved by only a select few and is usually considered to be going to a junior college or university. However, in some contexts, some may consider it to include trade school.

The survey participants were asked the following relevant questions about their water usage. The questions about water sources used were worded as follows: "From which water sources do you fetch water for domestic use?" (question 2.1) and "From which source do you normally fetch water for drinking?" (question 2.2). The options for water source used for both domestic and drinking uses included 'Borehole', 'rainwater-harvesting tank', 'Spring', 'Tap' and 'Unprotected Source'. In addition 
many respondents indicated they used a shallow well, which was also included in the survey responses. The respondents were also asked "Who fetches the water in the household" (question 2.7) to which they could indicate 'Man', 'Woman', 'Girls', 'Boys', 'All of the above' and 'Others'. Many of the respondents indicated that they bought water from porters, which was also included in the results. The respondents were then asked "How far is the water source from your household?", "How much time does it take for you to go and come back from fetching water?", "How many jerrycans of water does your household use in a day?" (questions 2.4, 2.5 and 2.6), and if your water source dries up during the dry season, "What distance do you travel to collect during the dry season" and "How much time do you take to fetch water during the dry season" (questions 2.10 and 2.11). The number of jerrycans used can be converted into liters by multiplying by 20 , which is the size of many of the jerrycans used in Uganda.

\subsubsection{Limitations and Possible Sources of Error of Survey}

The survey was able to capture over 1,500 households in three different districts throughout Uganda. This represents a broad cross section of different ethnic groups and customs with varying access to water and sanitation resources. However, there are several relevant limitations to this survey, some of which can be addressed.

The communities surveyed were not chosen randomly, but were chosen by NETWAS because of their extremely poor access to water facilities and their suitability for rainwater-harvesting technologies. The survey can therefore not be accurately considered a random sampling of households in the developing world. Despite that limitation, the author still believes the results to be generalizable because of the sheer 
scope and geographic diversity of the survey population.

The surveyors were spread out across the three districts and had very little formal training in surveying techniques. There was little effort made to harmonize the approach between the three districts and so it is likely that each district NGO, and in fact each surveyor, performed the survey slightly differently.

The respondents were asked to indicate the number of jerrycans used per day. However, the survey itself did not explicitly ask for the number of 20-liter jerrycans used per day. Although the 20 liter variety are the most common, many people also use 5 and 10 liter jerrycans. Although the survey assistants were told orally to inquire about the number of 20 liter jerrycans it is likely that many households included smaller ones as well. Since the 20 liter variety are the largest ones commonly used, it is likely that the true amount of water used in the household is somewhat less than that measured.

The respondents were simply asked to indicate how far and how long it takes to fetch water as well as how much they use. Although they travel the same distance every day and have a good idea about how far it is internally, converting that to a real distance in kilometers and time in hours is very difficult and prone to significant error. The average rural Ugandan has very little formal schooling and does not own a working clock. This was the primary reason why the data was divided into large, quasi-qualitative, ranges as is described in Section 3.1.3. Furthermore, the large data set allow broad trends to be identified if they exist. Despite the difficulties in those measurements, the number of jerrycans used per day is likely to be quite accurately estimated since the average respondent knows precisely how many jerrycans they need every day. 
Another limitation of the survey is that the respondents were never asked how much water they used during the dry season. It is possible that they use less water as their sources dry up and they must go farther in search of water and the water they do find is less abundant. For this survey, it was assumed that the households use the same amount of water year-round.

Strategic bias is one major concern of this study as well. Since it was introduced to the respondents as part of a rainwater-harvesting Project, many may have exaggerated the amount of time and effort it takes to get water in the hope that they will get the rainwater tanks.

\subsubsection{Statistical Analysis}

The data analysis was carried out using a combination of the Statistical Package for the Social Sciences (SPSS), Microsoft Excel and custom designed programs written in the Perl programming language.

Based on the discussion in Section 3.1.2 and to compare it to the work of Howard and Bartram and other literature as discussed in Section 2.1 the distance and time to source data were divided into the same service levels prescribed by Howard and Bartram. This has the added advantage that the data can be treated more qualitatively. Although most Ugandans cannot accurately estimate distances or times, their answers to such questions indicate the perceived effort they must make to fetch water. For instance, someone who claims that the closest water source is less than 100 meters away and takes about five minutes to fetch could reasonably be considered to have 'Intermediate' access to water. Alternatively, someone who says his or her water is five kilometers away can likewise be said to have little or 'No' access to wa- 
ter, even if the actual distance is close to two kilometers. It is therefore by grouping the data into wide service levels that the issue of the respondents' accuracy can be diminished.

Data analysis was conducted using $95 \%$ confidence intervals with standard statistical techniques for statistical hypothesis testing. The equations and procedures will therefore not be reproduced here.

\subsection{What Works Best in Diarrheal Disease Pre- vention Methods}

The concept behind this project is to assess the causes and prevention strategies of diarrheal diseases. To do this, a research collaboration was formed between the Rakai Health Sciences Program (RHSP), Michigan Technological University and Open Palm COWESER. The Rakai Health Sciences Program provided logistical support as well as data to assist in community selection and other technical support. Michigan Technological University provided the author of this report who devised the project, managed project implementation along with COWESER staff members, developed the survey and analyzed the data.

Six communities were selected near Kalisizo Town Council in consultation with RHSP. Five of those communities received one of the following interventions: a clean water source, a latrine improvement campaign, a hand-washing advocacy campaign, installation of household water filters and an intervention that combines most of the above interventions. A sixth community was used as a control. A random sample of the households with children under five were then asked about their child's diarrheal in- 
cidences over the proceeding three months. Other questions about the households' water and sanitation status were likewise asked to assess the program's effectiveness. Finally, a follow-up survey was conducted a number of months after implementation. Each intervention's effectiveness was then determined by the overall decrease in diarrheal disease prevalence in each community and compared to determine 'What Works Best?'

\subsubsection{Project Goals and Objectives}

This project was initiated with two main goals. The first goal was to improve the health and sanitation situation for rural Ugandans in the vicinity of Kalisizo Town Council. The second goal was to provide a quantitative analysis of the causes and prevention strategies of diarrheal diseases by surveying the parents of under-5 year old babies about diarrheal disease cases over the proceeding three-month period. These goals, along with their related objectives are listed below:

Goal 1: By the end of project implementation, five target villages will have increased access to water, hygiene or sanitation facilities thereby reducing diarrheal incidences for children under five.

Objective 1a: By the end of project implementation, one community will actively participate in the construction of a safe water source thereby increasing water quality, quantity and accessibility.

Objective 1b: By the end of project implementation, one community will significantly improve latrine cleanliness and maintenance habits through construction and advocacy work to reduce open defecation and improve sanitation. 
Objective 1c: By the end of project implementation, one community will have working household hand-washing facilities at $75 \%$ of homes and will be sensitized about the importance of their use to increase the practice of hand-washing.

Objective 1d: By the end of project implementation, one community will have working bio-sand household water treatment systems at homes with young children and will be sensitized about their operation, maintenance and importance of use to improve household water quality.

Objective 1f: By the end of project implementation, one community will have received most of the above interventions along with an intensive health education campaign to comprehensively improve the water, sanitation and hygiene situation in that community.

Goal 2: Six months after the interventions are installed, the project staff will have a quantitative measure of the relative effectiveness of the intervention strategies.

Objective 2a: Before project implementation, representatives from the collaboration will survey the target community to ascertain the diarrheal incidences for children under 5 years old.

Objective 2b: Within six months of project implementation, representatives from the Rakai Health Sciences Program will again survey the diarrheal incidences for children under 5 years old.

\subsubsection{Community Selection Criteria}

Six communities were identified where RHSP works and lack adequate health and sanitation facilities. The following is a list of criteria that was used to choose the 
target villages:

1. All communities should be poor performers in health and sanitation.

2. All communities should be approximately equal in health and sanitation conditions.

3. All communities should have approximately equal socioeconomic conditions.

4. All communities should be geographically close to Kalisizo and geographically close to each other.

5. Community leaders should be enthusiastic about project and willing to support the project after implementation.

6. Communities should be enthusiastic about project and willing to support the project after implementation.

7. Communities should be as small as possible for effective program coverage.

Such criteria ensured that the communities were starting off at an approximately equal stage of development and could therefore be reasonably compared. However, the geographical constraints as well as the qualifications for supportive communities and leaders do compromise the survey's generalizability.

The control "community" was actually composed of parts of two communities adjacent to two of the intervention communities in which no interventions were carried out. The first half was in Lusaka, where the household water filters were installed. Due to limited project funds only 26 households were targeted for that intervention leaving the other households to act as a control. Since COWESER's advocacy work concentrated only on those households who received the intervention, the remaining households were considered to be adequate controls. The second control community 
was the half of Nsambya too distant from the shallow well constructed there to be

useful. Again, since COWESER's activities were confined to the area of town where the well was installed the area far from the intervention was considered an effective control community.

\subsubsection{Survey}

The same survey was carried out before and after implementation of the improvements to compare the effectiveness of each. The survey is reproduced in Appendix B. COWESER carried it out in collaboration with the Kalisizo Health Center IV and their health extensions workers. It was done with door-to-door interviews with the eldest or most appropriate available child caretaker. The households questioned were based on lists provided to the survey team by local government officials familiar with each community's children. Community members familiar with their location led the surveyors to the households. These survey assistants were asked to stand back during the interview to make sure that respondents' answers were kept confidential. Each survey participant was read and asked to sign a consent form that received Institutional Review Board Approval from Michigan Technological University and was likewise approved by RHSP and the Uganda National Council of Science and Technology. The survey assistants were asked to complete approximately 20 surveys per day. To the maximum extent possible the same surveyor completed both the baseline and post-implementation survey for a given household.

Diarrheal disease, particularly among babies is not traditionally considered to be a separate, preventable disease in Uganda, but rather a symptom of more serious conditions like malaria. In addition, many Ugandans think that diarrhea is caused 
by teething and is a natural part of development.

With this in mind, the survey was designed to query the respondents in such a way as to tease out cases of diarrheal disease by asking the respondents some general questions about the health and well-being of their child during the previous three months. Although these preliminary questions were not used directly in this analysis they were integral part of the questionnaire. In addition, the health questions were asked at the end of each interview once the surveyor had developed a rapport with the respondents. The health questions included inquiries about all illnesses over the proceeding three months and the causes and treatments for those diseases before finally asking about diarrhea disease.

Part II of the survey (but the first to be asked) concerns the water and sanitation status of the communities and households queried. These questions aimed to assess the impact of the interventions and to more precisely correlate reductions in diarrheal disease to specific improvements in the water and sanitation situation. It also measured the specificity of the interventions. For instance, was the decrease in diarrheal disease in the community where the shallow well was constructed due to increased usage of that well or due to improved practices of household water purification and storage which was a byproduct of the interventions. The questions were asked in relation to the six main different intervention strategies: water source status and usage, latrine prevalence and cleanliness, household water treatment practices, hand-washing practices, knowledge about diarrhea causes and prevention strategies as well as presence of different household sanitation improvements. 


\subsubsection{Health Survey Questions in Detail}

Although many of the questions asked are straightforward, several demand further explanation and discussion.

The number of household members is a fluid question in rural Uganda. For this study a household was defined as a group of people living in close proximity who regularly share meals together. Household numbers are in constant flux and the number of children in a household is particularly variable. Children come and go to and from boarding school. Parents who cannot afford to keep their children often send them to relatives for some length of time. Fathers sometimes also leave for a while forcing their wives and children to move in with relatives. This flux was the primary reason why the number of children surveyed was less in the follow-up survey.

The main question analyzed for his survey was "In the past 3 months how many times have your under-5 year old children had diarrhea?" This question is the most common metric used to define health improvements due to water and sanitation interventions. However, it is based on a caretaker recalling the number of times a child had diarrhea for the previous three months, which can be difficult for most people. Asking for a shorter time period, i.e., one month, could provide more accurate results, but the researchers were concerned with getting the maximum number of positive responses for statistical purposes. It is worth noting that many people responded that their child's diarrhea was caused by malaria. It is true that severe malaria can and does cause diarrhea, which would not be due directly to poor water quality. However, it is also true that malaria is the default diagnosis for children seen in area health clinics and hospitals and is therefore highly over-reported. Essentially anyone with flu-like symptoms is given anti-malarial medicines as a precautionary step since malaria tests 
are more expensive than the cure.

Another potentially significant source of error is the fact that the community members were nearly universally appreciative of the work done by COWESER. For the followup survey they may have not reported some diarrhea cases because they wanted the surveyors to feel that the project was completely successful at eliminating diarrhea from the community to show their appreciation for the work done. This source of error would be very difficult to quantify with the methods employed for this survey.

It is also true that the exact way a surveyor asked a question can have a huge impact on the response rate. For instance, the original diarrhea rate reported in the community that received multiple interventions was $0.27 \pm 0.07(\mathrm{n}=39,95 \%$ CI) cases per child during the previous three months. ${ }^{1}$ Since this value was significantly lower than for the other communities the research staff suspected that there were some systemic errors due to the fact that it was the first community studied. The households were re-questioned and found a rate of $0.69 \pm 0.07(\mathrm{n}=39,95 \% \mathrm{CI})$. This $156 \%$ increase indicates the difficulty with the recall approach to this research.

Interviewer bias was a second serious source of error in the survey. Although the surveyors discussed at length how there were to ask about diarrheal diseases beforehand, the diarrhea rates each found differed significantly. The diarrheal disease rates for the baseline survey for the four different surveyors are given in Table 3.1. Although there should not have been any significant difference in diarrhea rates because the surveyors were randomly assigned, there were clearly significant differences as can be seen in that table. However, this issue was gradually resolved on subsequent days as the surveyors became more aware of how to ask those questions and harmonized their

\footnotetext{
${ }^{1}$ Subsequent diarrhea rates will all be quoted (unless otherwise noted) as the reported cases per child for the previous three month period.
} 
questioning methods.

Table 3.1: Interviewer bias was a significant source of error in the baseline survey. Although the surveyors did not all survey the same villages, the large spread is higher than one would expect given the random nature of their assigned survey area.

\begin{tabular}{|c|c|c|}
\hline Surveyor & Diarrheal Disease Rate & Sample Size \\
\hline $\mathbf{1}$ & 0.253 & 99 \\
$\mathbf{2}$ & 0.877 & 155 \\
$\mathbf{3}$ & 0.495 & 109 \\
$\mathbf{4}$ & 0.618 & 152 \\
\hline
\end{tabular}

\subsubsection{Water and Sanitation Questions in Detail}

The questions about water source usage, distance and time to collect water and the number of jerrycans collected per day and the reasons for selecting the current water source are fairly straightforward and were based on responses from the participants.

Initially, the plan was to install new latrines at as many households as possible. However, based on data from the RHSP, it was found that around $95 \%$ of households in the survey area already had latrines. The focus was therefore shifted to be a latrine improvement campaign in which households in need would receive concrete slabs to put over new or existing latrine holes and a system of community outreach volunteers would encourage people to maintain their latrines in a more sanitary manner. Therefore the research staff expected and did see improvements in latrine construction, improved latrine cleanliness and an increased awareness of sanitation issues. The latrine cleanliness score was based on a 1 to 8 scale in which the surveyors gauged the cleanliness of a latrine based on the presence or absence of the following eight items: no urine present, no feces present, few flies present, clean, latrine hole covered, 
wiping material present, hand-washing facility present with soap, broom present. A household received a positive point for each of the eight items they had.

The household water treatment questions are also fairly straightforward and were based on responses from the survey participants.

The hand-washing questions should have been easily answered, however, the survey staff answered many of the hand-washing facility questioned incorrectly. A handwashing station was supposed to only be considered present if it was semi-permanent and always filled with water. Very few Ugandan households have such devices and the baseline results should have been near zero. However, the surveyors answered this question inconsistently with some including the presence of the tippy-tap installed for the project to have been present before implementation while others considered temporary jerrycans that are sometimes filled when guests are present to be hand-washing stations. Likewise the questions regarding hand-washing practices were based on responses of the survey participants, are of poor quality and show many inconsistencies and are largely left out of these findings.

Questions about health knowledge were recorded by the surveyors and later translated into a systematic numbered score based on their responses. If a participant could not name any cause or prevention strategy they were given a score of 0 for each. If a participant could name one cause and prevention strategy they were given a score of 1 for each. If a participant could name two or more they were given a score of 2 . Trends in these scores were then tabulated and are summarized in this report. Any increase in knowledge is considered to be due to the outreach actives carried out by COWESER.

The last set of questions was in regard to the presence or absence of various sanitation 
improvements in the home. A rubbish pit is a shallow pit used by many homes to dispose of trash in a more sanitary way. The bathroom is a simple area set aside for bathing and does not have a latrine connected to it like American homes. A drying rack is a wooden rack used to dry dishes, which is better than the alternative, which is dry them on the ground or another unsanitary location. The water container is a designated jerry-can or pot used solely for drinking water. Ugandan NGOs and other health workers actively advocate for all of the above technologies. An ideal home should have all of the above.

Finally, the compound cleanliness was a score generated by the surveyor based on a pre-determined set of indices namely: little rubbish in compound, well kept appearance, few flies, buildings well maintained, animals kept in enclosed areas and no potholes. Like the latrine cleanliness score a household could gain points for the presence of the above items. A perfect house would have a score of 6 . An increase in compound cleanliness was assumed to be due to the advocacy work done by COWESER. 


\section{Chapter 4}

\section{Implementation of WWB}

\section{Improvements}

The WWB project was implemented by Open Palm COWESER herein referred to as COWESER in conjunction with myself who acted as project manager while serving as a United States Peace Corps Volunteer assigned to work with COWESER. Implementation of the project started with the initial community visits on September 1, 2008. The main implementation phase of the project was completed in early January 2009, with follow-up activities continuing through the beginning of May 2009. The COWESER staff did an excellent job in ensuring the effective and targeted implementation of the prescribed interventions as is proven in Section 6.2. 


\subsection{Initial Community Selection}

Based on the criteria laid out in Section 3.2.2 we selected six communities in collaboration with RHSP to be part of the project. Our indicators included latrine coverage, safe water sources, similar setting (i.e., mostly rural) and household type and were based on RHSP cohort data collected during previous surveys. The six selected communities included: Lusaka, Mitondo, Manyama, Nsambya, Kalagala and Kikungwe. This number was later decreased to five when Mitondo proved to be unwilling to support a project in their community.

Before work could begin, we had to meet with the relevant sub-county officials to introduce ourselves and the project's goals and objectives. All relevant officials welcomed our project and gave us permission to work in their communities.

\subsection{Needs Assessment}

As an initial assessment, we first held a series of informal interviews and preliminary community meetings. We held informal interviews with about 8-10 randomly selected households in each community to get an initial picture of their situation. We asked the eldest person present about the water and sanitation situation in each household and in the community as a whole. We also asked each household what they deemed to be the most pressing water or sanitation-related problem in their community.

After these informal visits we held community meetings with each community. The first set of meetings in each community were aimed at introducing ourselves and the project to the community, discussing their current water and sanitation situation and 
conducting a needs analysis of possible interventions.

Of the five villages where we had successful meetings most of them said that lack of access to safe drinking water sources or lack of permanent latrines was their biggest problem. This is not surprising since several of the communities lack even basic access to a safe water source and most households have very poorly constructed latrines. Interventions such as hand-washing or health education are generally not seen as high priorities, and water filters are a new and unknown technology in rural Uganda.

One of the biggest challenges in holding such meetings is getting the community to attend. We utilized the local village leaders called LC1s (Local Council 1), which are the lowest level of government leaders in the highly decentralized government structure of Uganda. These local leaders, elected by their neighborhood, vary tremendously in quality and enthusiasm for community projects. Some were very active in promoting the project, while others were not. Where they were not effective at mobilizing the community we had to reschedule a number of meetings. We also found that those communities with poor LC1s were, in many cases, able to mobilize themselves effectively without the help of their LC1 once they realized that our project could be of help to their communities. Of the six communities we had originally targeted for interventions, Lusaka, Manyama and Kalagala villages effectively mobilized themselves the first time. In both Kikungwe and Nsambya we had to return three times until we gathered a quorum of around 30 households in each community. Both Kikungwe and Nsambya later fully embraced the work and the project after those initial meetings. Unfortunately, Mitondo village was never able to garner the necessary enthusiasm for the project due to poor LC1 leadership and little community support. 


\subsection{Intervention Selection}

The five communities chosen for interventions were Lusaka, Kikungwe, Kalagala, Manyama and Nsambya. The control community was comprised of parts of Lusaka and Nsambya. All communities are located within 10 kilometers of Kalisizo and all had approximately the same socioeconomic and water and sanitation characteristics as indicated by the follow data that was collected by RHSP surveyors in January and February 2008. Pre-intervention latrine coverage as provided by RHSP is given in Table 4.1 and indicates consistently high latrine coverages across all five communities. Table 4.2 gives the percentage of respondents indicating that they use a particular water source. Lusaka, Nsambya and Manyama all had similar safe water coverages while Kikungwe and Kalagala had lower coverages. Kalagala has a few piped water stands from the Kalisizo Town Council municipal system, but they work on an intermittent basis. Kikungwe has at least one borehole that is not functioning and so many residents have reverted to their traditional, unprotected sources.

Table 4.1: Latrine coverage and total community size for each of the five communities. This data indicates that all communities had nearly the same latrine initial latrine coverage. Note that this is the total community size and each includes many households that were not included in the interventions or surveys since they did not have children under five.

\begin{tabular}{|c|c|c|}
\hline Community Name & Latrine Coverage & Number of HHs \\
\hline Lusaka & 96.6 & 264 \\
\hline Kikungwe & 94.7 & 228 \\
\hline Nsambya & 96.9 & 488 \\
\hline Kalagala & 98.4 & 303 \\
\hline Manyama & 94.7 & 301 \\
\hline
\end{tabular}

Socioeconomic status was assessed by looking at the percentage of houses in each community with different common improvements. These improvements include: iron roof, cement floor and brick walls. Those with none of the improvements were con- 
Table 4.2: Water source used by respondents in the five communities before intervention. Lusaka, Nsambya and Manyama all had similar safe water coverages while Kikungwe and Kalagala had lower initial coverages. All numbers indicate the percentage of respondents who indicated that they use a particular type of source.

\begin{tabular}{|c|c|c|c|c|}
\hline Community Name & Unprotected & Borehole & $\begin{array}{c}\text { Water } \\
\text { Tap }\end{array}$ & $\begin{array}{c}\text { Protected } \\
\text { Well }\end{array}$ \\
\hline Lusaka & 51.6 & 1.6 & 0 & 46.3 \\
\hline Kikungwe & 5.3 & 10.1 & 0 & 84.0 \\
\hline Nsambya & 49.1 & 0.5 & 0 & 49.9 \\
\hline Kalagala & 26.2 & 1.3 & 44.1 & 28.4 \\
\hline Manyama & 51.4 & 19.4 & 0 & 28.9 \\
\hline
\end{tabular}

sidered 'poor'. The households with one or two of the improvements were given an 'average' rating while those with all three were categorized as 'good'. These indicators are summarized in Table 4.3. As the data indicates, all five communities exhibited similar levels of 'poor', 'average' and 'good' households.

Table 4.3: Percentage of households in each community with a given household type. This data indicates that all of the communities have an approximately equal socioeconomic status.

\begin{tabular}{|c|c|c|c|}
\hline Community Name & Poor & Average & Good \\
\hline Lusaka & 0 & 50.8 & 49.2 \\
\hline Kikungwe & 0.4 & 69.7 & 29.8 \\
\hline Nsambya & 0.4 & 60.5 & 39.1 \\
\hline Kalagala & 0.7 & 48.7 & 50.7 \\
\hline Manyama & 0.3 & 63.5 & 36.2 \\
\hline
\end{tabular}

Based on our needs assessment and the data above, we decided to distribute the interventions as is laid out in Table 4.4.

Lusaka was chosen to receive the water filters because they already had a shallow well that was operational, but few used it because the community members did not like the taste of the water, which they said was metallic. Most community members use a nearby unprotected spring. Kikungwe was chosen for the hand-washing intervention because they already have two protected water sources (one is functional) and the 
Table 4.4: The interventions planned for each community.

\begin{tabular}{|c|c|}
\hline Community Name & Intervention(s) \\
\hline Lusaka & Household Water Filters \\
\hline Kikungwe & Hand-Washing Campaign \\
\hline Nsambya & Shallow Well \\
\hline Kalagala & Latrine Improvement Campaign \\
\hline Manyama & $\begin{array}{l}\text { Shallow Well, Latrines Improvement, } \\
\text { Health Education and Hand-Washing }\end{array}$ \\
\hline
\end{tabular}

large population would have made latrine promotion ineffective because of our limited funds. Nsambya was chosen for the shallow well intervention because they lacked a protected source, had a prefect location for a shallow well and requested it. Kalagala received the latrine improvement campaign because they already had two protected water sources and specifically asked for help in constructing latrines. Manyama had a good location for a shallow well. They had also asked for help with latrines and were very enthusiastic about the project, which is why we also promoted hand-washing and conducted health education there.

\subsection{Community Planning Meetings}

After deciding which community would receive each intervention, we held a second round of meetings in each community. These meetings were aimed at garnering community support for project, discussing local contributions and the roles and responsibilities of all the players. We formed committees in each community to oversee our interventions there. Those present selected these committees through nomination and efforts were made to assure gender, age and socioeconomic balance. Over the course of the project these committees proved invaluable in our efforts to mobilize the community members and resources, advocate for the project and to oversee the 
project on a daily basis.

It is common in Uganda for NGOs and local government entities to come to villages, promise interventions and then not follow through. Such behavior has generated a great deal of distrust amongst villagers for such projects. To stem this feeling and to lay out roles and responsibilities of all the partners, we signed community contracts with each community at the community planning meetings. An example of the contract used in Kalagala where we conducted the latrine construction program is attached in Appendix C. The communities embraced these contracts because they knew exactly what they were expecting to receive and what exactly they would need to provide.

\subsection{Shallow Wells}

We constructed two shallow wells with the help of a local water engineer in Nsambya and Manyama Villages. Both were located in low-lying areas next to their traditional sources where the water table was very high. Both were supposedly dug to a depth of approximately 5 meters but, the engineer measured the depth incorrectly in both instances by about a half-meter so both ended up being about 4.5 feet.

The communities provided the majority of the unskilled labor including most of the digging. In both cases the digging took approximately three days, and was complicated by a high water table, requiring us to bail the wells constantly. Fortunately, we

were able to hire a gas-powered water pump that significantly increased the digging speed and efficiency.

Both wells were then lined with pre-fabricated concrete culverts purchased nearby 


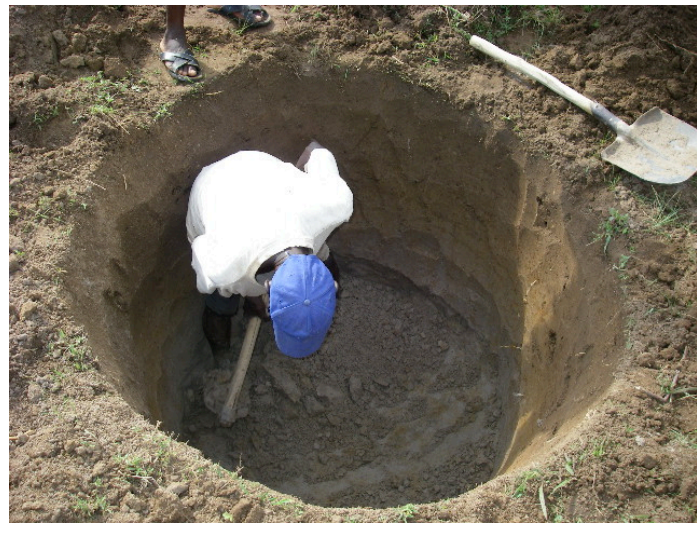

(a)

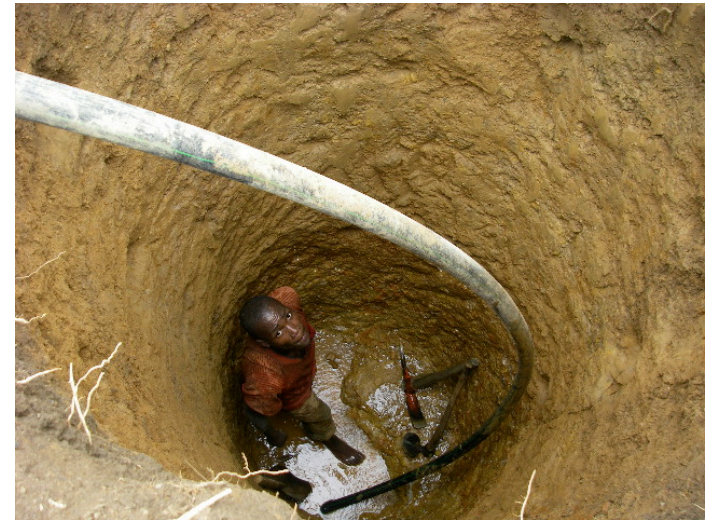

(b)

Figure 4.1: (a) Digging was easy at first, (b) but became increasingly difficult when once we reached the water table. A gas-power water pump made it much easier.

and transported to the site. The weight of the culverts made their insertion tricky, but was managed by the engineer and about 20 community members with ropes as shown in Figure 4.2. A concrete spillway was then constructed which will prevent the water from collecting around the base.

Rope pumps were installed at both locations. These pumps, shown in Figures 4.3 to 4.6, are manufactured in Kampala by Watcom Technical Services, a profit-making venture who was trained by the international NGO, WaterAid. The pumps are made using locally available parts and have been successfully used in countries all over the world. They work by forcing water up a PCV pipe (Figure 4.5 (a)) with washers (Figure 4.4 (a)) attached to a rope. The looped rope is placed over the top of a wheel made out of an old tire (Figure 4.6 (a)) and rotated. Water is picked up in the base at the bottom of the well (Figure $4.4(\mathrm{~b})$ ).

Their main advantages are their low-cost and the ability of local communities to fix them using parts and knowledge available locally. The pumps were 300,000 Shillings (\$US154) each. Labor, transportation and installation was an additional 590,000 


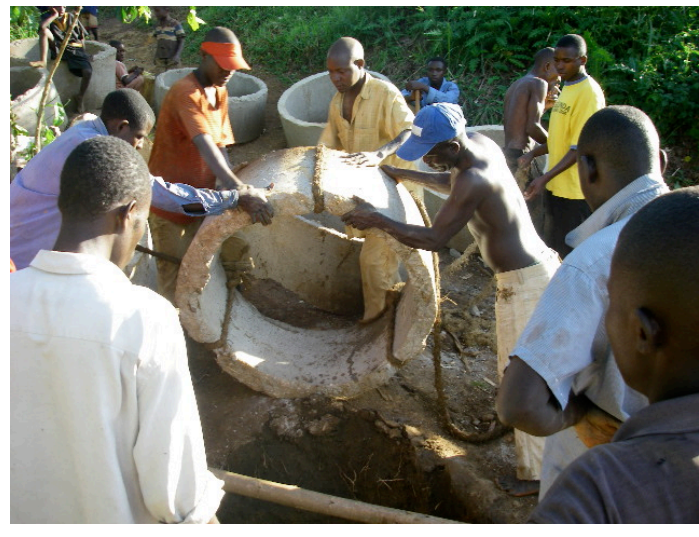

(a)

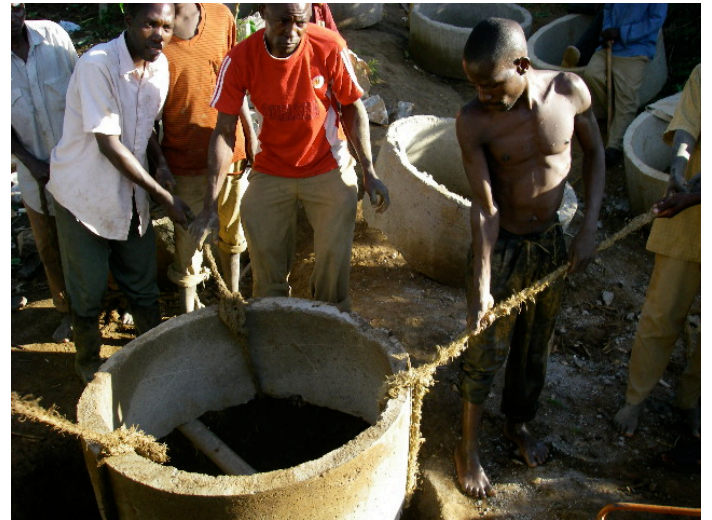

(b)

Figure 4.2: Lowering the extremely heavy culverts was a tricky task. To accomplish it we attached three ropes to each culvert and lowered them down slowly with the help of about 20 community members.

Shillings (\$US303) for the two pumps. The most likely item to break is the rope, which can be purchased in Kalisizo or other nearby trading centers. The handle or other metal parts could also break, but can be fixed by local welders or other handymen cheaply. The PVC washers are not available locally, they are fabricated in Kampala, but we left both communities with ample replacements. The PVC piping is available in Masaka, a larger town about $30 \mathrm{~km}$ to the north.

The first step in the installation was to cast the top slab, which is reinforced with iron rebar and has to be custom made to accommodate the pump. Inlets and outlets for the rope, a maintenance hatch and bolts to secure the pump all have to be cast into the top itself. The top was then left to cure for about a week. The well pedestal also had to be extended vertically so that it was about one-meter above the spillway to assure that a jerry-can could be placed underneath the pump outlet.

Upon their return, the technical staff placed the pump top onto the pedestal where it was cemented into place. The washers were tied to the rope at one meter intervals. 


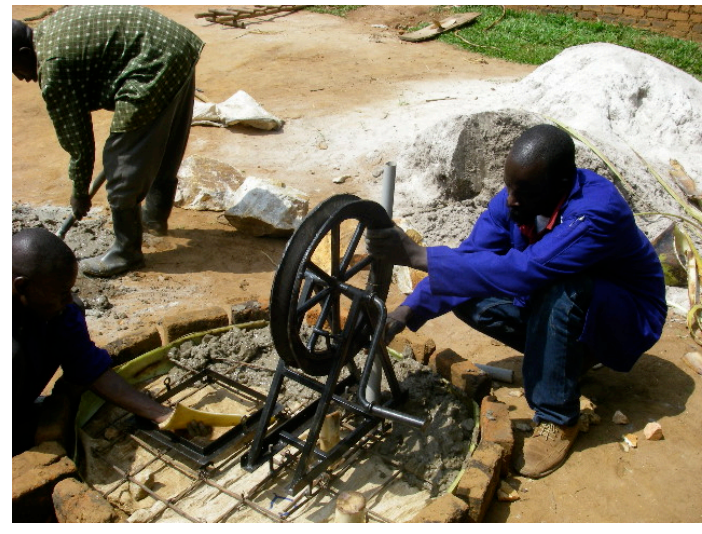

(a)

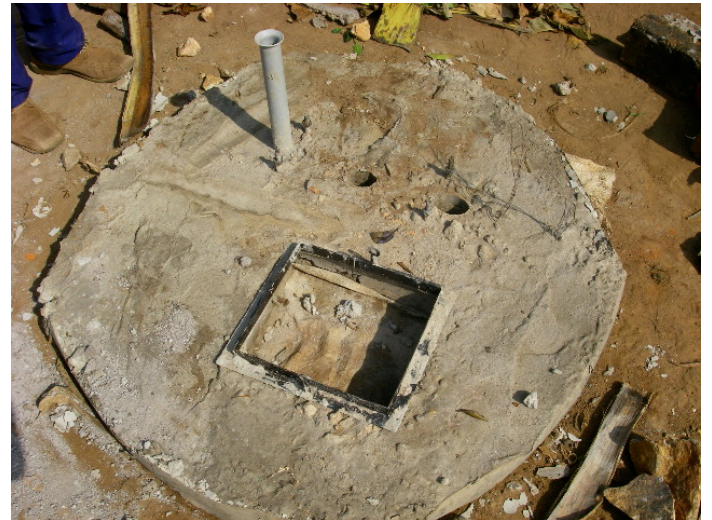

(b)

Figure 4.3: (a) Reinforcement bars being cast into the pump-top along with water inlet and outlet pipes, a maintenance hatch and bolts to secure the pump itself. (b) The finished pump-top.

The spacing can vary, but was chosen so that the most frequent users of the pumps, children, can use the pump. Closer spacing would have led to a higher flow rate, but would have made pumping difficult for the small children. The pump base with the rope already attached was then lowered into the well and PVC piping was lowered with it. The rope was then placed over the pump wheel. It was taut, but not too tight. After some adjustments the water flowed very well with minimal effort at both sites.

We also trained local handymen to fix the wells at both sites during the installation. Although the pumps are easily repairable in the field, they are made using locally available parts meaning that their quality is variable. The fact that both wells are heavily used also contributes to some of the mechanical problems. The handymen we trained are all part of the water users' committees. Since the pumps are so simple, and the parts are available locally, these handymen should be able to fix the pumps when they break. In fact, they have repaired the wells on multiple occasions as the ropes became loose or the washers wore out. Figure 4.7 shows the Nsambya handyman 


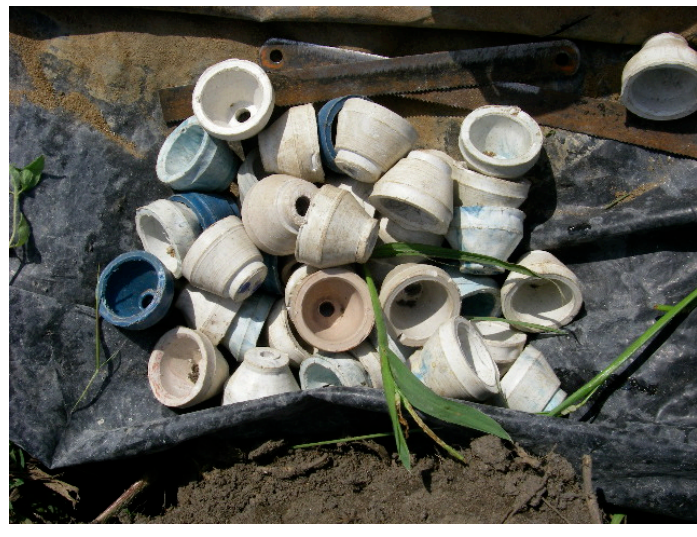

(a)

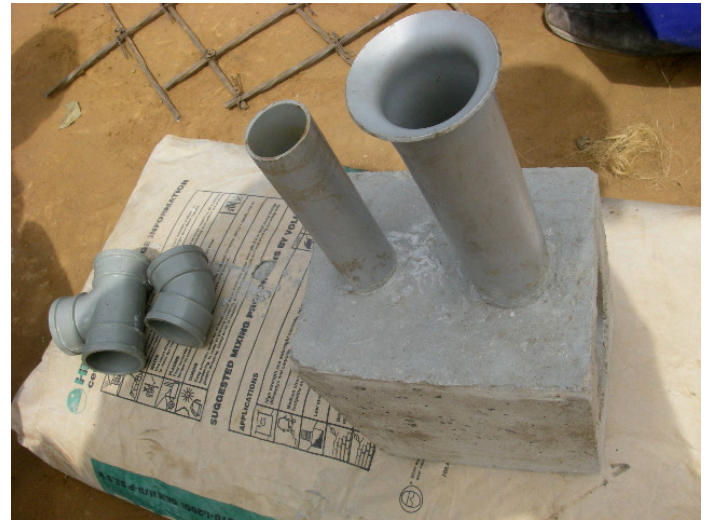

(b)

Figure 4.4: (a) Washers that are tied to the rope and act to push the water up the PVC piping. (b) The pump base that is lowered down to the bottom of the well. As the operator turns the crank, the rope with washers tied to it enters the widened PVC pipe on the right. The washers then collect water in the open section of this block (not visible) before returning up through the PVC pipe on the left.

repairing their well.

Although both wells worked well as constructed the original pipe outlet was about one meter off the ground. Since the biggest jerrycans used by community members are only about 50 centimeters tall, a lot of water is wasted as can be seen Figure 4.6 (b). We therefore extended the PVC piping down to a more reasonable level and encased it in bricks to prevent breakage. The outlet was also divided into two to allow to jerrycans to be filled simultaneously. The finished pump is shown being operated by my brother in Figure 4.8 .

Overall, both communities have embraced their wells wells and their operation and maintenance is going extremely well. In fact, now many people in the communities scorn their old water sources because they say they now don't like its taste and they prefer the clean water of the new wells. 


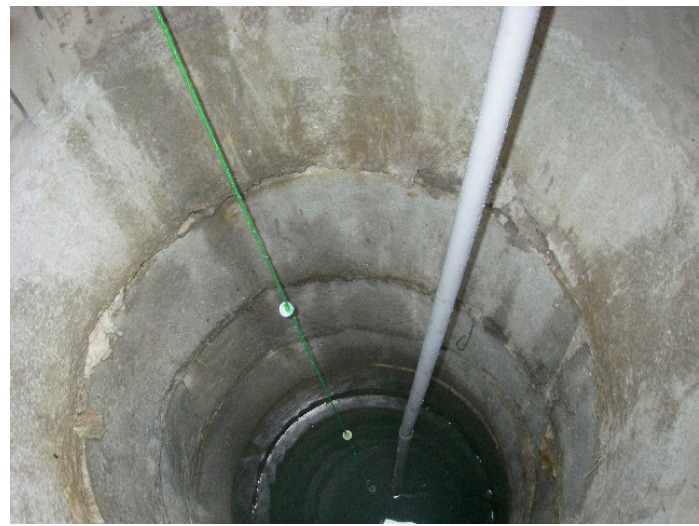

(a)

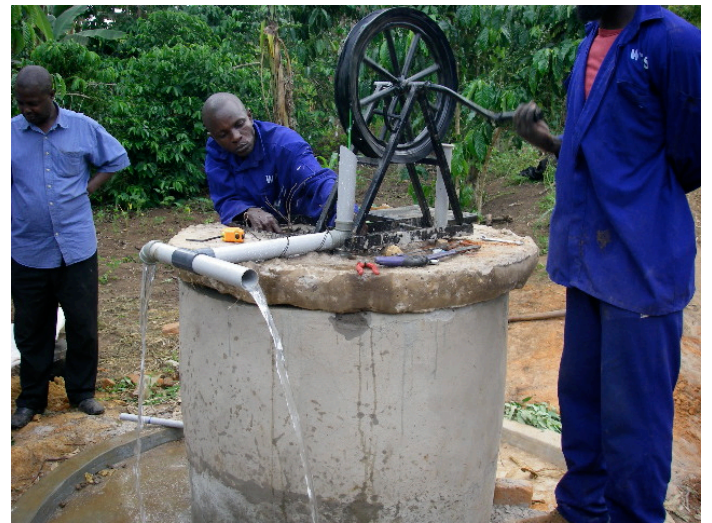

(b)

Figure 4.5: (a) The water is pushed up by washers tied to the rope up the grey PVC pipe to the right. It then returns down to the left. (b) The pump is operated by turning the crank as seen here. The flow was so good that we added a second outlet.

\subsection{Latrines Improvement Campaign}

The latrine promotion project centered on the fabrication of latrine slabs for households who were responsible for digging their own pits and constructing a superstructure. About five masons were trained in both Manyama and Kalagala by a skilled mason from Kalagala in the design outlined below. An additional advocacy campaign was carried out by community health extension volunteers who encouraged households to maintain their new existing latrines better by cleaning them, ensuring the latrine holes are covered at all times and keeping hand-washing materials nearby.

The finished slabs, shown in Figure 4.10 (b), are three inches thick and are reinforced with iron mesh and rebar, which is tied to the mesh as shown in Figure 4.9. The dimensions were chosen to allow ample room to dig the pits. The slabs themselves are 2.5 feet wide by 3 feet long. Two slabs will be placed next to each other over a 4 by 2 foot pit. This allowed six inches of earth on each side to support the slabs. 


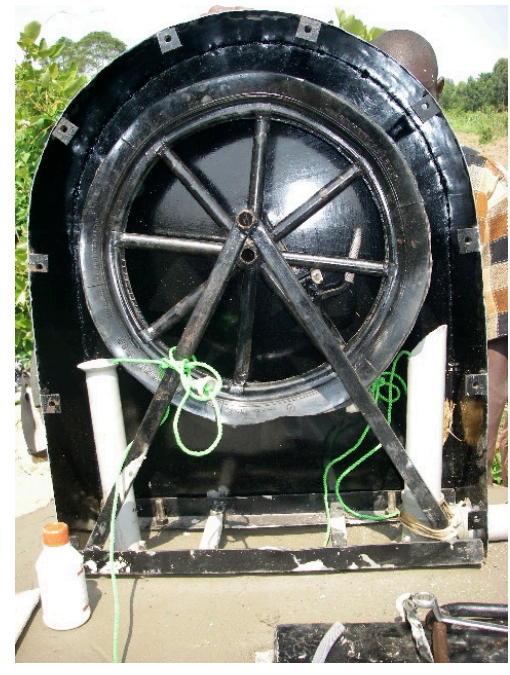

(a)

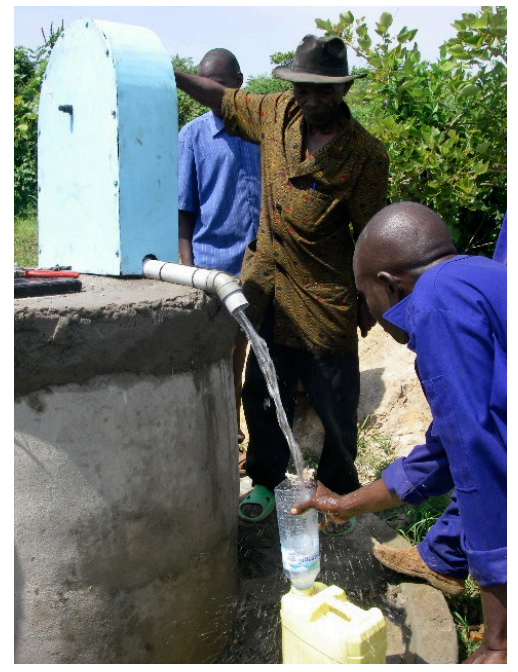

(b)

Figure 4.6: (a) The pump is enclosed in its housing. (b) A finished pump!

An all-in mixture of high-quality sand and aggregate available locally was used and mixed with concrete in a 1:6 ratio. The slabs were poured into wooden moulds and allowed to cure for 4 days.

The final number of latrine slabs constructed was a synthesis of the funds available and the number of households with children under five willing to participate. However a few slabs were reserved for households with elderly or very poor inhabitants. Since the households had to dig their own holes and construct the superstructure, some decided not to participate. The project staff encouraged the households to work together to dig their holes, but such collaborative efforts are difficult to carry out in Uganda. These criteria delayed the installation of a number of slabs since the community members could not take their slabs until their holes were dug. However, the extra requirement on their part increases the likelihood that the project will be ultimately sustainable since the households have made a significant in-kind contribution to their latrines. In the end a total of 38 latrine slabs were constructed for 


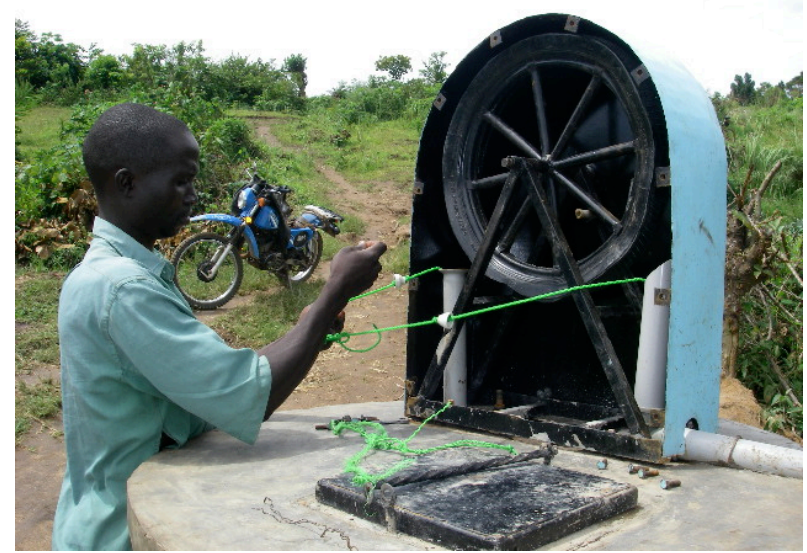

Figure 4.7: Local handyman trained by COWESER staff members repairing the shallow well at Nsambya.

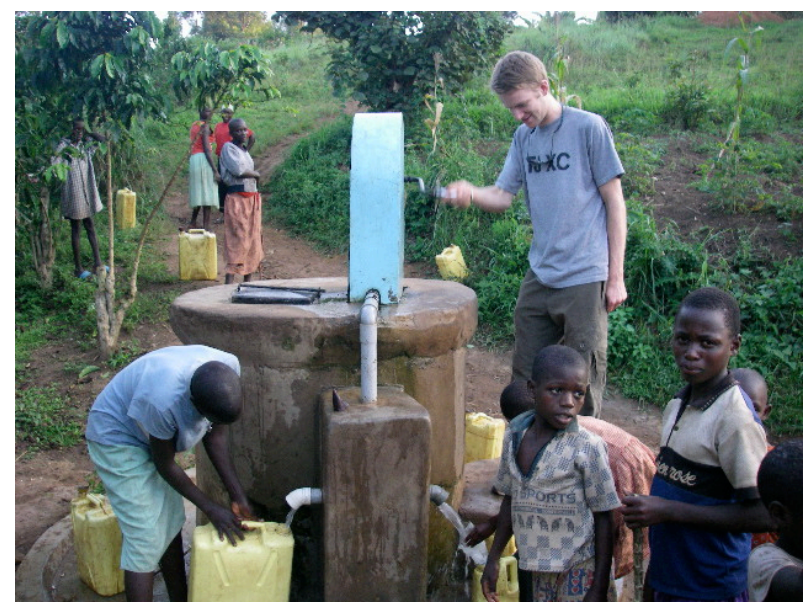

Figure 4.8: My brother David operating the finished well at Manyama after the outlets had been encased in brick, lowered to a suitable height and split into two doubling the rate at which jerrycans can be filled. 


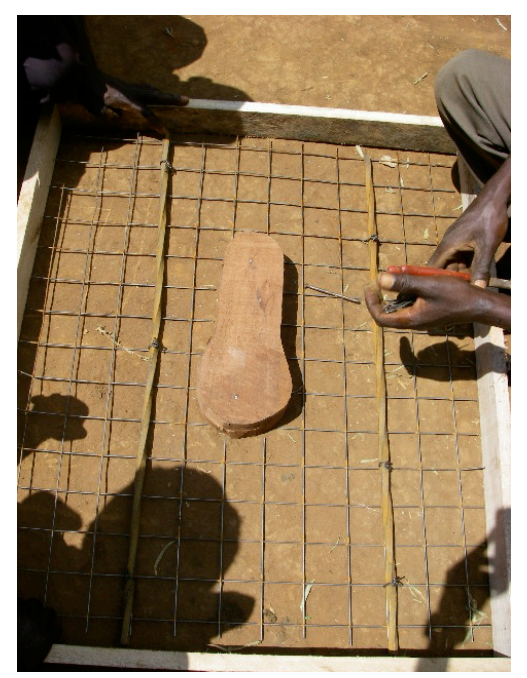

Figure 4.9: The latrine mould with two pieces of rebar tied to the wire mesh.

homes in Manyama and Kalagala Villages. In addition, the improvement campaign focused on making sure both new and existing latrines were free of feces, urine and flies. In addition, hand-washing stations were encouraged along with teaching people about the importance of keeping wiping material and a hand-washing station nearby. Finally, people were encouraged to clean their latrines on a regular basis.

\subsection{Water Filters}

Water filters were installed in 26 households in Lusaka Village. These filters were purchased from the Center for Affordable Water and Sanitation Technology (CAWST) in Kampala. The filters are essentially concrete basins with a small flexible tube cast into them. The basin is filled with two inches of coarse gravel, two inches of finer gravel and about two feet of sand. The outlet of the flexible tube is placed such that water dumped into the top will flow out until the water level equilibrates about two inches above the sand layer. Harmful pathogens are killed in one of three ways: 


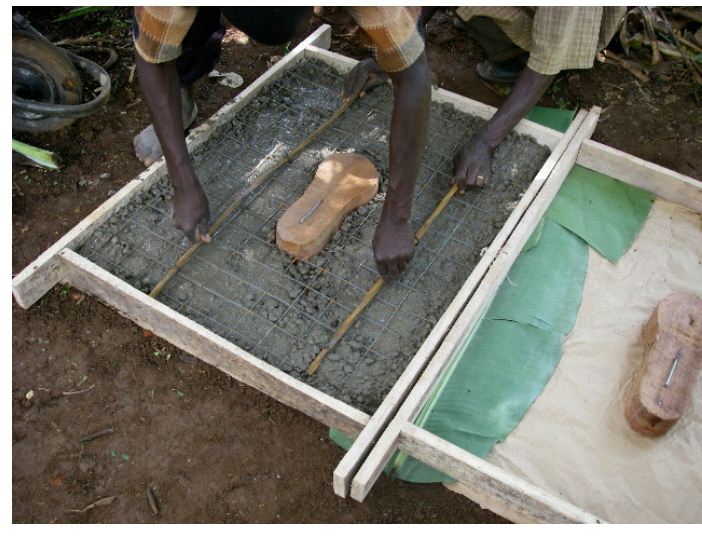

(a)

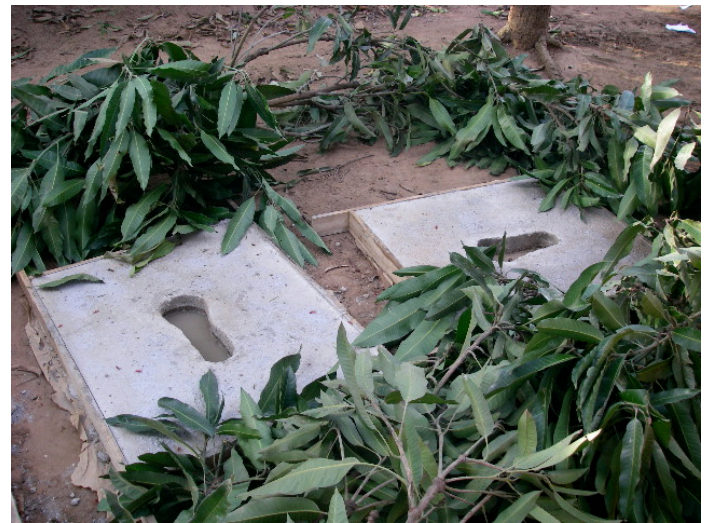

(b)

Figure 4.10: (a) The wire mesh being placed on the top of half the concrete mixture. (b) Two finished slabs.

through a biologically active layer that forms naturally on the top of the sand, by being filtered physically by the sand or through natural death. The filters require very limited maintenance and last indefinitely.

Although a very simple technology, local construction proved to be too difficult because of the difficulty of finding locally available sand with the correct qualities. Ideally, the sand should come from a quarry that mechanically crushes stones. The excess tailings from these operations are ideal because such crushed sand has ragged edges and is free from organic compounds. The only sand available locally is from streambeds. Aside from being smooth, it also has a high organic component that would have to be baked away. The sand used by CAWST is mechanically crushed by a quarry in Kampala and is therefore ideal.

As a first step to introduce the filters to the community, we had a single filter delivered to the LC1's house to act as a demonstration filter. This generated community interest in the filters and convinced many that it was worth the 10,000 Shilling community contribution that we were charging residents. 


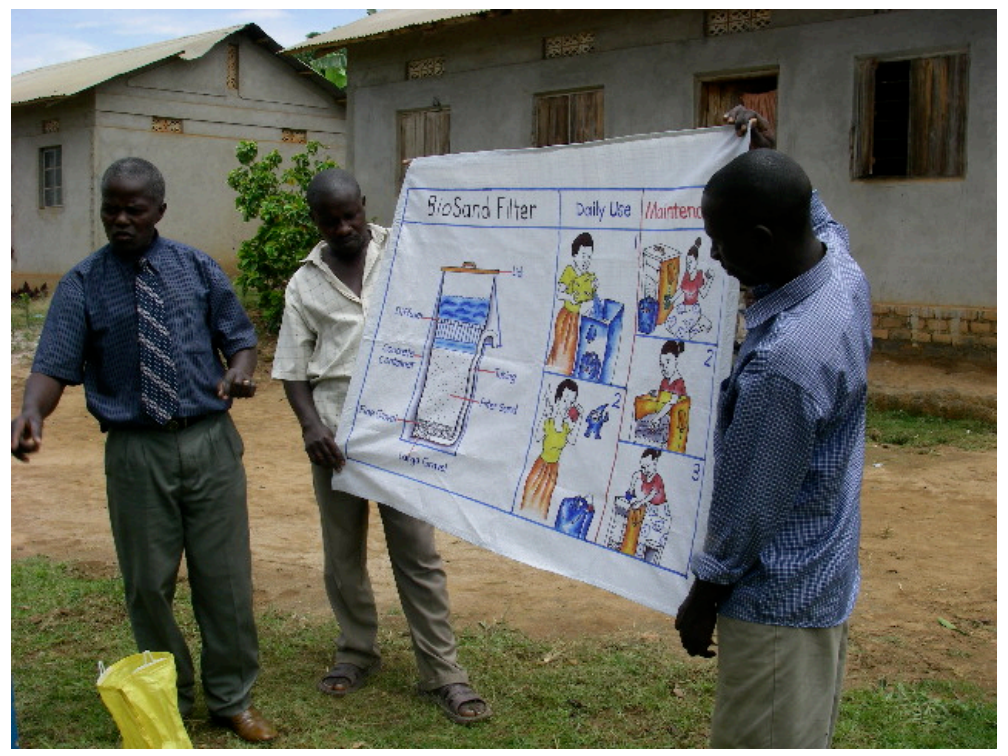

Figure 4.11: Daniel from CAWST describing filter operation and maintenance to the community.

The rest of the filters were delivered along with the media in a flatbed truck a few weeks later. A representative from CAWST then came to install the first several filters and train my counterpart and I, who installed the remaining filters over the next couple of weeks.

Installation is a simple process, but must be done in a specific manner to assure that the filters operate properly. The first step is to clean the inside of the filters with washing soap since they have been exposed to the elements for several days prior to installation. Next, two capfuls of chlorine are put into the filters along with about 15 liters of water. After that the course gravel is added to a depth of two inches. One must be careful that the gravel is placed relatively evenly by sprinkling it slowly. The finer gravel is then also added to a depth of two additional inches. The sand media is then added in one quick dumping motion. This is to assure that it is dumped evenly and that no layers of fine sediment form that would slow the flow. The installer then must make sure that the water level is two inches above the sand layer by adding or 
removing some sand. This is where the bio-layer forms over the course of about 21 days.

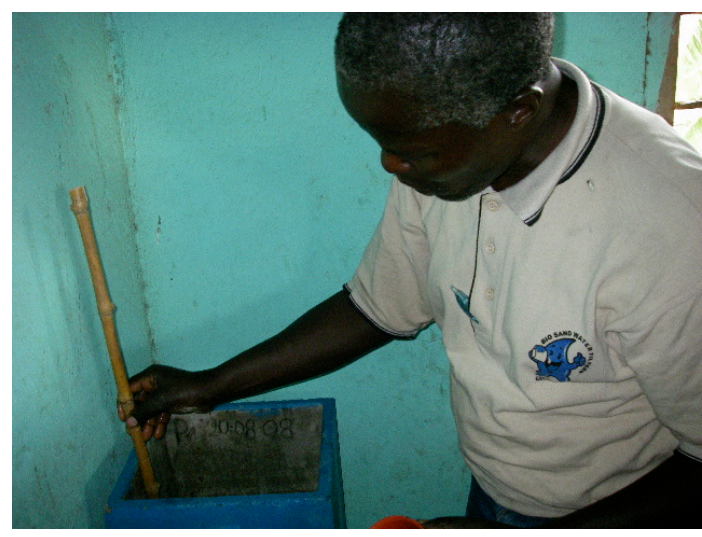

(a)

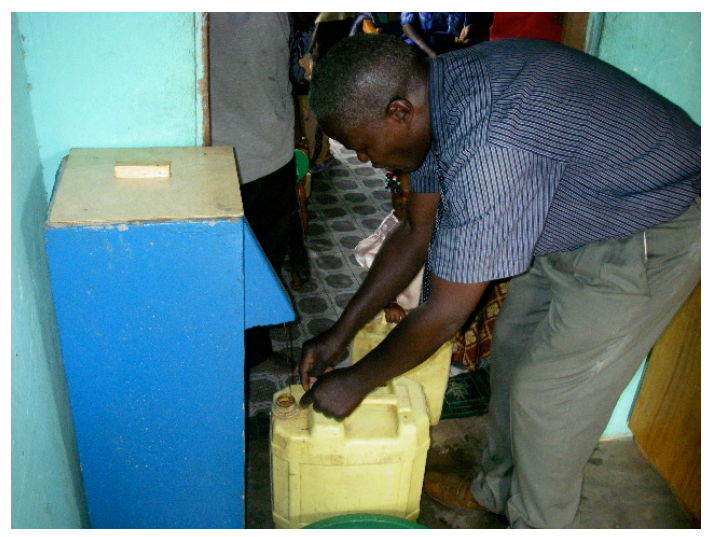

(b)

Figure 4.12: (a) Making sure the sand is of the correct depth. (b) Measuring the flow rate of the filters.

The flow rate must then be checked. This is done with a $300 \mathrm{ml}$ soda bottle. The time to fill this bottle should ideally be between 26 and 30 seconds. This translates into 29-33 minutes to fill a 20 liter jerry-can. Faster flow rates would make the water flow through too fast and the water would not be properly filtered. Slower flow rates would be fine, except that the users may get impatient if they need the water urgently.

If the flow rate is too slow the installer uses his or her hand to dig down into the sand to stir up any layers of fine sediments. After the water has been agitated and the fine sediments suspended, it is then removed quickly using a cup. This process is repeated until the flow rate is optimal. If, after repeated attempts, the flow rate is still not fast enough, the filter can be used, it will just be slower. If the flow rate is too fast a similar procedure is done, but the sediments are not removed with cup. Rather, they are allowed to settle on top of the sand layer where they will slow the rate. The flow rate largely depends on how well the sand was washed initially because washing 
it well reduces the amount of fine particles thereby increasing the flow rate.

Community members contributed 10,000 Shillings (\$US5) towards the filters, which cost 100,000 (\$US51) each excluding transportation and associated delivery and training costs. 25 households with children under five quickly paid the fees and were given a filter.

To date all households are happy with their filters, which they use to clean their water every day. They have raved about the quality of water that comes out as well as their ease of use and would love to have more filters installed. Use and maintenance issues will be handled by the water filter committee, a group of eight persons who were trained by COWESER staff members in filter operation and maintenance.

\subsection{Hand-Washing Stations}

We constructed approximately 145 household hand-washing stations (aka tippy-taps) in Kikungwe and Manyama. These stations, shown in Figure 4.13 are simple to construct, use locally-available parts, use little water and are easy to maintain.

Each tippy-tap consists of a jerry-can tied to a wooden support with rope. It is balanced such that it can be tipped downwards by pressing on a foot peddle attached to the can. Water then sprinkles out via a small holes punched in the handle. Since the holes are small, only a small amount of water trickles out, but it is more than enough water to wash thoroughly. The little water used means that the users have to refill it less frequently and do not have to haul as much water up from the well everyday. A soap holder made out of an old water bottle can also be attached.

We formed hand-washing committees in both communities who we subsequently 
trained to construct the tippy-taps in households. Most of the committee members were women who split up the jerrycans, rope and nails we delivered amongst them. We trained approximately five community members in each community who each then constructed 10-15 each. Work was completed in both communities within a week of each training.

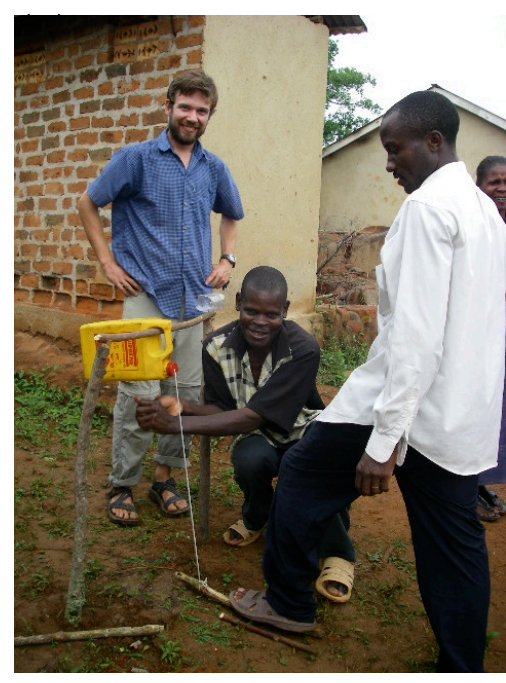

(a)

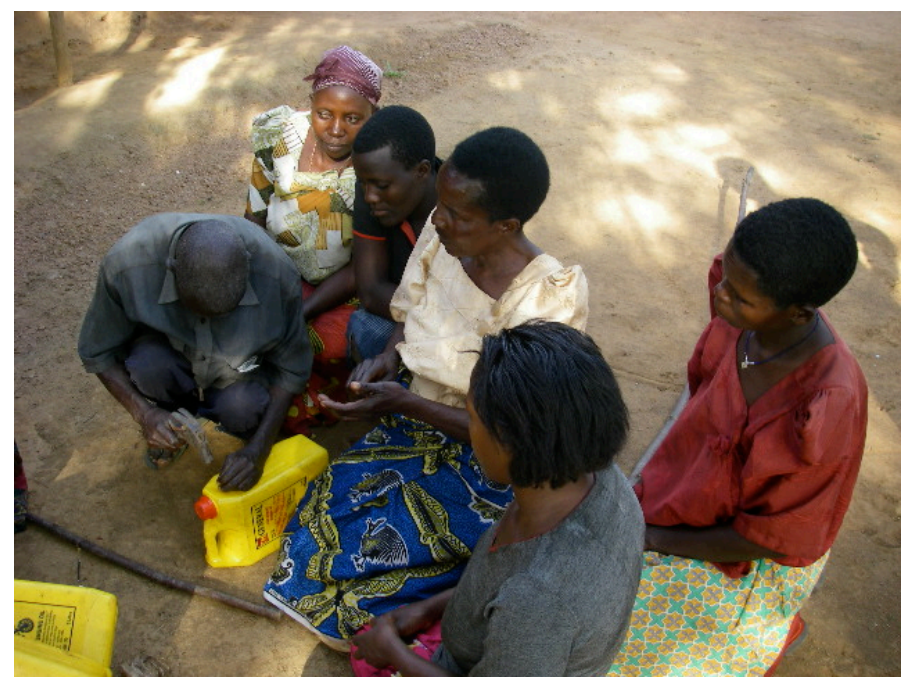

(b)

Figure 4.13: (a) Conducting a tippy-tap training at Kikungwe Village. (b) The LC1 from Kalagala showing the hand-washing committee how to make the holes.

The next step was to conduct a health-education campaign in both communities to encourage people to wash their hands with soap at critical times. This campaign was based on the National Hand-Washing Campaign, which COWESER was involved in during early 2008. That campaign aims to increase hand-washing at the critical times which include before eating, before breast-feeding, after defecating and after wiping a baby's bottom.

We will did this by conducting a drama show in both Manyama and Kikungwe community focusing on hand-washing and sanitation issues by a local community group that was trained by COWESER. Such performances are a great way to advocate for 
such things because music, dance and drama are such an important part of Bugandan culture. Most schools have competitive teams and take great pride in their accomplishments. It also gets people interested and encourages them to attend. These performances were a couple of hours long and drew crowds of a few hundred people. The actors all came from a model village not far from Kalisizo and were trained by COWESER staff members for the Eco-Friendly Project. Both shows covered the basics of hygiene and sanitation through the story for a man who used to live in squalor, but who learned his lesson and is now a fine local citizen. The Kikungwe show put a stronger emphasis on hand-washing with soap as a diarrhea prevention strategy. The drama parts are interspersed with drumming and dancing sections to keep the crowd's interest.

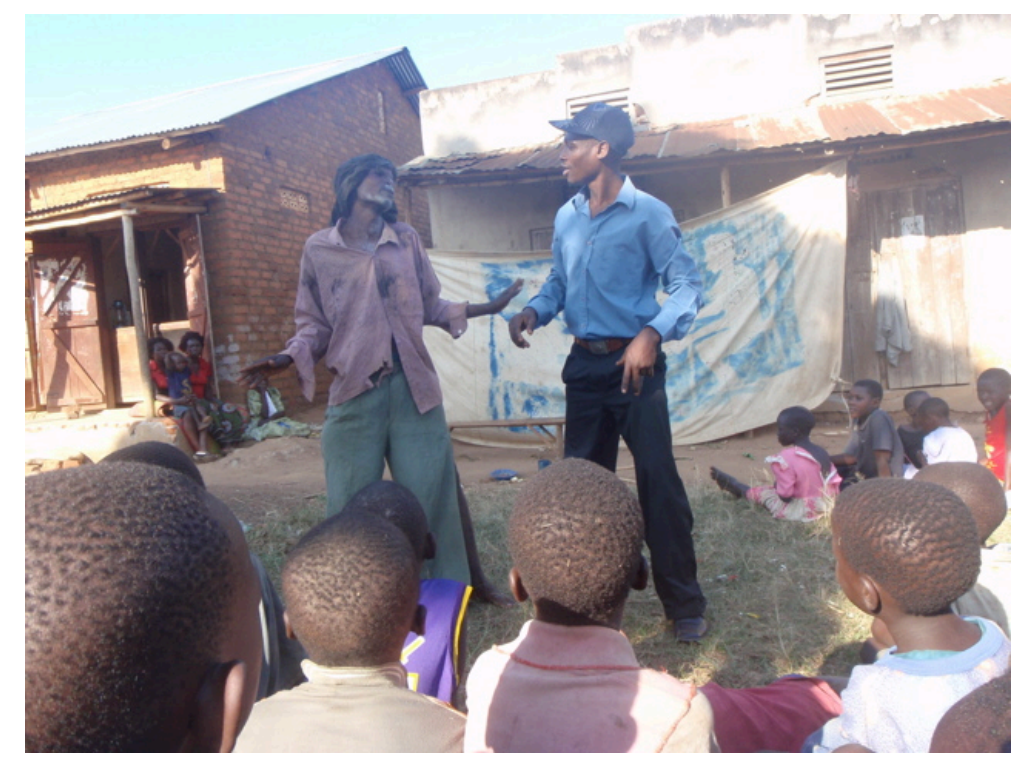

Figure 4.14: The music dance and drama in Kikungwe Village focusing on hand-washing also highlighted improved hygiene and sanitation. A total of 150 people attended shows in both Manyama and Kikungwe.

To further promote hand-washing with soap at critical times, we developed a calendar shown in Figure 4.15 that we printed out and distributed to both Manyama and 
Kikungwe communities as well as a number of health centers, schools and businesses in and around Kalisizo. In total, we distributed 1,000 calendars. We had a local artist depict these scenes in four drawings. We choose to print calendars because they are so valued by Ugandans, who love to hang them in prominent places around their homes. Many of the calendars they purchase commemorate their favorite British football teams or Barack Obama, but many also have social marketing messages like the one we made. The calendars were all very well received and are now displayed prominently throughout the work area.

\subsection{Health Education}

For the health education campaign in Manyama, done as part of the multiple interventions completed there, we again utilized drama shows. This time they were focused on general health topics.

We also had the community sanitation committee that we formed advocate for increased awareness of improved sanitation issues with their neighbors. Lessons concentrated on encouraging households to have a sanitary latrine, wash their hands at critical times, have a drying rack for their dishes, keep their yard neat and clean, treat their drinking water, keep animals penned in, keep a rubbish pit for solid waste, have a sanitary bathing area, use protected water sources if available and to educate them about sound sanitation practices. However, it is unclear how much the committee members actually carried out their tasks. 


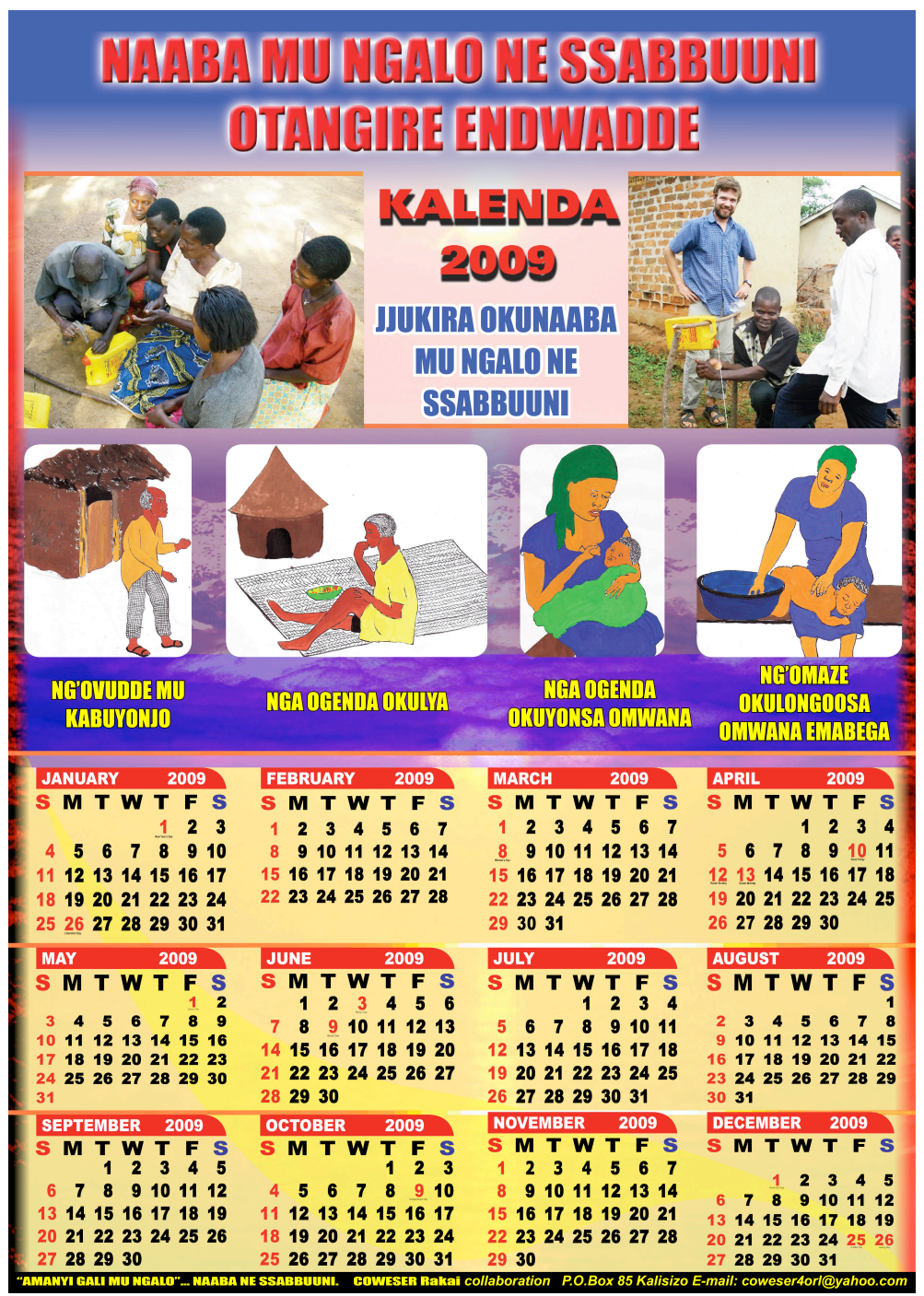

Figure 4.15: A calendar promoting hand-washing with soap. The title at the top says "Wash Your Hand with Soap For better Health." The four pictures depict the four times we want people to washing their hands with soap: after using the toilet, before eating, before breast-feeding and after cleaning a baby's bottom. 


\subsection{Playing Catch Model of Development}

The COWESER team tried as much as possible to utilize the 'playing catch' model of development work throughout the project. In this model, the community is asked to do a certain task. The development workers then wait for the community to respond. Once completed, the development team then implements the next step in the project. This back and forth is continued until the project is complete and sustainability is assured.

The first step in this methodology in our case was to have the communities adequately mobilize themselves for initial meetings. This step was slow and frustrating in some communities, but was highly beneficial because it spread word about the project to community members and allowed us to pick out the most motivated individuals. These were the ones who took over mobilization when the LC leaders proved unwilling to do so and were the most active at the meetings.

The next steps varied from intervention to intervention, but all involved the signing of a community contract to lay out the roles and responsibilities of each party and, in essence, the steps in the 'playing catch model'.

In the case of the shallow well, the community was to provide the majority of the unskilled labor and lunch for the work crew. This empowered the water committees in those communities to organization the work effort and to provide lunch. Our responsibilities were to provide all non-locally available materials and to hire the technical staff. Once the materials were purchased and delivered, it was up to the community to organize themselves, after which we came with the technical staff to oversee the work done. The community was involved in all aspects of the construction process and was trained in pump maintenance and repair. By involving them in every 
step of the process we ensured that they were intimately knowledgeable about the well and made sure they were committed to the new water source.

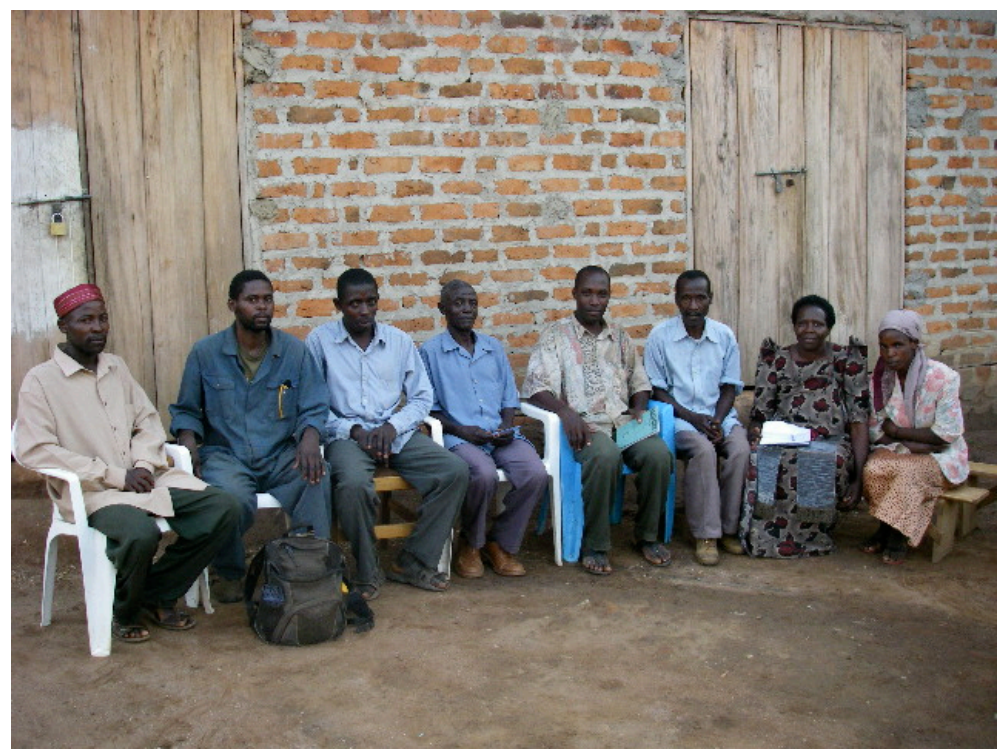

Figure 4.16: The water committee at Manyama Village played an integral part in the 'play catch' model used there.

For the latrines, we first trained approximately five local masons how to construct the latrine slabs in both Manyama and Kalagala. We then paid the masons to construct the latrine slabs at a central location. In this case the 'playing catch' model worked as follows. Individual households dug their own pits. Once dug, they were to get a latrine slab. Once the latrine slab was in place they were responsible for constructing the superstructure. The sanitation committee was instrumental in organizing the effort by encouraging households to dig their pits, keeping a list of the beneficiary households and motivating the masons to complete the work on time.

The water filter project had less obvious opportunities for playing catch. However, households contributed 10,000 shillings $(\$ 5)$ each for their filters. This assures that they really want the filters and that will cherish them. The filters are only delivered to households that have already paid. In addition, the water filter committee was in- 
strumental in mobilizing the community, installing the filters and helping households with operation and maintenance.

The hand-washing programs utilized the hand-washing committees extensively. After training them, they were responsible for constructing the tippy-taps at all households and distributing the calendars. Households were responsible for keeping water and soap at the stations at all times.

\subsection{Sustainability Plan}

Most development projects are successfully completed within the given time frame, but there is usually little follow-up work done with the communities after formal implementation. This mentality was partially offset by frequent follow-up visits to the communities by COWESER staff members to follow-up with the improvements made. On these visits we met with various committees formed, assured that the improvements made were still functioning, encouraged community members to not become lax in their efforts and to rectify any problems faced. The number of visits gradually decreased from January until the end of project implementation in May. It is hoped that after this period of declining direct involvement, the work we did with the communities will be self-sustaining. 


\section{Chapter 5}

\section{Water Accessibility Verses Usage}

\section{Results}

The results from the water accessibility and usage survey conducted by NETWAS Uganda in collaboration with three local NGOs clearly indicate that the established literature on the subject is insufficient to explain water usage in the context of Ugandan rural communities. In what follows, the data is analyzed and compared to the service levels of Howard and Bartram[15].

\section{$5.1 \quad$ Water Usage Trends}

The data presented in the following sections concerning the average per capita usage rates as well as sources used and average distances to sources cannot be taken to be a representative sample of Ugandan households. The survey cohort was specifically chosen because of their poor access to water and the remoteness of their homes. It 
does however give a snapshot at the three districts and gives important information regarding the efforts households in these remote regions of Uganda go to for their daily survival. The data clearly indicates that the vast majority of the survey respondents does not have sustainable access to safe drinking water facilities and are severely water stressed due to the lack of nearby protected or even unprotected sources.

\subsubsection{Average and Variation of Household Usage}

By looking at the survey data one can garner some interesting information about water usage in rural Uganda. First, it is interesting to look at the per capita water usage $^{1}$ to ascertain average values for the amount of water used in the household and the variation in that usage. This data is plotted in histogram form in Figure 5.1. This plot shows that the majority $(77.6 \%, \mathrm{n}=1180)$ of people are getting less than the requisite $20 \mathrm{l} / \mathrm{p} / \mathrm{d}$ to be considered to have 'Basic Access' to water. It also shows that the vast majority of people use between 5 and 25 liters of water per day, which is consistent with expectations.

The second plot, shown in Figure 5.2 is a box and whisker plot showing the per capita usage in all three districts. The average usage was $15.42 \pm 0.50$ liters $(n=1541,95 \%$ CI) per capita per day. The lower median of $13.33 \mathrm{l} / \mathrm{p} / \mathrm{d}$ indicates that the data is skewed towards lower usage rates. However, the data has a very large valid range of 1.50 to $29.44 \mathrm{l} / \mathrm{p} / \mathrm{d}$. The higher value is a reasonable maximum, but the lower value is probably a gross underestimation.

The valid range was defined as follows. The minimum value was calculated by taking

\footnotetext{
${ }^{1}$ It is important to note that since the survey did not differentiate between wet and dry seasons the water usage data shown is assumed to represent a yearly average.
} 


\section{Per Capita Usage}

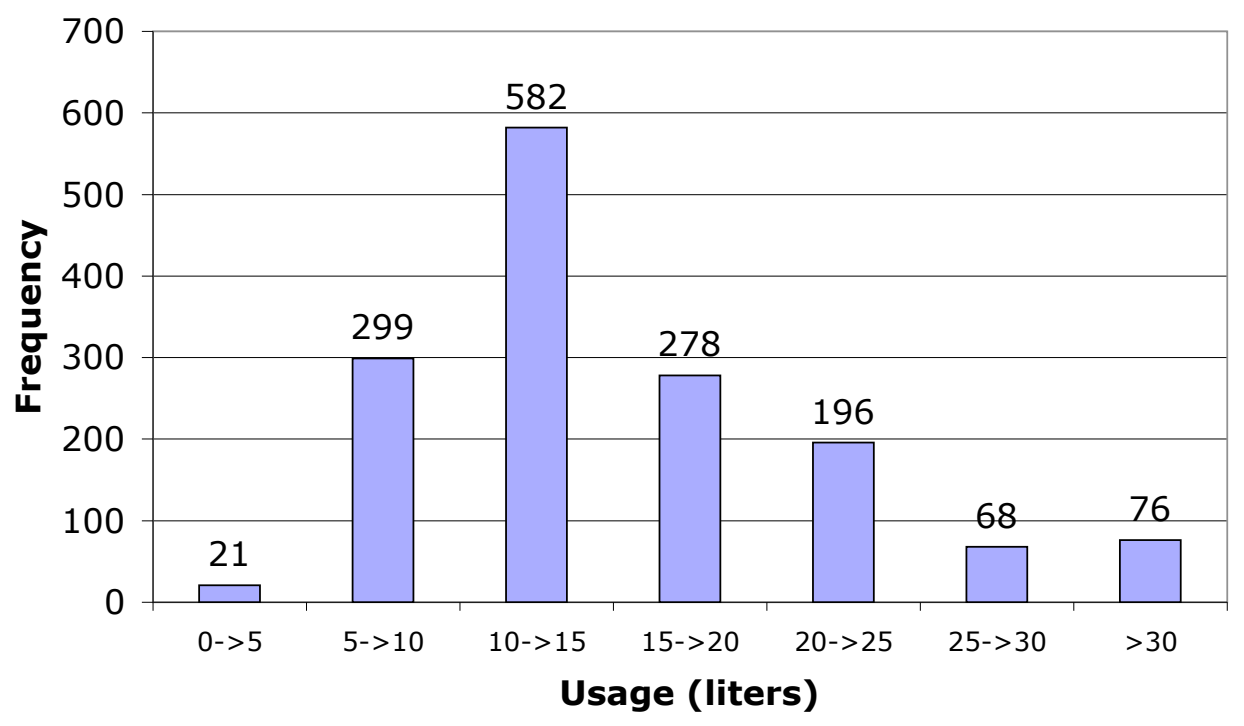

Figure 5.1: A histogram of per capita usage in liters per person per day. It is clear from this plot that the vast majority of people are getting less that their requisite 20 liters per person per day. 
the maximum of either the absolute minimum or the value calculated according to this following equation:

$$
\text { Minimum_Valid }=\text { First_Quartile }-1.5 \times \text { Quartile_Range }
$$

Analogously, the maximum valid was calculated by taking the minimum of either the absolute maximum or the following value:

$$
\text { Maximum_Valid }=\text { Third_Quartile }+1.5 \times \text { Quartile_Range }
$$

Where the quartile range is, in both cases, simply the difference between the first and third quartile values.

\subsubsection{Water Protection Status}

The data also indicates that very few people have what is considered sustainable access to safe water facilities. The pie chart in Figure 5.3 shows that most people $82 \%(\mathrm{n}=1,267)$ get their drinking water from unprotected sources (rivers, swamps, unprotect spring wells etc.) while many of the rest get their water from protected springs $8 \%(n=123)$, boreholes $6 \%(n=91)$ or shallow wells $3 \%(n=45)$. The respon-

dents were also asked whether they got water used for other domestic chores from the same source and the vast majority indicated that they did. 


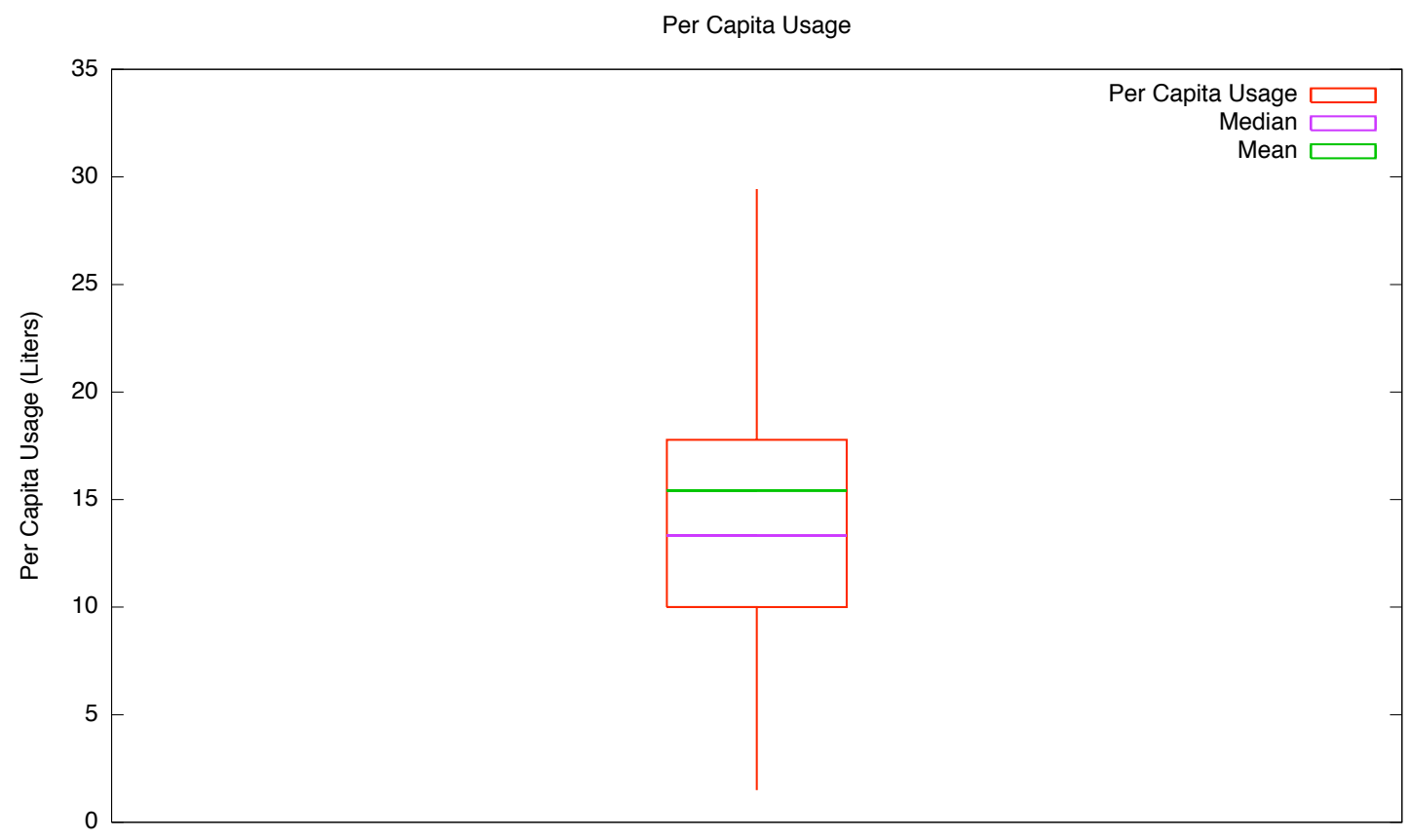

Figure 5.2: $A$ box and whisker plot showing the Per Capita Waster Usage in all three districts. The lower quartile is represented by the bottom of the box while the upper quartile the top. The mean and median values are also shown. The whiskers represent the minimum and maximum valid values. This plot shows that there is a wide variation in values that are skewed towards the upper end. 


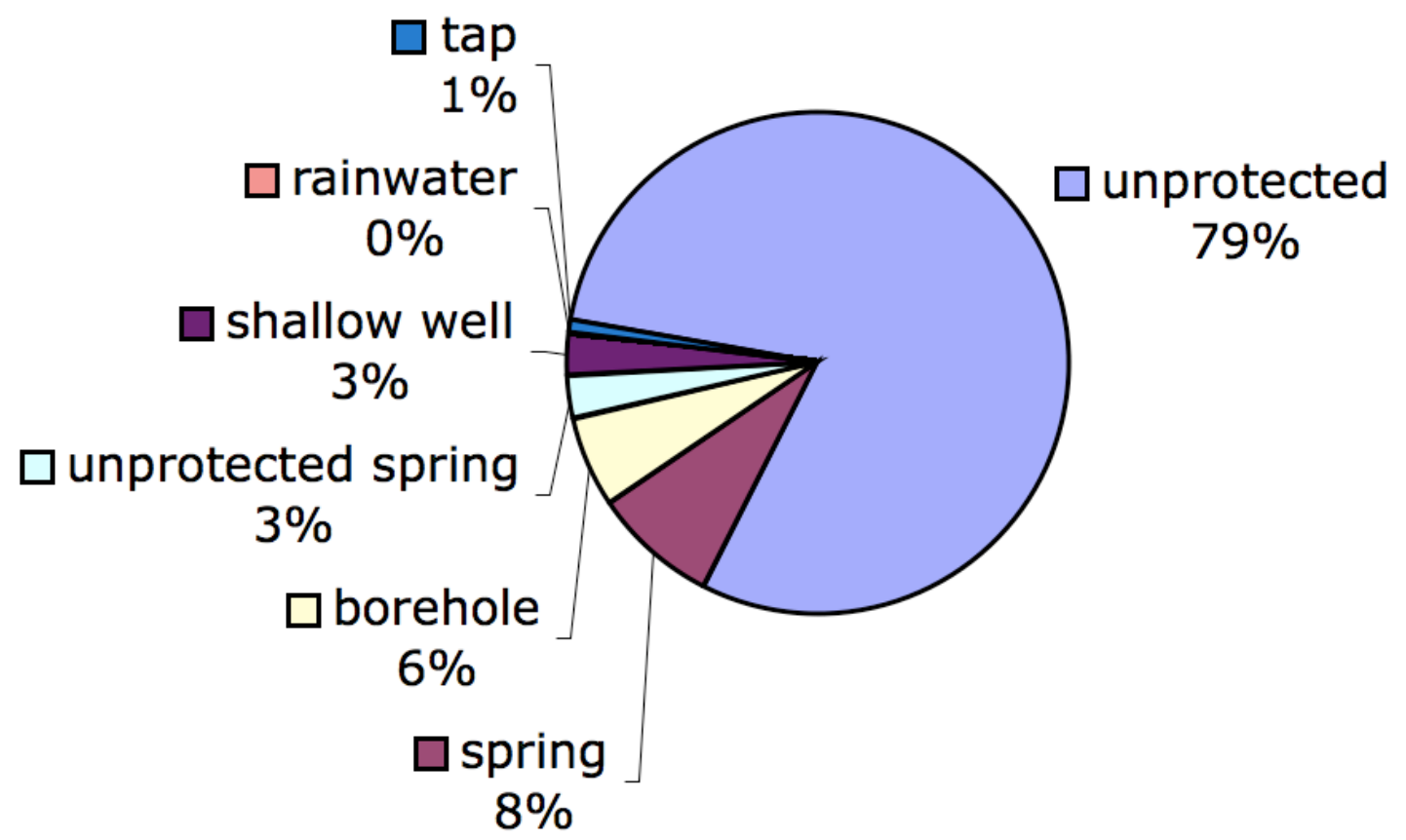

Figure 5.3: A pie chart of water sources used by the population. Most people, 82\% $(n=1,267)$ get their water from unprotected sources, while minorities get their water from springs $8 \%(n=123)$, boreholes $6 \%(n=91)$ or shallow wells $3 \%(n=45)$. 
Wet vs Dry Distance to Source

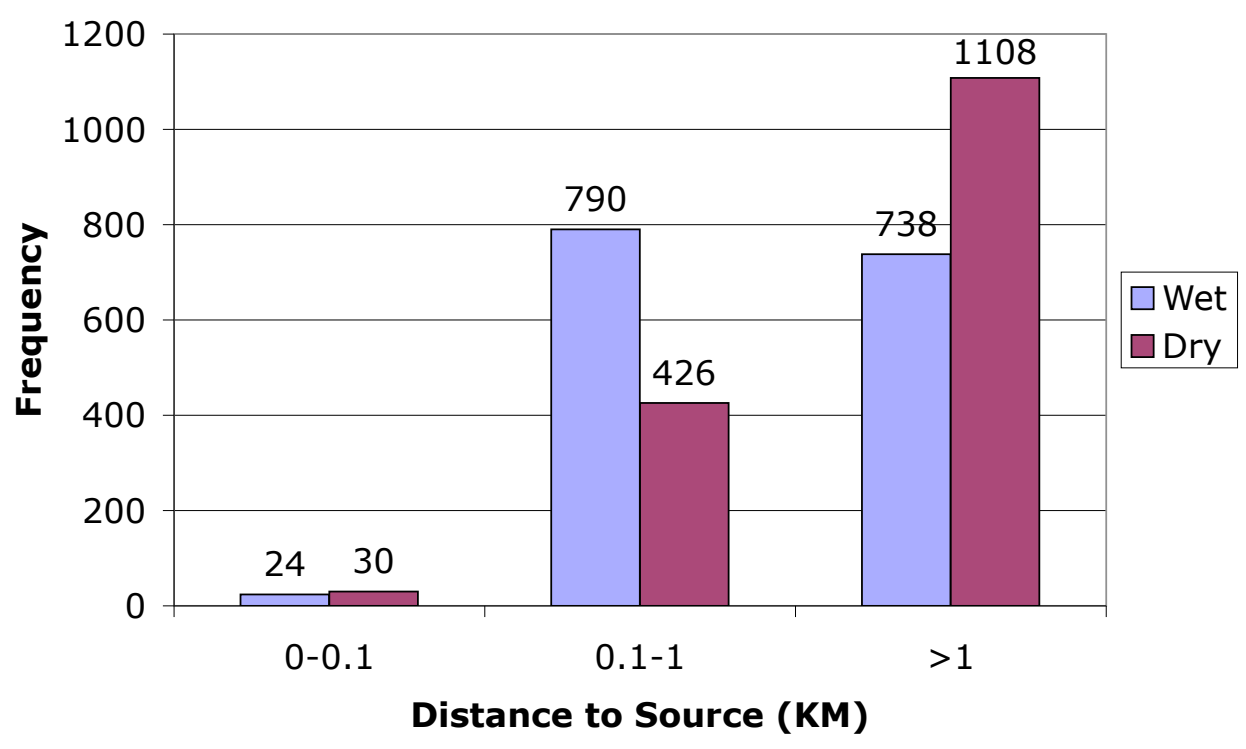

Figure 5.4: A histogram comparing the wet versus dry seasons travel distances to water sources. The data indicates that only 52.4\% ( $n=814)$ of households are located within 1 kilometer of a water source during the wet season while only 29.2\% $(n=456)$ are as close during the dry season. 


\subsubsection{Distance and Time to Source and Seasonal Variation}

In addition to the poor quality of water sources used, travel distance to sources was very high in almost all cases and is exacerbated during the two dry seasons which last for about half the year. Figure 5.4 is a histogram that compares the distance villagers must travel to fetch water. It is clear that many have to travel much farther during the dry season, but that, even in the wet season, most people still do not have any water source within 1 kilometer of their home. In fact, only $54.2 \%(\mathrm{n}=814)$ are $1 \mathrm{~km}$ or less from a source in the rainy season which decreases to $29.2 \%(\mathrm{n}=456)$ in the dry season. Note that these statistics are the distance to any water source. As Figure 5.3 indicates, most people gather their water from unprotected sources.

Figure 5.4 gives a snapshot of the distances people have to go to fetch water and is important for understanding the generalizability of the results. This diagram clearly shows that the vast majority (98.5\%) of the survey respondents had to travel more than 100 meters to fetch water. This led to large statistical uncertainties for this group that was considered to have 'Intermediate' access to water facilities. However, the authors ran all of the analyses for various distance ranges thereby ensuring that conclusions made are valid no matter how the data was divided.

Figure 5.5 compares both wet and dry season distances that the research participants had to travel to get water. The mean value in the wet season was $1.64 \pm 0.07 \mathrm{~km}$ (n $=1,534,95 \% \mathrm{CI})$. Households had to travel farther in the dry season $2.57 \pm 0.09 \mathrm{~km}$ $(\mathrm{n}=1,541,95 \%$ CI $)$.

The wet and dry season box and whisker plots for the collection time, shown in Figure 5.6, shows a similar trend. The average time to collect water during the wet and dry seasons was respectively $1.37 \pm 0.03$ hours $(\mathrm{n}=1,519,95 \% \mathrm{CI})$ and $2.19 \pm 0.04$ 


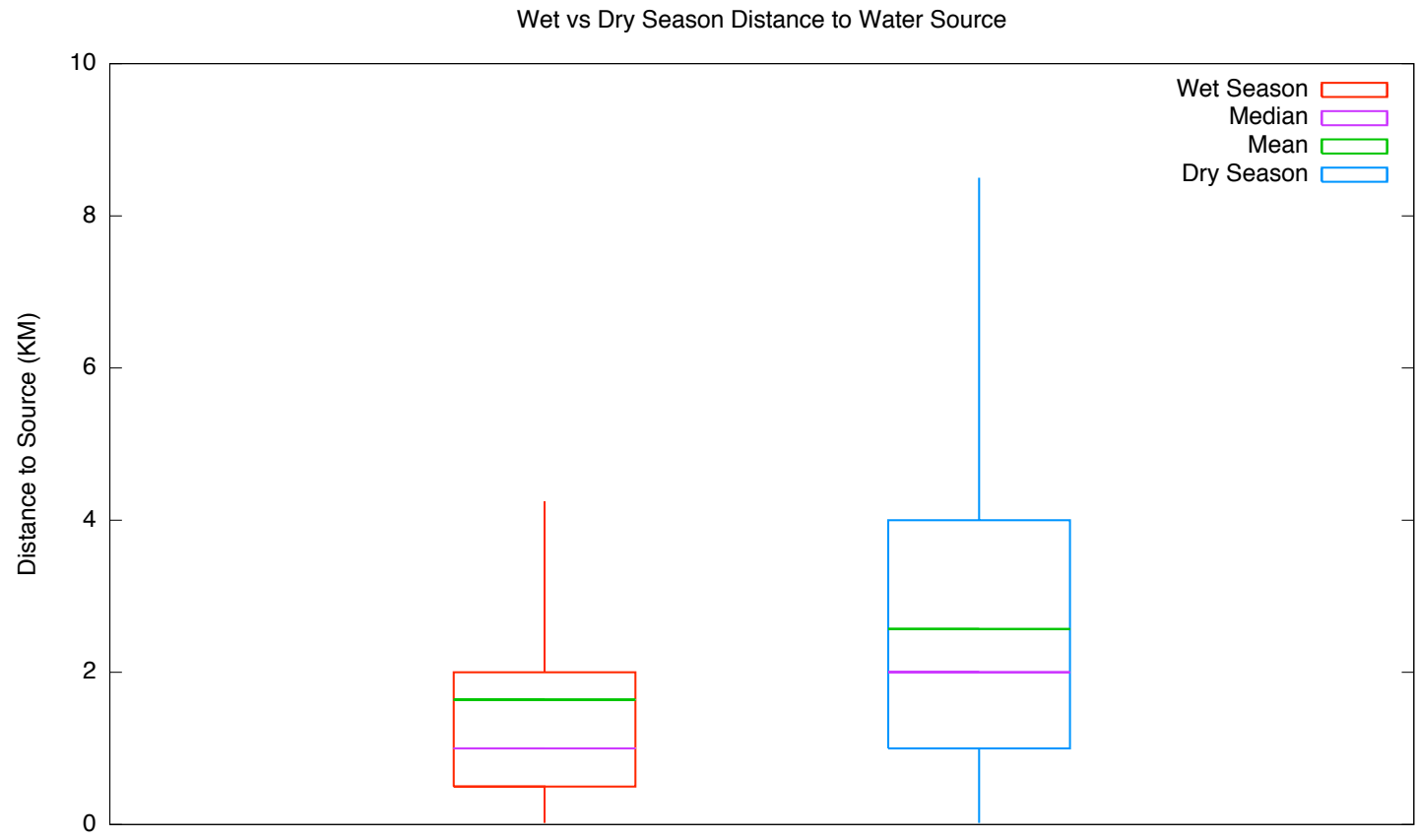

Figure 5.5: $A$ box and whisker plot showing the distance to water sources in all three districts. The lower quartile is represented by the bottom of the box while the upper quartile the top. The mean and median values are also shown. The whiskers represent the minimum and maximum valid values. These plots show a definite increase in the distance the research participants had to travel to get water during the dry season. Both also indicate a large spread in the data and are both weighted towards the lower values. 
hours $(\mathrm{n}=1,526,95 \% \mathrm{CI})$.

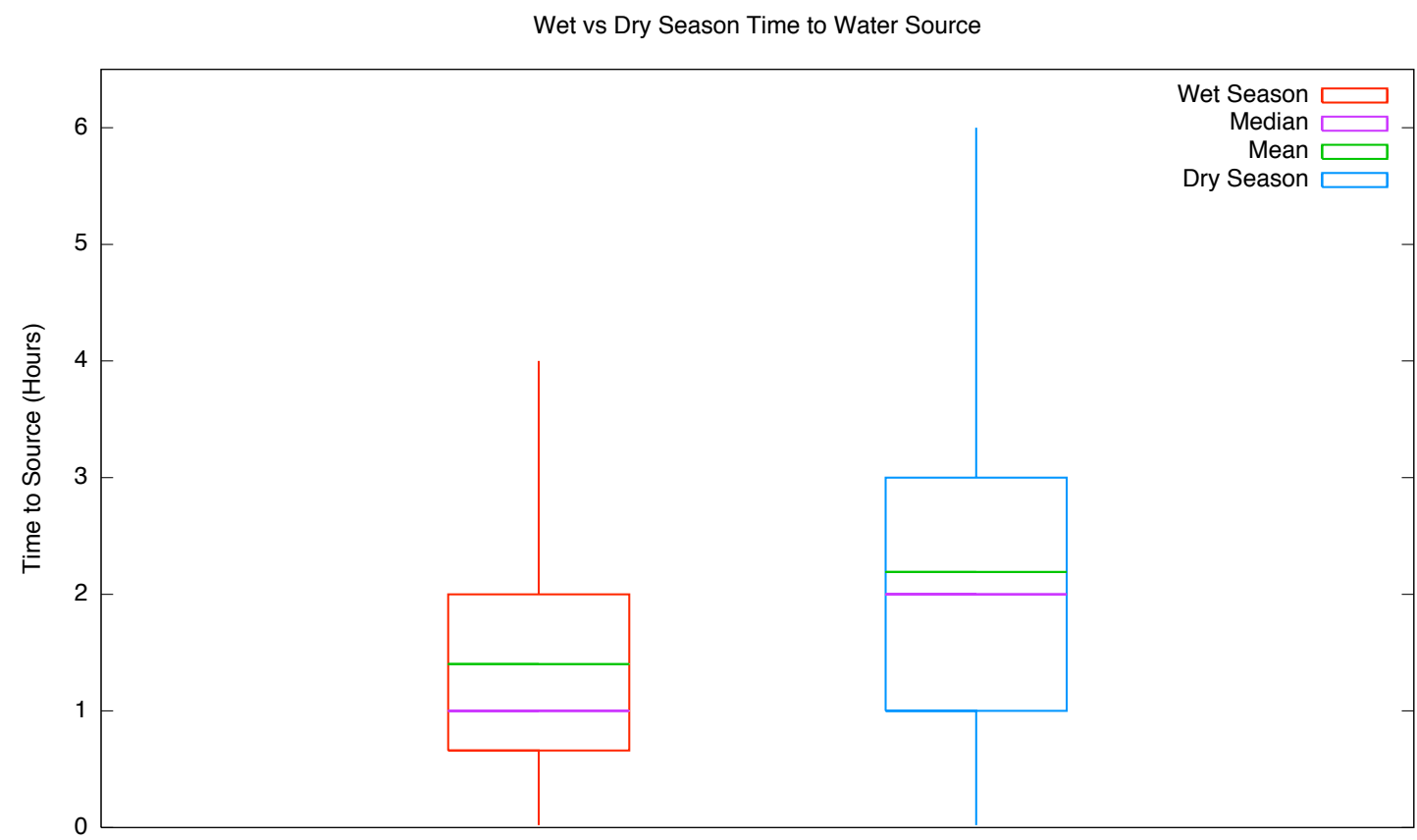

Figure 5.6: $A$ box and whisker plot showing the time to water sources in all three districts. The lower quartile is represented by the bottom of the box while the upper quartile the top. The mean and median values are also shown. The whiskers represent the minimum and maximum valid values. These plots show a definite increase in the distance the research participants had to travel to get water during the dry season. The dry season values also indicate a larger spread in the data as some, but not all, families have to travel farther during the drier parts of year. Both skewed towards the lower values as indicated by the median values.

The data in Figures 5.4 and 5.5 shows that many, but not all, people have to travel farther during the dry season to fetch water, adding to an already heave burden. In fact, households had to travel an average of $0.93 \mathrm{~km}$ farther during the dry season. The fact that medians during the wet and dry season (1 and $2 \mathrm{~km}$ respectively) were both below their means indicates that the data is skewed to the lower end. The large range is also visually evident in both cases in the figure. The valid ranges were 0.02 - $4.25 \mathrm{~km}$ versus $0.02-8.5 \mathrm{~km}$ for the wet and dry season respectively. The increased range indicates that as sources dry up, some families must travel farther and farther 
to fetch water, but many also can continue to get water from their old sources.

The fact that the time plots shown in Figure 5.6 are similar to the distance plots confirms that both time and distance to the source represent similar measures of the effort households take to fetch water. As with the distance data, the increased spread of the data indicates that some, but not all families must travel farther for water during the dry season thereby increasing the spread of the data. The valid ranges are large in both cases, but increase dramatically during the dry season as can be seen from the numbers as well as visually in the plot (.02 - 4.01 versus $.02-6$ hours).

\subsubsection{Time vs Distance Measurements}

The measurements for this study were all taken from recall data from the study participants. They were simply asked how far and how long it takes to collect their water. This therefore begs the question of how correlated the two measurements were. The box plot shown in Figure 5.7 shows that, to a large extent, the two measures are equivalent. Despite the fact that there are outliers, the limits on the upper and lower quartile indicate that most of the measurements were fairly precisely obtained. For instance, the quartile range for the three ranges, $<0.1 \mathrm{~km}, 0.1$ to $1 \mathrm{~km}$ and $>1 \mathrm{~km}$ were respectively $0.16,0.50$ and 1 hour. This is a remarkable correlation particularly for the longer distances because of the fact some with 'No Access' (collection distances greater than $1 \mathrm{~km}$ ) had collection distances ranging up to $5 \mathrm{~km}$.

To further investigate the correlation between the time and distance, the Pearson's Coefficient for the two was calculated to be $r=0.474$ making the coefficient of determination $r^{2}=0.22$ and $\left(F_{(1550)}=21.171, p<0.001\right)$, indicating a weak, but statistically significant correlation between the two. 


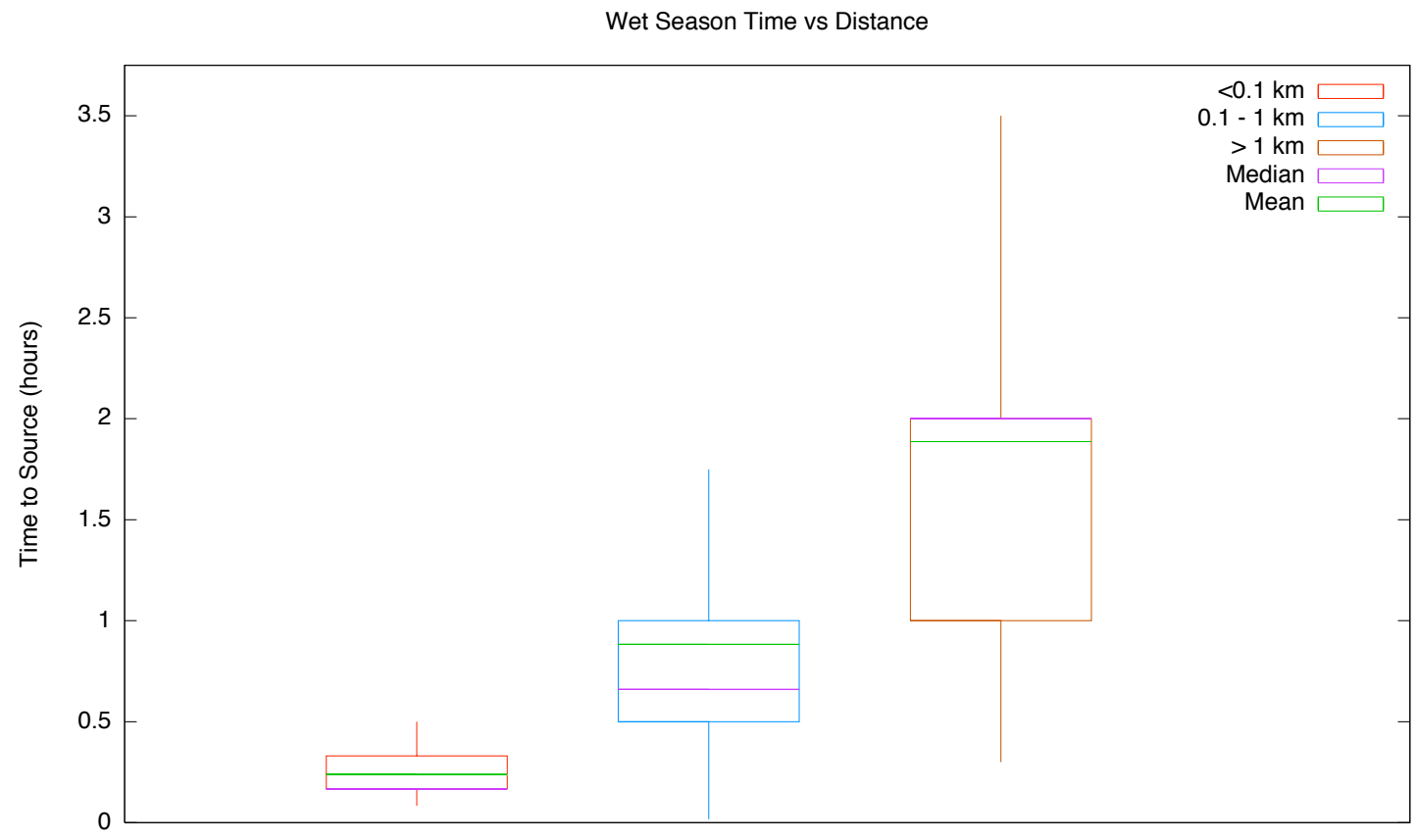

Figure 5.7: $A$ box and whisker plot giving the range of the collection time for the three service levels during the wet season. The lower quartile is represented by the bottom of the box while the upper quartile the top. The mean and median values are also shown. The whiskers represent the minimum and maximum valid values. Although there is a significant amount of variability in the data, the trend of increasing collection times with increasing distances indicates that the distance and time measurements are highly correlated. 


\subsection{Collection Effort and Usage Correlation}

According to the prevailing literature there should be a measurable correlation between the amount of water people use and the effort they take to collect it. Whether that effort can be divided up by service levels or is a simpler linear correlation should be apparent from this data.

\subsubsection{Simple Correlations and Histograms}

As the linear correlations show, this proved not to be the case. Figure 5.8 shows the per capita usage as a function of source distance for all three districts for both the wet and dry seasons. Also shown on the graph are the best-fit linear regression lines. In both cases, the slope is close to 0 and $R^{2}$ values are likewise very small indicating there is essentially no change in water usage even when collection distance exceeds 5 kilometers.

Furthermore a plot of water usage as a function of collection times, shown in Figure 5.9 , reinforces the distance data. The small slopes of the best-fit lines and the low $R^{2}$ values indicate an essentially constant usage.

Although quick visual glances at both plots seem to indicate a prevalence of data points in the upper left (short collection distances/times and high usage) this must be an optical illusion due to the pixilation of the of the plotting program used. The linear correlations indicate that most points overlap each other and are therefore not visible.

This same data is also given in histogram form in Figure 5.10. It is clear from this data that water usage remains relatively constant for all service levels. Although, 

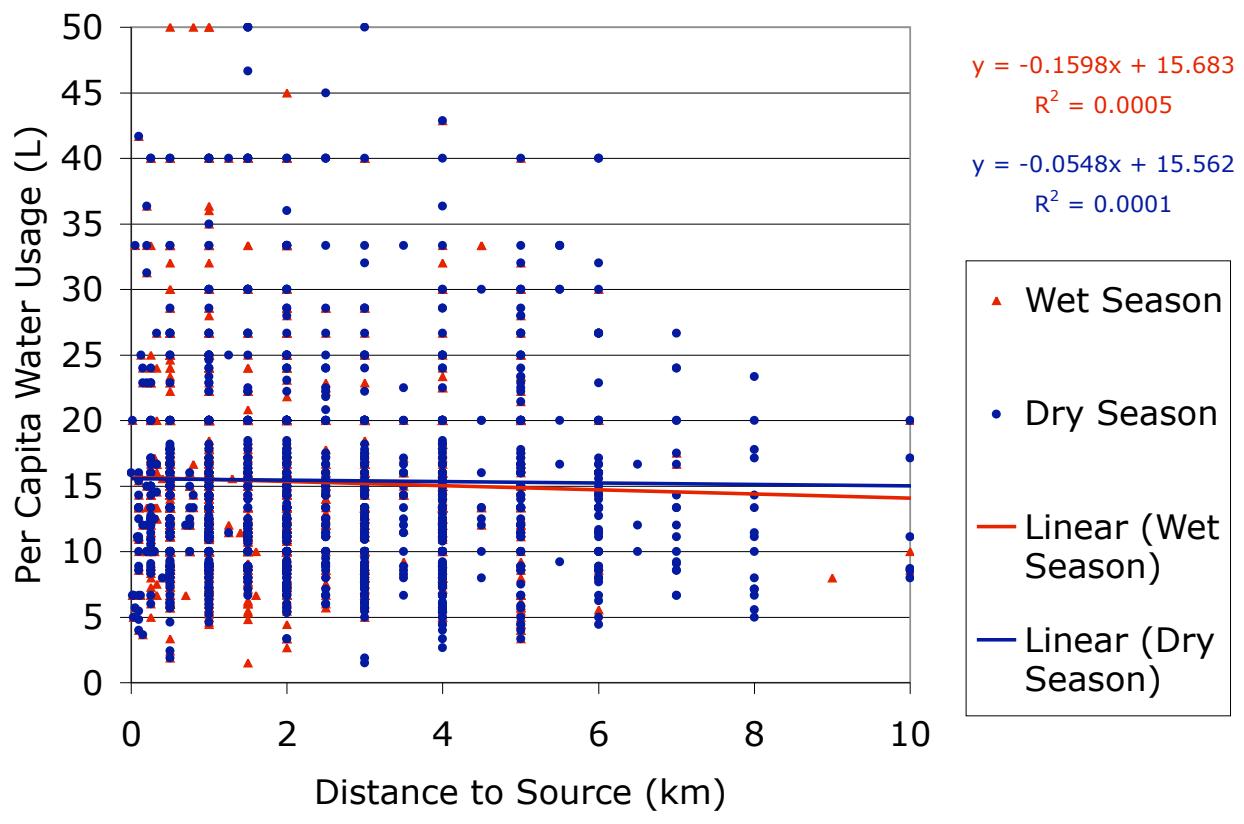

Figure 5.8: Per capita usage as a function of water source distance for both wet (red points) and dry seasons (blue points) in all districts surveyed. The red and blue lines are the best-fit lines whose slopes indicate that usage is not correlated with collection distances or times. 


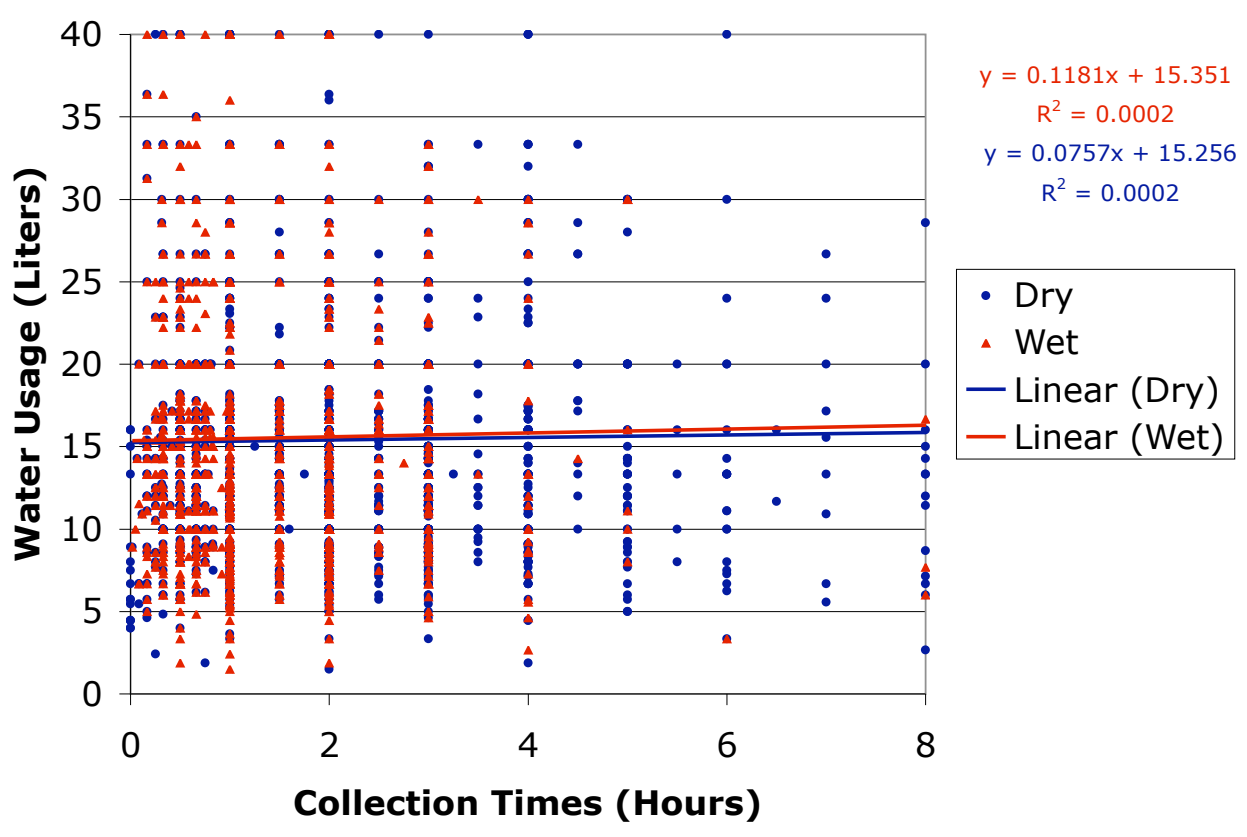

Figure 5.9: Per capita usage as a function of collection time for both wet (red points) and dry seasons (blue points) in all districts surveyed. The red and blue lines are the best-fit lines whose slope and small $R^{2}$ value indicates a very weak correlation. 
surprisingly, the per capita usage rates for those with 'Intermediate Access' are less than the others this is probably due to the low statistics since the $95 \%$ confidence level intervals are much larger for this data set. Plotted on the same plot in yellow are the quantities of water typically consumed according to Howard and Bartram at the various service levels. It is clear from this data that the per capita usage values obtained for this survey are far different from their values.

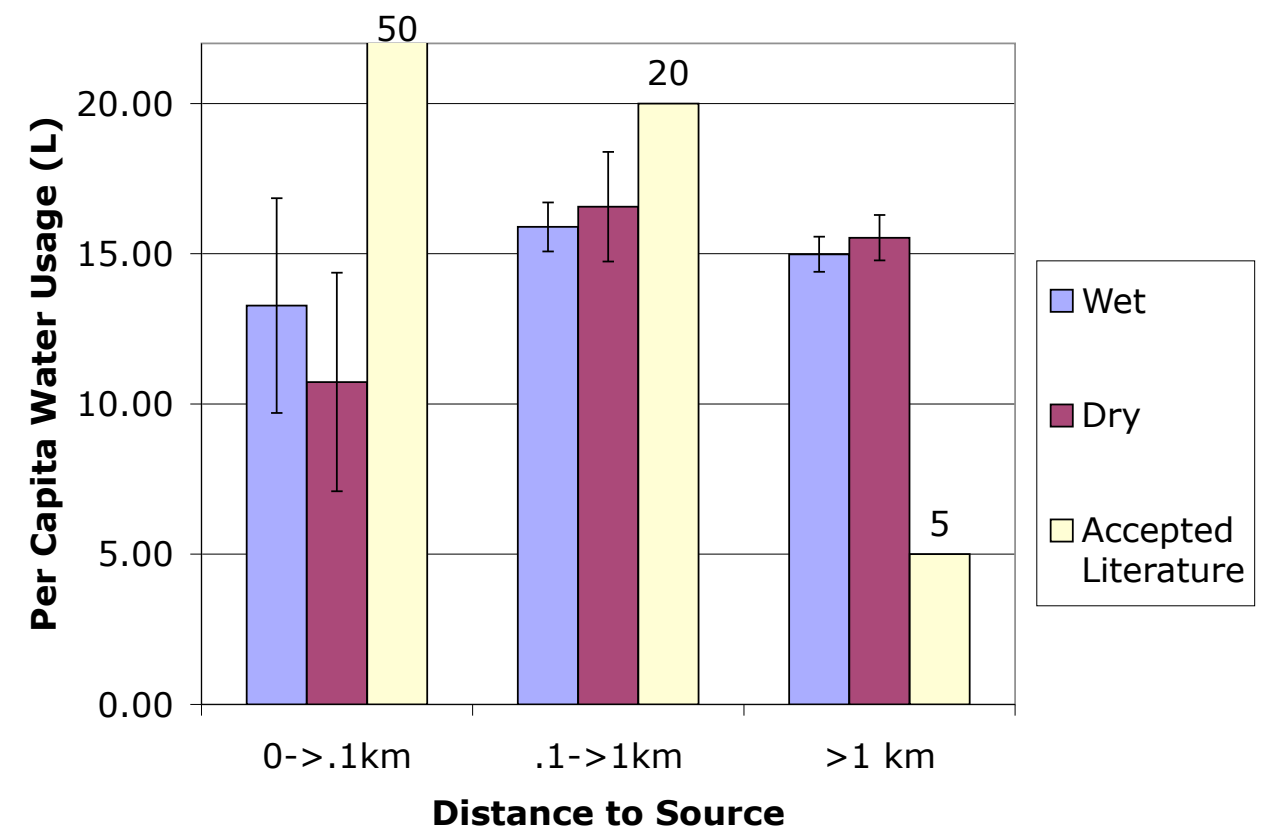

Figure 5.10: A histogram of per capita usage and distance to source. It is clear from this data that the water used per capita does not change significantly for any of the service levels. It is also relevant to note that the quantities of water typical for different service levels defined by [15] and shown in yellow are not consistent with this data. [Note that the Accepted Literature value for distances less than $0.1 \mathrm{~km}$ is far off the chart.] Error bars indicate the $95 \%$ confidence intervals. 


\subsubsection{Regional Variation}

Given the varied cultural, tribal, geographical and climatic variations between the three districts surveyed and the high number of individual surveyor techniques used by the different NGOs, one would expect there to be a variation in the per capita usage from district to district. However, the data shows a remarkable degree of consistency as can be seen in Figure 5.11. Although data for those with 'Intermediate Access' has large error bars due to the low number of respondents, those with 'Basic' and 'No' access show a very high degree of consistency across all three districts.

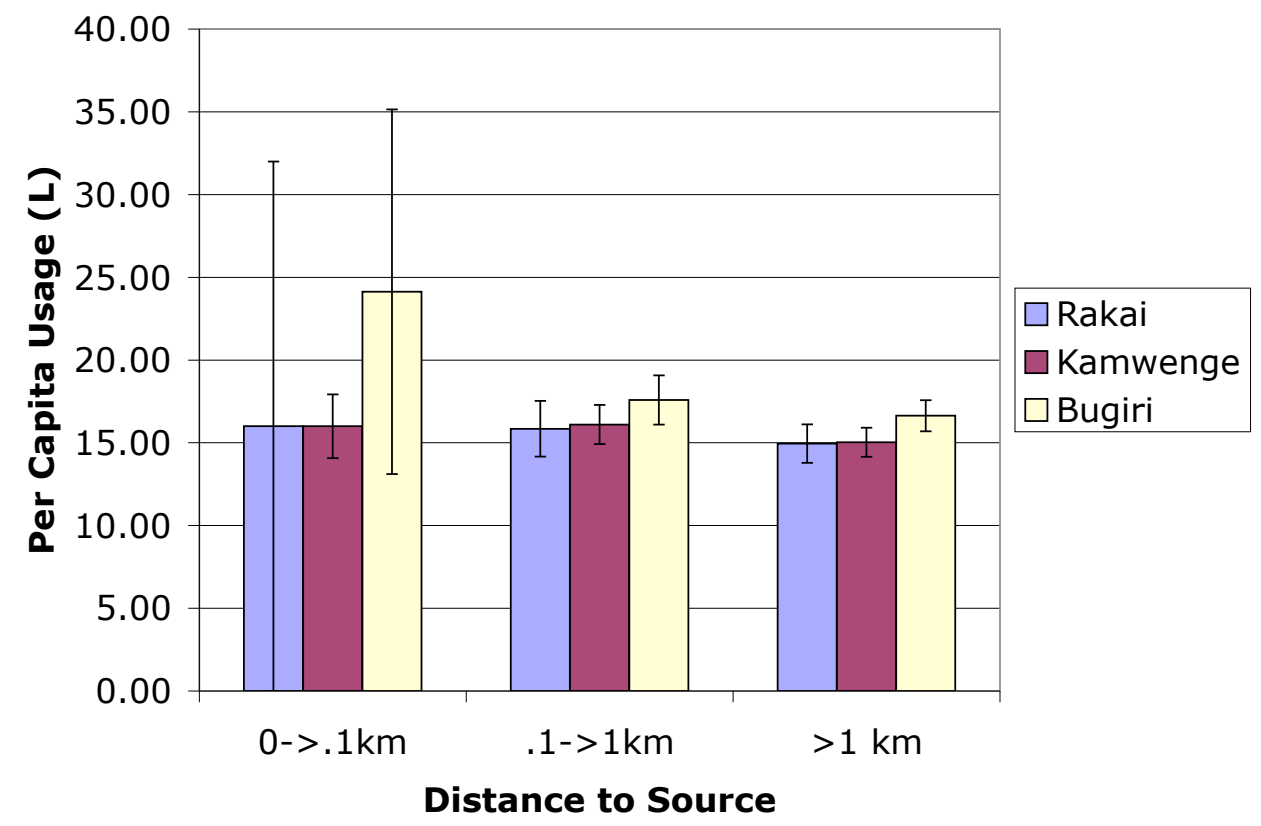

Figure 5.11: Per capita usage across the three districts is remarkably consistent. The large error bars for those with 'Intermediate Access' are due to the low number of respondents in that category. The other levels of access are statistically equal across all districts. 


\subsubsection{Pearson's Coefficient of Correlation}

In an attempt to find correlations between the amount of water used and the distance to the source the Pearson's coefficients of correlation were calculated for the data set as a whole as well as for segments of the data.

The data for both wet and dry season distance and time measurements is summarized in Table 5.1. In all cases, the distance/time to the source is considered the independent variable and the per capita usage is the dependent variable. The data is divided into the standard ranges representing the 'Intermediate,' 'Basic' and 'No' access service levels defined earlier. The number of households falling into those ranges as well as the Pearson's coefficient, coefficient of determination and the test statistic $t$ is given.

In all cases the values of the Pearson's coefficients are all very low with large probable errors due to the variability of the data. The coefficients of determination are likewise very low with explained variances being no more than $3.5 \%$ of the total variance in the data. Data for the time measurements shows the same patterns as the distance measurements.

The test statistic $t$ was also calculated and is defined as:

$$
t=r \sqrt{\frac{n-2}{1-r^{2}}}
$$

where $r$ is the Pearson's Coefficient and $n$ is the number of households. Tabulated

$t$ values at the $5 \%$ confidence levels for the degrees of freedom in question are all between 1.65 and 2.13. When compared with the values in Figure 5.1 it is apparent that there is essentially no correlation within any of the service level ranges or within 
Table 5.1: Pearson's Coefficients, Coefficients of Determination and the test statistic $t$ calculated for the wet and dry season distance and time measurements. The universally small Pearson's Coefficients, Coefficients of Determination and t values all indicate essentially no correlation within the three service levels or the range as a whole. This was true not only for the data as it was divided here, but also with all other divisions investigated by the author, but not included in this report.

\begin{tabular}{|c|c|c|c|c|c|}
\hline & $\begin{array}{c}\text { Dist/Time } \\
\text { Range } \\
(\mathrm{km} / \mathrm{min})\end{array}$ & Households & $\begin{array}{l}\text { Pearson's } \\
\text { Coefficient }\end{array}$ & $\begin{array}{l}\text { Coeff. } \\
\text { of } \\
\text { Det. }\end{array}$ & $\begin{array}{c}\text { Test } \\
\text { Statistic } \\
t(0.05)\end{array}$ \\
\hline \multirow{2}{*}{\multicolumn{6}{|c|}{$\begin{array}{c}\text { Wet Season } \\
\text { Distance }\end{array}$}} \\
\hline & & & & & \\
\hline & $<.1$ & 23 & $0.15 \pm 0.14$ & 0.022 & 0.69 \\
\hline & $.1-1$ & 780 & $0.04 \pm 0.02$ & 0.001 & 1.04 \\
\hline & $>1$ & 419 & $0.00 \pm 0.02$ & 0.000 & 0.04 \\
\hline & all & 1534 & $-0.02 \pm 0.02$ & 0.000 & -0.87 \\
\hline \multicolumn{6}{|l|}{ Dry Season } \\
\hline \multicolumn{6}{|l|}{ Distance } \\
\hline & $<.1$ & 26 & $0.06 \pm 0.13$ & 0.004 & 0.31 \\
\hline & $.1-1$ & 419 & $-0.01 \pm 0.03$ & 0.000 & -0.30 \\
\hline & $>1$ & 1096 & $-0.03 \pm 0.02$ & 0.001 & -0.89 \\
\hline & all & 1541 & $-0.01 \pm 0.02$ & 0.000 & -0.40 \\
\hline \multirow{2}{*}{\multicolumn{6}{|c|}{$\begin{array}{c}\text { Wet Season } \\
\text { Time }\end{array}$}} \\
\hline & & & & & \\
\hline & $<5$ & 7 & $0.19 \pm 0.25$ & 0.036 & 0.43 \\
\hline & $5-30$ & 330 & $-0.05 \pm 0.04$ & 0.003 & -0.93 \\
\hline & $>60$ & 1182 & $0.02 \pm 0.02$ & 0.000 & 0.75 \\
\hline & all & 1519 & $0.01 \pm 0.02$ & 0.000 & 0.58 \\
\hline \multirow{2}{*}{\multicolumn{6}{|c|}{$\begin{array}{c}\text { Dry Season } \\
\text { Time }\end{array}$}} \\
\hline & & & & & \\
\hline & $<5$ & 6 & $0.04 \pm 0.27$ & 0.002 & 0.08 \\
\hline & $5-30$ & 199 & $-0.03 \pm 0.05$ & 0.001 & -0.45 \\
\hline & $>30$ & 1321 & $0.01 \pm 0.02$ & 0.000 & 0.37 \\
\hline & all & 1526 & $0.00 \pm 0.02$ & 0.000 & 0.14 \\
\hline
\end{tabular}


whole range. Furthermore, the author calculated all of the above parameters for a myriad of different distance and time ranges never finding a statistically significant correlation at the $5 \%$ significance level.

\subsubsection{Analysis of Variance}

The data was divided into the standard service level divisions defined earlier to confirm the previous analysis - that there is no difference in per capita water usage for the different service levels.

The analysis was performed using standard techniques using the SPSS data analysis tool and the output is shown in Tables 5.2 and 5.3. As is shown in Table 5.3, in all cases the null hypothesis is most attractive option since the tabulated $F$ values calculated at the $95 \%$ confidence levels are all more than the calculated $F$ values. This same conclusion holds true not only for the divisions shown in this report, but also for a number of different divisions of the time and distance data.

\subsubsection{Synthesis and Conclusions of Usage and Effort Corre- lations}

Based on the analysis presented in Section 5.2 there is no evidence to suggest any differences in water usage for any of the service levels. This holds true not only for the service-level divisions presented in this report, but also for all the divisions tried by the researchers. Although this finding is somewhat surprising, it is plausible given the daily lives of rural Ugandans. Even if the data for those with 'Intermediate' access is considered to be inaccurate due to the low statistics this data implies, at a minimum, 
Table 5.2: ANOVA analyses for both distance and time to source measurements during both seasons. In each case the data was divided into three different service categories and the variance was calculated both between and within the sample ranges.

\begin{tabular}{|c|c|c|c|c|}
\hline Variable & Season & $\begin{array}{l}\text { Source of } \\
\text { Variation }\end{array}$ & $\begin{array}{l}\text { Sum of } \\
\text { Squares }\end{array}$ & $\begin{array}{c}\text { Degrees } \\
\text { Freedom }\end{array}$ \\
\hline \multirow[t]{3}{*}{ Distance } & Wet & & & \\
\hline & & Between Groups & 422.352 & 2 \\
\hline & & Within Groups & 154,006 & 1,531 \\
\hline \multirow[t]{3}{*}{ Distance } & Dry & & & \\
\hline & & Between Samples & 264.327 & 2 \\
\hline & & Within Samples & 155,398 & 1,538 \\
\hline \multirow[t]{3}{*}{ Time } & Wet & & & \\
\hline & & Between Samples & 146.775 & 2 \\
\hline & & Within Samples & 154,224 & 1,516 \\
\hline \multirow[t]{3}{*}{ Time } & $\overline{\text { Dry }}$ & & & \\
\hline & & Between Samples & 208.653 & 2 \\
\hline & & Within Samples & 154,293 & 1,523 \\
\hline
\end{tabular}

Table 5.3: Summary Table of ANOVA F Values for all seasons. F as calculated from tables is more than $F$ calculated from the data in all cases implying that there is no significant difference (95\% confidence levels) in the data means.

\begin{tabular}{cccc}
\hline Variable & Season & Tabulated F & Calculated F \\
\hline \hline Distance & Wet & 3.002 & 2.099 \\
\hline Distance & Dry & 3.002 & 1.308 \\
\hline Time & Wet & 3.002 & 0.721 \\
\hline Time & Dry & 3.002 & 1.030 \\
\hline
\end{tabular}


the water usage plateau is much longer than that supposed by Howard and Bartram. In fact, even when one looks at the amount of water collected by those who have to travel more than 5 kilometers, per capita usage remains relatively constant. This data also shows that nearly all the survey participants use more than $5 \mathrm{l} / \mathrm{p} / \mathrm{d}$, the assumed usage for those who have to travel farther than $1 \mathrm{~km}$ to collect water.

The data is displayed in tabular form in Figure 5.4 alongside service levels described by Howard and Bartram to further emphasize the point being made.

Table 5.4: Howard and Bartram service levels in terms of distance and time. The data indicates that, contrary to Howard and Bartram's assumptions, that the amount of water used per capita is not strongly correlated with the service levels they define. In addition, there is no obvious drop off for very long collection times as predicted by those authors.

\begin{tabular}{|c|c|c|c|}
\hline Service Level & $\begin{array}{c}\text { Access Level } \\
\text { (Distance) }\end{array}$ & $\begin{array}{c}\text { Per Capita } \\
\text { Water Usage (L) }\end{array}$ & Sample Size \\
\hline No Access & more than 1 km & $14.98 \pm 0.58$ & 731 \\
\hline Basic Access & $100 \mathrm{~m}-1 \mathrm{~km}$ & $15.89 \pm 0.81$ & 780 \\
\hline Intermediate Access & less than 100 m & $13.27 \pm 3.57$ & 23 \\
\hline Service Level & $\begin{array}{c}\text { Access Level } \\
\text { Collection Time) }\end{array}$ & $\begin{array}{c}\text { a } \\
\text { Water Usage (L) }\end{array}$ & Sample Size \\
\hline No Access & more than 30 min & $15.48 \pm 0.57$ & 1182 \\
\hline Basic Access & $5-30$ min & $15.71 \pm 1.11$ & 330 \\
\hline Intermediate Access & less than 5 min & $11.15 \pm 3.51$ & 7 \\
\hline
\end{tabular}

These results are consistent with the results of Kennedy [19] who found that those with collection times between 5 and 30 minutes used $15.8 \mathrm{l} / \mathrm{p} / \mathrm{d}$ and those with collection times greater than 30 minutes used $16.4 \mathrm{l} / \mathrm{p} / \mathrm{d}$. Although, he did find that those with 'Intermediate' access used $20.6 \mathrm{l} / \mathrm{p} / \mathrm{d}$, which is more than these findings. Kennedy also found a longer than expected plateau of collection amounts.

This author agrees with Kennedy's assertions that people need a certain amount of water to maintain their households, they will collect that same amount of water regardless of the distance or time they must travel to get it and that amount of water 
is around $15 \mathrm{l} / \mathrm{p} / \mathrm{d}$.

\subsection{Socioeconomic Indicators}

\subsubsection{Household Size}

Although the distance and time to source shows little correlation to the amount of water used, socioeconomic indicators do appear to show real trends. The first strong correlation is with household size. According to Figure 5.12 smaller households tend to use far more water per capita than larger households. Ugandan households are very large - the average woman has around 7 children. In this study the average household size was a $7.80 \pm 0.22$ persons $(n=1,563,95 \%$ CI).

This plot is supported by the Pearson's analysis that was conducted. For the data in question the Pearson's $R$ was 0.302 making the coefficient of determination 0.091. In other words approximately $9.1 \%$ of the variance in per capita usage can be explained by household size. The $t$ statistic was then calculated to be 12.45 compared to the table value at the $95 \%$ confidence level of 1.645 , indicating that there is a statistically significant correlation between the two.

Taken together there seems to be a moderate relationship in the amount of water used per capita and the household size. Those with larger households use less water per capita. There could be multiple factors behind this trend. The first is an economy of scale argument. Larger households need less water per capita because, for instance, doing twice as much laundry does not necessarily mean families use twice as much water. Secondly, even with very large households with lots of idle children mobilizing 
Household Size vs Per Capita Usage

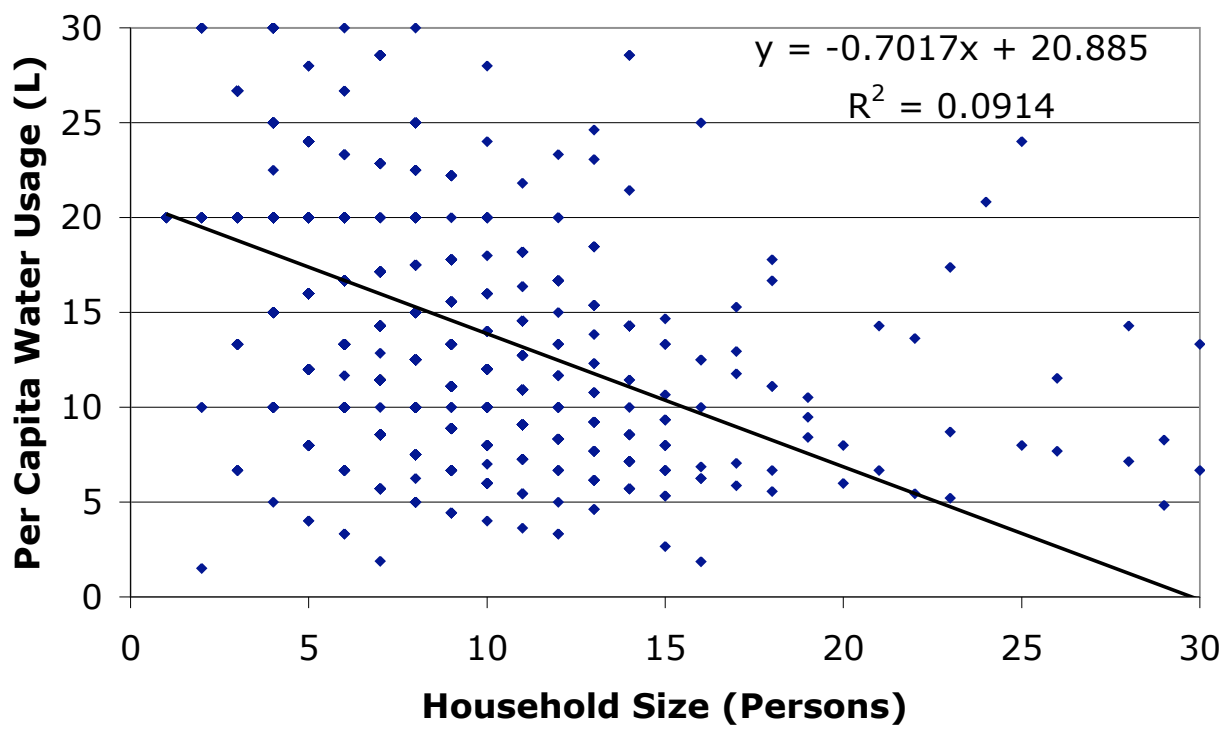

Figure 5.12: This graph indicates a relatively strong $\left(R^{2}=.09\right)$ correlation between per capita usage and household size. As indicated by the best-fit line, larger households use significantly less water per capita. 
that much water is a difficult task. A household of 15 would need a staggering 300 liters of water so that each person could have their requisite 20 liters per day. This is not practical in most cases.

\subsubsection{Housing Type and Educational Level}

The second possible correlation is with the social indicators of wealth, dwelling type and highest educational level achieved by the household head. Those with increased eduction levels or socioeconomic status have, in most cases, a better knowledge about the causes and prevention strategies of diarrheal diseases and may therefore put a greater emphasis on water quantity. They may also be more able to afford porters or have other means available to fetch water.

Figure 5.13 indicates that those with a 'Post Secondary Education' used over 18.16 \pm 14.20 liters $(\mathrm{n}=38,95 \% \mathrm{CI})$ liters per person on average, while those with less education used $14.98 \pm 0.53$ liters $(\mathrm{n}=941,95 \%$ CI $)$ to $16.05 \pm 1.45(\mathrm{n}=356,95 \%$ CI $)$ per capita. In addition, those who lived in a 'Hut' used about 1.5 less liters per capita than those with a permanent house.

Since the type of house one lives in is clearly correlated to their educational levels it is informative to look at the correlation between the two variables. It is also interesting to look at the per capita usage with both the level of schooling and housing types held constant.

Figure 5.14 displays housing types for the different levels of education obtained by the household head. The percentage of permanent houses increases from $8.3 \%$ for those with no school to $57.9 \%$ for those with a post-secondary education. Likewise, 


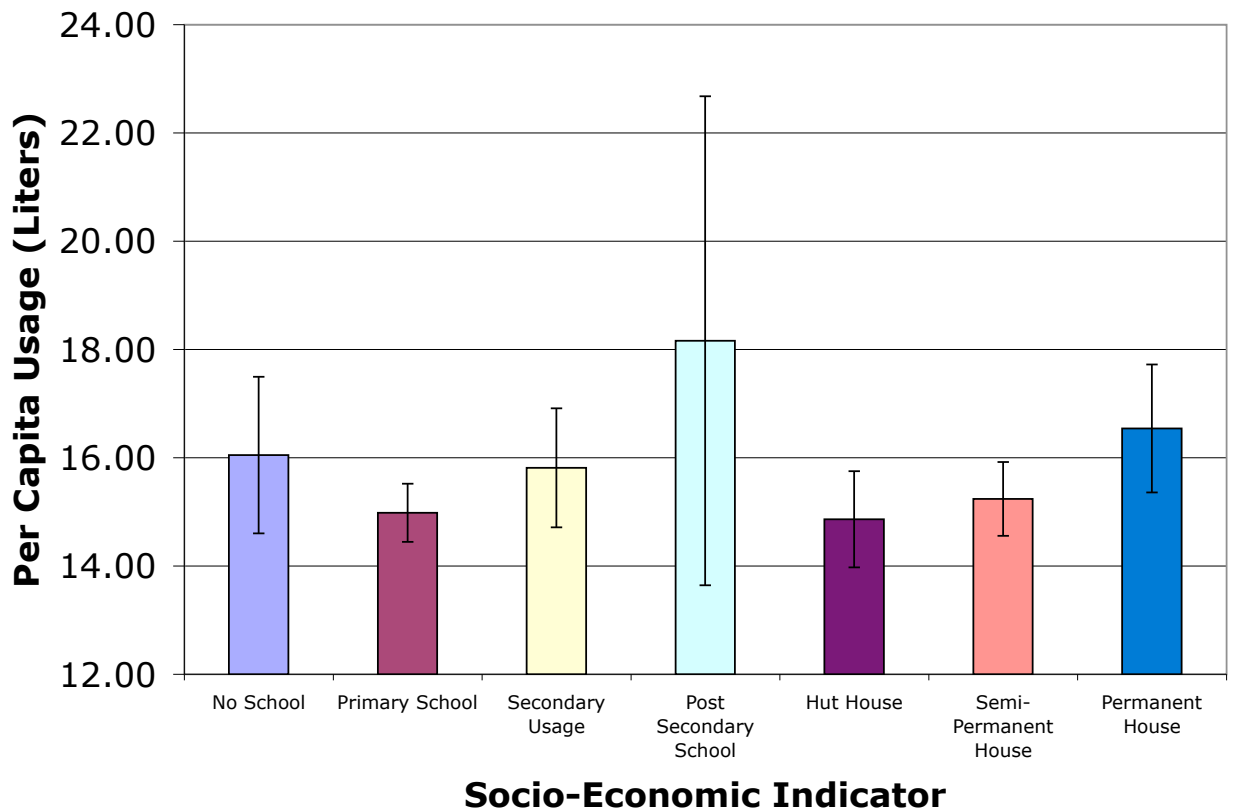

Figure 5.13: This plot seems to indicate that those with great socioeconomic status, i.e. with a higher education or better dwelling tend to use more water per capita. However, large errors bars make it difficult to draw any definitive conclusions. 


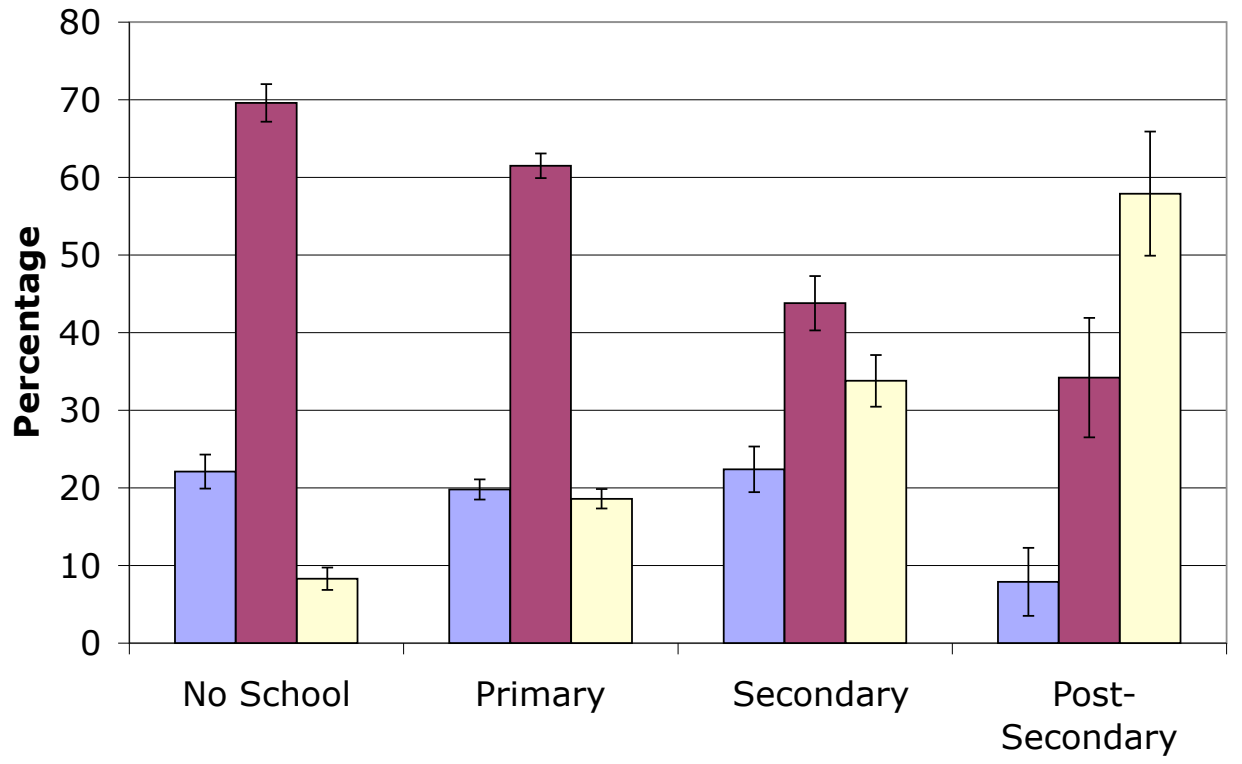

$\square$ Hut $\square$ Semi-Permanent $\square$ Permanent

Figure 5.14: A comparison of housing types for different levels of schooling. The percentage of those having a permanent house clearly rises with educational levels, while the percentage of those having a semi-permanent house clearly decreases. Those having a hut decrease slightly, but the trend is not as well-defined. 
the prevalence of semi-permanent housing decreases from $69.6 \%$ to $34.2 \%$. However, the percentage of those having a hut does not show as strong a trend, although it does decrease from $22.1 \%$ to $7.9 \%$. From this data it is clear that housing type and educational levels are strongly correlated.

The per capita usage with both the highest level of schooling obtained and the housing type held constant are displayed in Figure 5.15. With the level of schooling held constant, there is an increase in the per capita usage between those with a hut and those with a permanent residence. For instance, the increase varies from $0.7 \mathrm{l} / \mathrm{p} / \mathrm{d}$ for those with a primary school education to a rise of $3.6 \mathrm{l} / \mathrm{p} / \mathrm{d}$ for those with a postsecondary education. However, the usage for semi-permanent houses does not follow as clear a trend. In some cases those respondents used more water than those with a permanent house while in other cases they used less than those with a hut. However, relatively large error bars representing $95 \%$ confidence levels indicate that, when household type is held constant, the effect of educational levels on usage diminishes significantly.

\section{ANOVA of Socioeconomic Indicators}

To better assess the correlations an ANOVA analysis was performed for both the educational level of the household head and the household type to determine if the differences shown in Figure 5.13 are statistically significant.

For the educational levels, the ANOVA analysis indicated $\mathrm{F}_{(3,1531)}=2.181, p=0.088$. Likewise the ANOVA analysis for the household type resulted in $\mathrm{F}_{(2,1530)}=2.480, p=$ 0.084. Although $p$ is higher than the $5 \%$ confidence levels used for most of this report, the relative low $p$ values do indicate that a correlation is likely. 


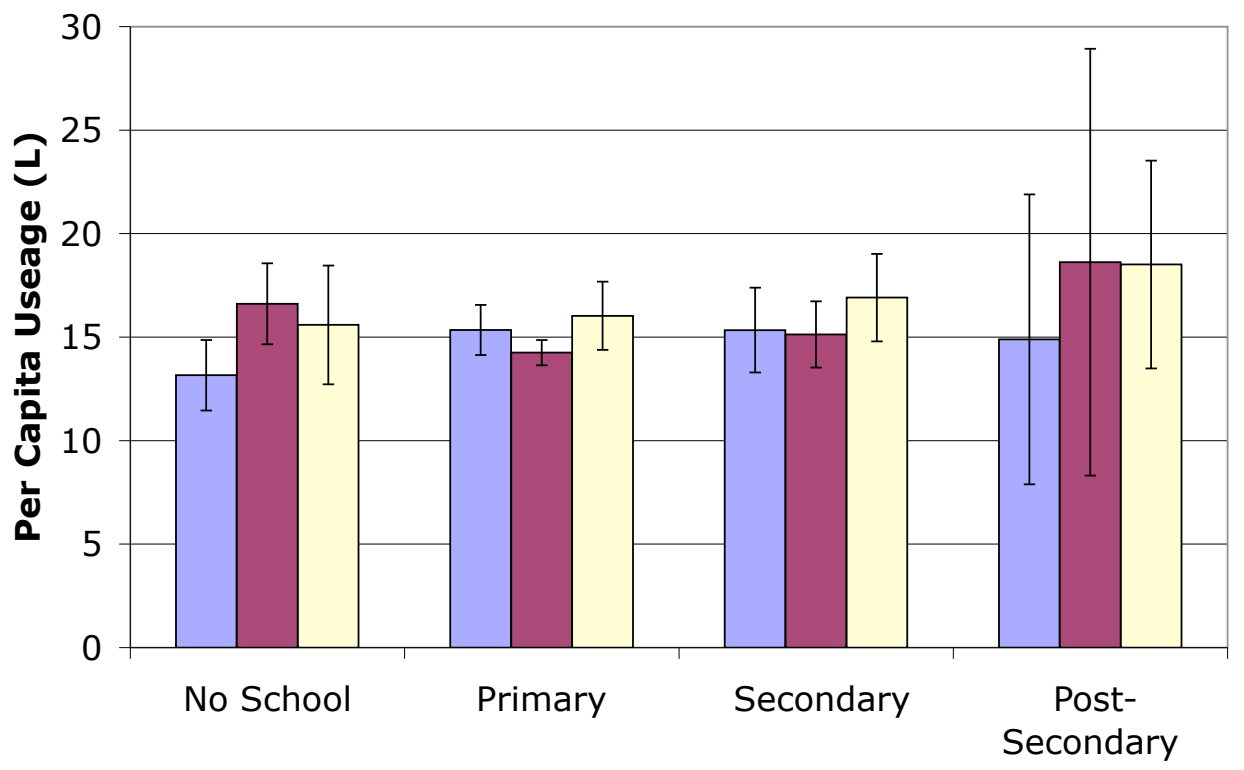

$\square$ Hut $\square$ Semi-Permanent $\square$ Permanent

Figure 5.15: A comparison of per capita usage as a function of school and housing type. When the level of schooling is held constant the per capita usage does increase from those living in a hut to those living in a permanent house, but the data for those living in a semipermanent does not as clearly follow that trend. However, the large error bars make this correlation weak. 
The ANOVA analysis seems to confirm the moderate relationships seen in Figure 5.13 between educational levels, socioeconomic status and water usage. However, future studies are necessary to conclusively link the two. 


\section{Chapter 6}

\section{WWB Results}

An analysis of the preliminary survey indicated that there were a number of different factors that can contribute to reductions in diarrheal disease rates and anticipated some of the findings that would later be apparent in the final analysis.

The final analysis showed statistically significant decreases in diarrheal disease rates in

all communities, including the control community. Based on the analysis presented here, the introduction of household water filters was the most effective means of reducing diarrheal disease rates.

In all cases, diarrhea rates are reported in terms of reported cases per child over the proceeding three months. 


\subsection{Diarrhea Rates for Varying Water and Sanita- tion Practices from Baseline Data}

The baseline data allows us to examine how diarrheal rates are affected by the presence or absence of various water and sanitation infrastructure and practices. The data for seven different improvements is summarized in Figure 6.1. The use of an unprotected or protected water source, whether or not a family treats their water and the presence or absence of the following sanitation improvements were compared: latrine, rubbish pit, bathroom, drying rack and a clean drinking water container. A family who reported using a protected water source, treated their water or had one of the other sanitation improvements would be considered to be a "satisfactory" performer in a particular area. The absence of those would indicate a "poor" performer.

As Figure 6.1 shows there are no statistically significant differences between poor and satisfactory performers for most of the categories. However, those who reported treating their water have an average diarrhea rate of $0.57 \pm 0.04(\mathrm{n}=450,95 \% \mathrm{CI})^{1}$ versus $0.85 \pm 0.03(\mathrm{n}=62,95 \% \mathrm{CI})$ for those who do not treat their water. Similarly, those who kept their drinking water in a separate, sanitary container had much lower rates of diarrheal disease than those who did not. Those who had a container experienced an average of $0.57 \pm 0.04(\mathrm{n}=441,95 \% \mathrm{CI})$ cases per child in the previous three months those without a container had a rate of $0.79 \pm 0.04(\mathrm{n}=71,95 \% \mathrm{CI})$. Theses differences were further backed up with a t-test analysis showing that, in the case of household water treatment $t_{(270)}=2.26, p=0.02$ and, for the water container $t_{(263)}=1.97, p=0.05$.

\footnotetext{
${ }^{1}$ As noted previously, unless otherwise stated, diarrhea rates quoted for this report are the average number of diarrhea cases reported over the proceeding three months.
} 


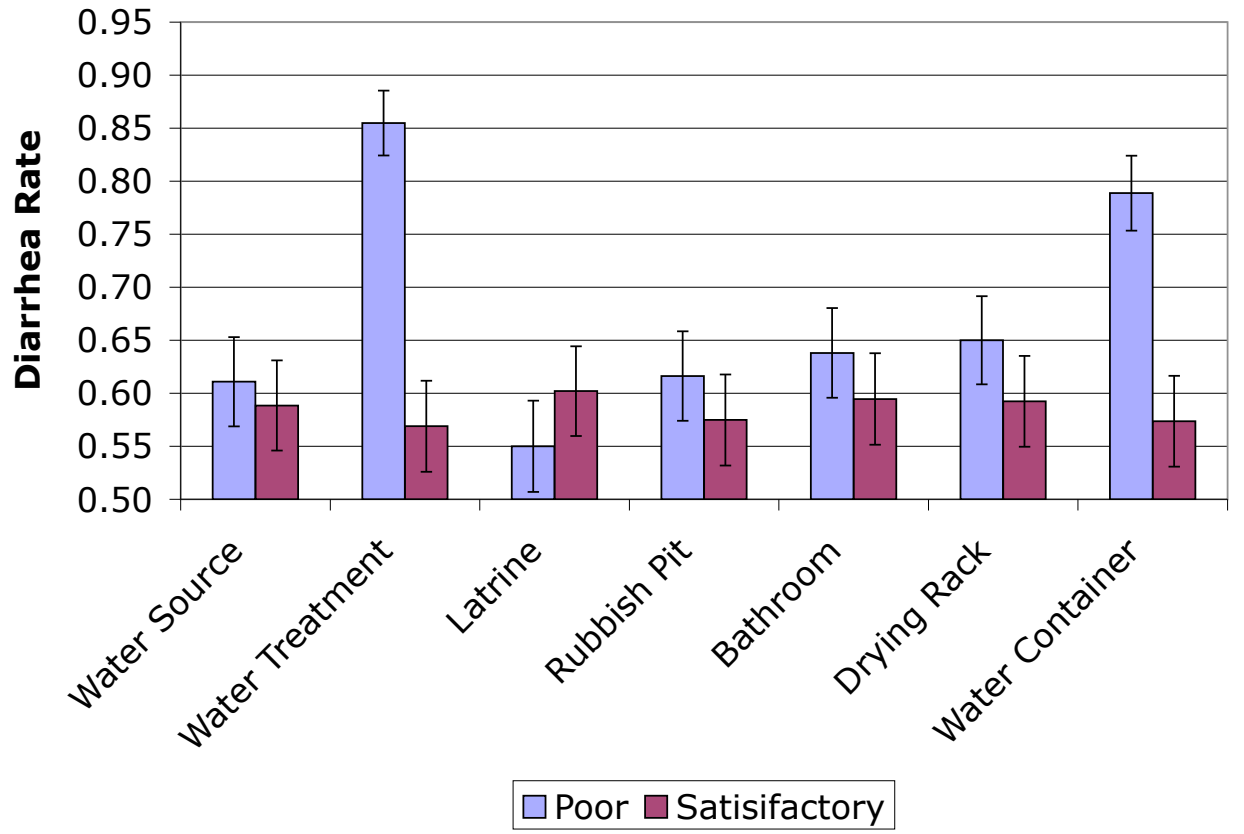

Figure 6.1: Diarrhea rates for poor and satisfactory performers for seven different water and sanitation practices. Most of the improvements show no statistically significant differences in rates. However, those who reported treating their water and those who reported to use a clean water container have reduced diarrhea rates. 
The relative importance of water treatment over water source protection status is given a further backing by Table 6.1. It is clear from this that the treatment practices for a household are much more important than the actual water source used. In fact, the rate is nearly constant for those who do not treat their water regardless of the water source they use $(0.84 \pm 0.03(\mathrm{n}=50,95 \% \mathrm{CI})$ versus $0.85 \pm 0.03(\mathrm{n}=13,95 \%$ CI) cases per child). Likewise, the rate is very similar for those who treat their water $(0.67 \pm 0.03(\mathrm{n}=226,95 \% \mathrm{CI})$ versus $0.61 \pm 0.04(\mathrm{n}=450,95 \% \mathrm{CI}))$.

Table 6.1: Diarrheal Disease Rates compared across source protection status and reported treatment techniques. It is clear from this data that treatment practices are far more important than water source protection status.

\begin{tabular}{cccc}
\hline & $\begin{array}{c}\text { Diarrheal Disease } \\
\text { Rate }\end{array}$ & $\begin{array}{c}\text { 95\% Confidence } \\
\text { Interval }\end{array}$ & Sample Size \\
\hline \hline Protected Sources & & & \\
Treat & 0.61 & \pm 0.04 & 450 \\
Do Not Treat & 0.84 & \pm 0.03 & 50 \\
\hline Un-Protected Sources & & & \\
Treat & 0.67 & \pm 0.03 & 226 \\
Do Not Treat & 0.85 & \pm 0.03 & 13 \\
\hline
\end{tabular}

An additional analysis was done comparing diarrhea rates as a function of per capita usage. Surprisingly, there was no correlation between the two since the Pearson's Coefficient was calculated to be -0.023 making the coefficient of determination 0.001 indicating essentially no correlation. Likewise, the distance to water source or the time to collect water did not show any significant correlation with diarrhea rates with Person Coefficients of -0.027 and -0.065 respectively. 


\subsubsection{Baseline Survey Analysis}

The baseline survey data gives some interesting insight into the practices and improvements that may have some impact on diarrheal diseases. That data is summarized in Figure 6.1. Those with satisfactory performance had essentially equivalent rates of diarrhea to those who were poor performers in most cases. Even those who were consistently higher performers across many different categories did not necessarily have lower diarrhea rates. Therefore, based on this analysis, those who used protected water sources and have a latrine, rubbish pit or drying rack do not necessarily have significantly less diarrhea. Furthermore, the correlations calculated between water usage, distance and time to collect versus diarrhea rates indicated that access to water is not a primary indicator of diarrhea rates.

The most significant exception to this trend are those who treat their water or those who have a clean water container. This is not surprising when one considers the most likely fecal-oral transmission routes from the F-diagram shown in Figure 2.1. When collecting water in Uganda, most people use jerrycans that are rarely clean. Children, who have little idea about the maintenance of the clean water chain, also usually collect it. It is therefore highly likely that even water from a protected source gets contaminated before it is consumed. This is why treating one's water (typically

by boiling) before consumption is so important. Furthermore, having a separate, clean drinking water container to store the boiled water is nearly as effective at reducing diarrheal disease.

The relatively small differences we see in the other interventions probably says more about the culture of cleanliness common in Ugandan culture. Even poor, rural Ugandans are very neat, clean people. They are always well dressed and always take care 
to bathe regularly. Most homes have soap and they are good about using it daily to clean their clothes, dishes and themselves. Many Ugandans also take pride in their surroundings as evidenced by their fanatical early morning sweeping and constantly weeding. They are also very careful about how they prepare their food and are good about eating off of clean dishes and covering their food to keep flies away. This is probably due to the relative abundance of water sources compared to other, drier parts of the developing world. It is therefore not surprising that the rubbish pit, bathroom and drying rack make relatively little difference because even those without those technologies keep themselves, their surroundings and their dishes relatively clean.

Taken together, the baseline data presented in Figure 6.1 seems to predict that interventions related to treating water at the household (i.e., the household water filters) or maintaining the safe water chain (health education and advocacy work) would be the best at preventing diarrheal disease. However, the data on hand-washing proved to not be of sufficient quality to use in this report so it is unclear from the baseline data whether or not that would be an effective technique or not.

\subsection{Measures of Program Effectiveness}

Different interventions were done in each community. Every effort was made by the COWESER staff to assure effective and thorough interventions. It was also necessary that the interventions be 'equal' as much as possible in terms of effort spent in each community on planning, outreach and educational components. In the subsequent sub-sections the effectiveness of each program will be analyzed by comparing baseline data with data from the follow-up survey to provide evidence 
that decreases in diarrheal disease rates were largely due to the particular programs in each community and not due to confounding variables.

\subsubsection{Water Filters}

Water filters were installed in Lusaka, a community that had a protected water source that was not used widely. There was no statistically significant difference at the $95 \%$ level between the baseline and follow-up surveys in water sources used, how far or how long people go to collect water, per-capita water consumption, peoples' preferences for 'near' or 'clean' sources, compound or latrine cleanliness, knowledge about the causes of diarrheal diseases, or reported water treatment rates. Likewise there was no statistically significant difference with rubbish pit, bathroom, drying rack, water container or latrine prevalence.

The only difference found was in the fact that before intervention 21 out of 22 respondents reported that they boiled their water. Now an identical proportion of the 22 respondents reports that they use their water filter regularly. It is also worth noting

that Coliscan Easygel ${ }^{\circledR}$ water testing kits manufactured by Micrology Laboratories were used to test the for fecal coliforms several weeks after the filters were in place. The results indicated that there was no fecal coliforms in the water treated by the filters.

\subsubsection{Water Source}

Before implementation there were other protected water sources in the community, however, they were located far away from the shallow well constructed for this project. 
Despite the distance to the other sources, $48 \%$ of those surveyed who use the new source now, used other protected sources before implementation. This fact had a significant convoluting effect on the diarrhea rates. In those households that switched from another protected source to the new one there was no statistically significant change in diarrhea rates once the control was subtracted out from the data. In fact, the rate change was $-0.02 \pm 0.13 \%(\mathrm{n}=51,95 \% \mathrm{CI})$ for that group versus $0.35 \pm 0.13 \%$ $(\mathrm{n}=51,95 \% \mathrm{CI})$ where positive numbers indicate reductions in diarrhea incidences. Therefore, for the purposes of this report, only those who used unprotected sources before implementation will be included.

There was a statistically significant difference in the number of people who reported why they use a certain source. The survey found that the percentage of respondents who stated that they chose their water source because it was the cleanest rose from $0.0 \%$ to $45 \pm 32.5 \%(\mathrm{n}=18,95 \% \mathrm{CI})$.

Unfortunately, there was a significant number of respondents who reported that they no longer boil their water. The survey found that before installation of the shallow well $88.9 \pm 14.5 \%$ ( $\mathrm{n}=18,95 \%$ CI $)$ indicated that they treated their water while, afterwards, only $65.0 \pm 20.9 \%(\mathrm{n}=20,95 \% \mathrm{CI})$ did. This $24 \%$ decrease could be a significant confounding variable and could be a major reason why diarrhea rates did not decline as much as other communities. However, the post-implementation unadjusted diarrhea rates were statistically equivalent at $0.35 \pm 0.17 \%(\mathrm{n}=29,95 \%$ CI) for those who treat their water and $0.33 \pm 0.17 \%(\mathrm{n}=29,95 \% \mathrm{CI})$ for those who do not.

There was no statistically significant change at the $95 \%$ level in how far or how long people have to go to fetch water, per-capita consumption, latrine prevalence or 
cleanliness, knowledge about causes of diarrheal diseases or compound cleanliness. There was also no difference in bathroom, drying rack or water container prevalence, although there was a moderate increase in the number of rubbish pits.

Easygel@testing kits from Micrology Laboratories indicated a fecal contamination rate of around 100 fecal coliforms per $100 \mathrm{ml}$ of water from the wells. Such contamination is likely due to surface run off since the culverts were not cemented together.

\subsubsection{Control}

A control community was composed of two parts. The first was the areas of Nsambya (where the shallow well was dug) that were too far from the new water source to be usable. The second half of the control area was the homes in Lusaka village that did not receive household water filters. Both sections of the communities benefited very little from the project since large-scale community education efforts were not done in either community.

In these communities there was no statistically significant change in the water sources used, how far or how long water collection takes, water source preferences, per capita water usage, knowledge about causes of diarrheal diseases or water treatment practices. Likewise, there was no difference in latrine, bathroom, drying rack or water container prevalence although there was a moderate increase in the number of rubbish pits. There was a moderate increase in latrine cleanliness from $3.4 \pm 0.41 \%$ ( $\mathrm{n}=54$, $95 \% \mathrm{CI})$ to $4.8 \pm 0.36 \%(\mathrm{n}=55,95 \% \mathrm{CI})$ and a much smaller increase in compound cleanliness. Despite the small cleanliness improvements, both sections of the control communities can be considered to be relatively unaffected by the WWB water and 
sanitation improvements made in surrounding communities.

\subsubsection{Latrines}

As it turned out nearly $95 \%$ most of the residents in the survey communities already had some form of latrine beforehand. However, many latrines were poorly constructed out of local materials that could not be easily cleaned or cared for. Therefore, the latrine program focused on providing latrine slabs to those who had only wooden latrine platforms before and on keeping existing latrines cleaner and more sanitary.

In the latrine communities there was no significant difference at the $95 \%$ confidence level in water collection times, water source preferences or water treatment practices. There was no increase in rubbish pit, bathroom, drying rack or water container prevalences. However, latrine prevalence did increase from $89.3 \%$ to $100 \%$.

There was a relatively large, but not statistically significant increase in collection distances, but this is likely a measurement error since no new sources were constructed during the survey period.

During the implementation period, the latrine cleanliness score increased from 3.85 $\pm 0.54(\mathrm{n}=26,95 \% \mathrm{CI})$ to $5.84 \pm 0.51(\mathrm{n}=25,95 \% \mathrm{CI}), t_{(24)}=5.74, p<0.001$. The practice of covering the latrine hole while the latrine is not in use increased from 36.0 to $79.2 \%$. Knowledge about diarrhea disease causes and prevention techniques increased significantly. For instance, those who had a 'good' knowledge about prevention practices increased from 6.9 to $38.5 \%$ of the respondents. While those with a poor knowledge decreased from $44.8 \%$ to $11.5 \%$. Likewise there was an increase in compound cleanliness from $3.33 \pm 0.37(\mathrm{n}=24,95 \% \mathrm{CI})$ to $4.56 \pm 0.41(\mathrm{n}=25$, 
$95 \% \mathrm{CI}), t_{(25)}=6.41, p<0.001$. This is not surprising since many of our community lessons focused on latrine cleanliness and sound sanitation practices as a method to prevent diarrheal disease.

\subsubsection{Hand-Washing}

In the hand-washing community there was no difference in water collection times or distances, per capita water usage, latrine cleanliness, water source preferences. Likewise, there was no change in latrine, bathroom or drying rack prevalence.

There was a small change in compound cleanliness from $3.2 \pm 0.50(\mathrm{n}=20,95 \% \mathrm{CI})$ to $3.8 \pm 0.33(\mathrm{n}=17,95 \% \mathrm{CI}), t_{(57)}=3.13, p<0.00$. There was also a increase in water treatment from $84.4 \pm 8.9 \%(\mathrm{n}=64,95 \% \mathrm{CI})$ to $100 \%$. There was a small change in knowledge about diarrheal causes and prevention practices. For instance, those with poor knowledge about prevention strategies decreased from $29.2 \%$ to $6.9 \%$ while those with satisfactory knowledge increased from 47.7 to $63.8 \%$.

Every household surveyed received a tippy-tap household hand-washing device, while there were very few beforehand. Unfortunately, the data about adherence to sound hand-washing practices was not satisfactory. However, the provisioning of handwashing stations at every household surveyed, the outreach activities of community members and COWESER staff members, the music, dance and drama show and the disbursal of calendars must have increased hand-washing practices by some amount.

Taken together, it is likely that much of the resulting diarrhea decrease seen in this community is probably due to the increased practice of hand-washing at critical 
times.

\subsubsection{All Interventions}

Manyama Village received all of the above interventions except for the water filters. The survey sample included 23 households representing 156 people and 33 children under five years of age.

People's reason for choosing a certain source did not change significantly nor did per capita water consumption. There was little change in latrine floor covering, superstructure construction or latrine cleanliness. However, there was a large increase (5.0 to $56.5 \%$ ) in the number of households who now cover their latrine holes. Also, all of the household members now have tippy-tap hand-washing stations. There was a small increase in peoples' knowledge about the causes of and preventions for diarrheal disease. For instance, those who had a 'good' understanding of prevention techniques increased from 22.7 to $52.5 \%$. Those who have a rubbish pit increased from $9.1 \% \pm 12.0 \%(\mathrm{n}=22,95 \% \mathrm{CI})$ to $39.1 \% \pm 19.9 \%(\mathrm{n}=23,95 \% \mathrm{CI})$ and those with a bathroom increased from $59.1 \% \pm 20.5 \%(\mathrm{n}=22,95 \% \mathrm{CI})$ to $91.3 \% \pm 11.5 \%$ ( $\mathrm{n}$ $=22,95 \%$ CI). Likewise those with a drying rack increased from $40.9 \% \pm 20.5 \%$ (n $=22,95 \% \mathrm{CI})$ to $78.3 \% \pm 16.9 \%(\mathrm{n}=23,95 \% \mathrm{CI})$. There was little change in water treatment practices (which were already high) or water container prevalence. Finally, there was a large increase in compound cleanliness. The average score jumped from $3.1 \pm 0.5(\mathrm{n}=22,95 \% \mathrm{CI})$ to $4.2 \pm 0.3(\mathrm{n}=23,95 \% \mathrm{CI}), t_{(23)}=3.31, p<0.001$.

As a result of the intervention, the residents reported that the distance to the water source had decreased from $1.12 \pm 0.45(\mathrm{n}=22,95 \% \mathrm{CI})$ to $0.36 \pm 0.07(\mathrm{n}=23,95 \%$ CI) kilometers, while their collection times remained nearly the same. This is likely 
due to the fact that people are now forced to wait in line to collect water rather than just scoop it from their traditional wells.

Before the construction of the shallow well $81.8 \pm 16.1 \%(\mathrm{n}=22,95 \% \mathrm{CI})$ of the population got their water from unprotected sources. After intervention $100 \%$ of those respondents got their water from the new shallow well.

\subsection{Prevalence of Diarrheal Disease}

Data was taken before and after implementation in all five intervention communities and the control areas. Post-implementation diarrhea rates were then simply subtracted from pre-intervention rates to get a net change. The control community was then subtracted out from the data to get an overall adjusted rate of diarrheal disease decrease.

The pre and post-intervention data is summarized in Table 6.2. The number of postintervention respondents is lower in all cases since the surveyors frequently could not find the same families for the follow-up survey. The very low number of reported cases in most communities during the follow-up survey makes errors larger than they would normally be.

A whisker plot is shown in Figure 6.2 comparing the number of diarrhea diseases reported over the previous three months at the household level for pre and postintervention. The long lines extruding from each box represent valid minimum and maximum values, while the boxes represent the upper and lower quartile. The green and pink lines represent the mean and median value respectively. It is clear from this diagram that diarrheal diseases decreased in all cases, even in the control community. 
It is also clear there is a wide range of values in each community indicating that diarrheal disease is not evenly spread even within a single community. It is also relevant to note that, in most cases the post-intervention communities had zero values for their quartile values thereby suppressing their boxes.

Table 6.2: Pre and post-intervention reported data for reported cases of diarrhea during the previous three months.

\begin{tabular}{lllll}
\hline Intervention & $\begin{array}{l}\text { Pre-Intervention } \\
\text { Total } \\
\text { Respondents }\end{array}$ & $\begin{array}{l}\text { Reported } \\
\text { Cases }\end{array}$ & $\begin{array}{l}\text { Post-Intervention } \\
\text { Total } \\
\text { Respondents }\end{array}$ & $\begin{array}{l}\text { Reported } \\
\text { Cases }\end{array}$ \\
\hline \hline Control & 114 & 74 & 92 & 30 \\
Filters & 47 & 37 & 37 & 3 \\
New Well & 36 & 32 & 29 & 10 \\
Hand-Washing & 134 & 65 & 101 & 3 \\
Latrines & 49 & 27 & 31 & 4 \\
All & 38 & 26 & 33 & 5 \\
\hline
\end{tabular}

Data for the absolute risk reduction is highlighted both in Table 6.3 and Figure 6.1. The table gives values for the absolute risk reduction which, is simply the pre minus post-intervention absolute risk (number of cases divided by the number of survey participants). Adjusted absolute risk rate is the absolute risk rate minus the control community. Relative risk is defined in Section 2.2. Adjusted relative risk was calculated as follows. The incidence rate after intervention was adjusted upwards by a correction factor while the incidence rate before interventions was adjusted downwards by an equal amount so that the difference in these new adjusted incidence rates equaled the adjusted absolute risk reduction. This correction factor was calculated by the following formula:

$$
\text { Correction_Factor }=\frac{A b s_{\_} R i s k_{\_} R e d u c t i o n-A d j \_A b s \_R i s k_{\_} R e d u c t i o n}{2}
$$




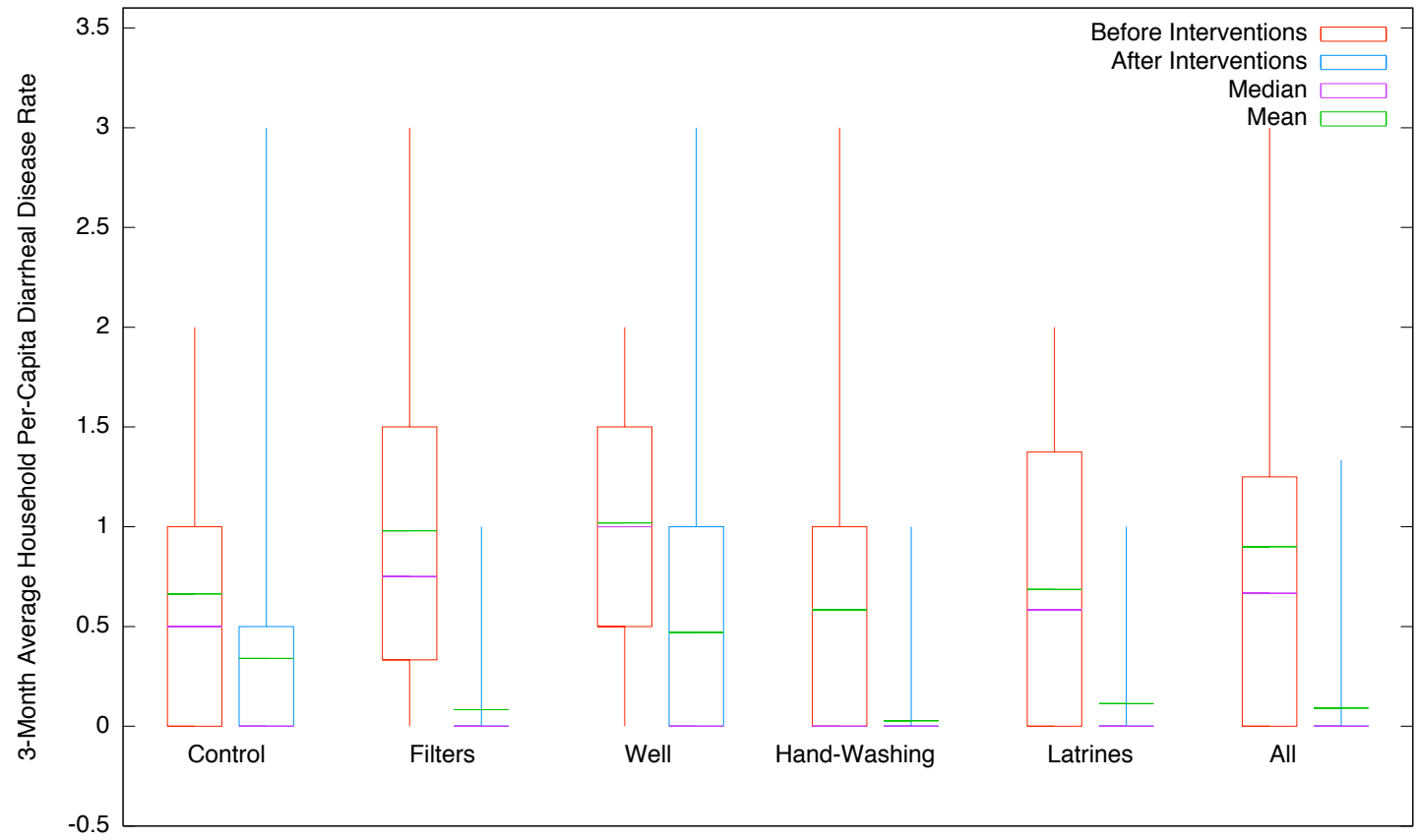

Figure 6.2: 3-Month average diarrheal rate displayed before and after interventions in all six communities. The lower quartile is represented by the bottom of the box while the upper quartile the top. The mean and median values are also shown. The whiskers represent the minimum and maximum valid values. The post-intervention mean and medians values were lower in all six cases. The plot highlights the high variability in the data. 
The relative risk was then calculated with Formula2.1 where the incidence rates are replaced with the corrected incidence rates defined here.

Based on Figures 6.3 and Figure 6.1 diarrheal disease is reduced substantially in all cases including the control community. Since the amount of reduction is different for each community and, based on the discussion of Section 6.2, the interventions were sufficiently targeted and effective, there are likely real differences in the effectiveness of each intervention. According to the data, household water filters clearly had the highest reduction rates.

Table 6.3: Absolute risk reduction, adjusted rate reduction, sample size, relative risk and adjusted relative risk for all six communities. As the adjusted risk reduction indicates, those households that received water filters experienced the greatest risk reduction, while the latrine intervention turned out to be the least effective intervention strategy. Likewise the latrines also had the lowest relative risk reduction associated with their use.

\begin{tabular}{lccccc}
\hline Intervention & $\begin{array}{c}\text { Absolute } \\
\text { Risk } \\
\text { Reduction }\end{array}$ & $\begin{array}{c}\text { Adjusted } \\
\text { Absolute Risk } \\
\text { Reduction }\end{array}$ & $\begin{array}{c}\text { Sample } \\
\text { Size }\end{array}$ & $\begin{array}{c}\text { Relative } \\
\text { Risk }\end{array}$ & $\begin{array}{c}\text { Adjusted } \\
\text { Relative } \\
\text { Risk }\end{array}$ \\
\hline \hline Control & $0.32 \pm 0.05$ & 0.0 & 92 & 0.50 & $\mathrm{n} / \mathrm{a}$ \\
Filters & $0.71 \pm 0.06$ & 0.38 & 37 & 0.10 & 0.39 \\
New Well & $0.54 \pm 0.05$ & 0.22 & 29 & 0.39 & 0.70 \\
Hand-Washing & $0.46 \pm 0.04$ & 0.13 & 101 & 0.06 & 0.59 \\
Latrines & $0.42 \pm 0.07$ & 0.10 & 31 & 0.23 & 0.75 \\
All & $0.53 \pm 0.08$ & 0.21 & 33 & 0.22 & 0.60 \\
\hline
\end{tabular}

\subsection{ANOVA Analysis of Results}

To further investigate the diarrheal disease rates before and after intervention a number of ANOVA analyses were carried out. These analyses were carried out on diarrhea rates at the household level.

First, standard ANOVA analyses were done on the before and after interventions to 


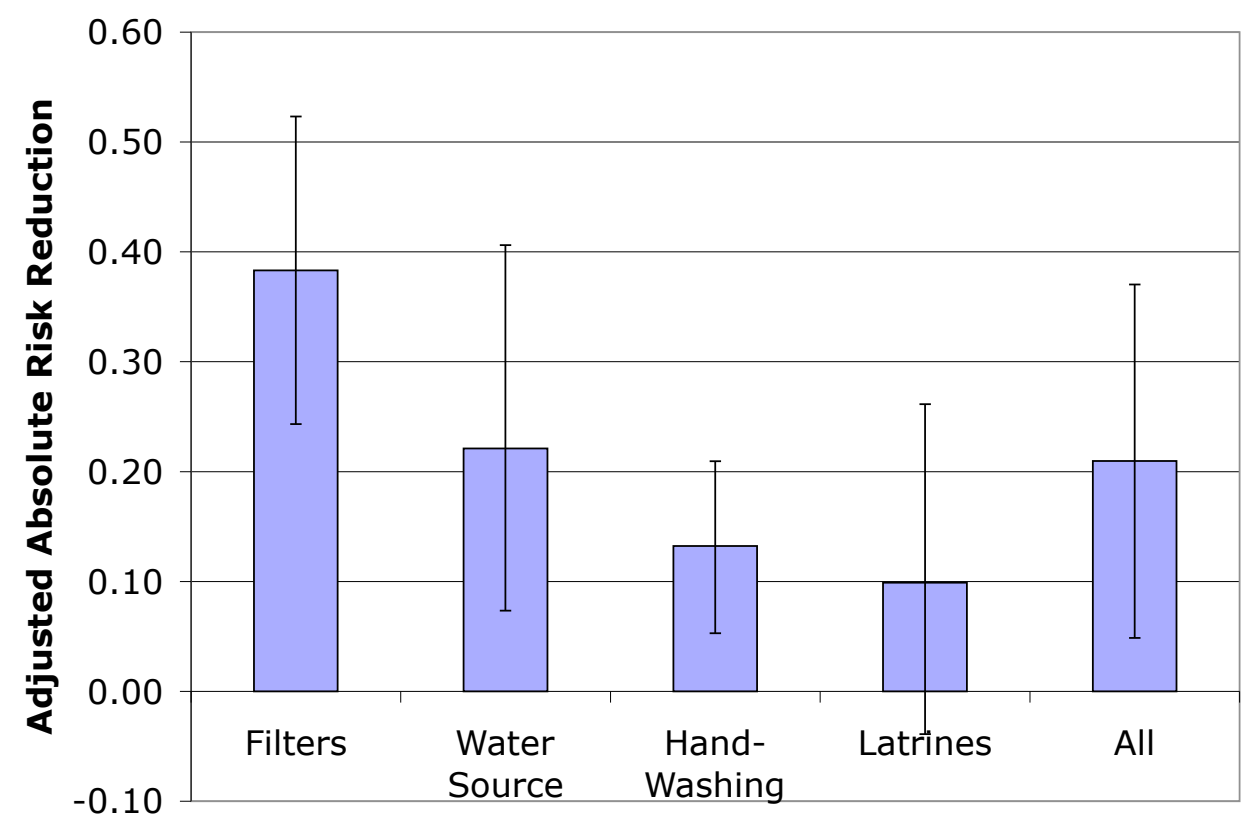

Figure 6.3: Adjusted absolute risk reduction for the five different communities. Household water filters showed the greatest reduction in diarrheal disease followed by the introduction of a water source and all interventions. Both hand-washing and latrine improvement had lower reductions. 
indicate that, before interventions there was no differences in the mean diarrhea rate between all the communities and after there was a significant difference. The ANOVA analysis run before interventions resulted in $F_{5,179}=1.404, p=0.223$ indicating the null hypothesis, i.e., that no significant differences in the means exist between the six communities. After interventions the analysis was conducted excluding the Control community to find $F_{4,129}=4.534, p=0.002$ indicating a significant amount of variation between the communities. A multiple comparisons Post hoc Turkey-HSD test indicated that the hand-washing campaign showed the largest mean difference from the control community, $p=0.011$.

A significant main effect was observed due to the different interventions carried out in the five communities as was seen in the ANOVA repeated measures analysis that was done. There was a decline in diarrheal disease rates after intervention in all cases from .765 initially to .120 after the interventions. The differences between these two were significant: $F={ }_{(1,190)}=69.857, p<0.001$ and least significant difference multiple comparisons confirm that each of the two means differs significantly from the other. In other words, the diarrhea rates did decline significantly.

\subsection{Synthesis and Conclusion of WWB}

Based on the above analysis, it is clear that the water filter intervention worked best. This is not surprising based on the baseline data indicating a strong correlation between low rates of diarrheal disease and the practice of treating one's water. It also makes sense given the societal factors discussed in Section 6.1.1.

The large error bars shown in Figure 6.3 make further assertions or a ranking of 
interventions difficult. However, it is clear that all interventions did improve the health of the participants.

Data from the literature review presented in Section 2.2 show significant variations complicating definitive comparisons. However, the data presented in Table 2.2 does lend itself to such comparisons. That table is reprinted in 6.4 with the adjusted absolute risk reduction numbers from this survey. Multiple interventions and water availability (i.e. the shall well) interventions are both consistent with the work presented in this report. However, the other interventions significantly different. In particular, earlier results indicated the effectiveness of hygiene (i.e. hand-washing) and sanitation (i.e. latrine) interventions over the health improvements that could be expected from water quality (i.e. water filters).

Table 6.4: A reprinting of Table 2.2 with the adjusted absolute risk reduction values from this survey compared to the older work or Esrey. Multiple interventions and water availability interventions are both consistent with the current results. However data for the other interventions is not.

\begin{tabular}{cccc}
\hline Type of Intervention & $\begin{array}{c}\text { Absolute } \\
\text { Esrey et al., 1985 }\end{array}$ & $\begin{array}{c}\text { Risk } \\
\text { Esrey et al., 1991 }\end{array}$ & $\begin{array}{c}\text { Reduction } \\
\text { This Survey }\end{array}$ \\
\hline Multiple Interventions & 22 & 30 & 21 \\
Water Quality & 16 & 15 & 38 \\
Water Availability & 25 & 20 & 22 \\
Sanitation & 22 & 36 & 10 \\
Hygiene & n/a & 33 & 13 \\
\hline
\end{tabular}

The adjusted relative risk measurements of this report can also be compared to the relative risks summarized in Figure 2.3 (b). Relative risks for hygiene interventions centered around 0.65 for the three meta-analyses summarized, while the relative risk calculated for the hand-washing intervention this time was 0.59. Similarly the average relative risk for sanitation interventions was around 0.75 , while this research produced an identical value. The older surveys had indicated that water supply interventions 
should lead to relative risk measurements of around 0.82 compared to 0.70 for this survey. The range for water quality improvements was somewhere between 0.62 and 0.88 which are both less than the filter measurement presented here of 0.39. Finally, that research indicated that multiple interventions should yield a relative risk of around 0.71 , while this report found a relative risk of 0.60 .

Taken as a whole, the relative risk measurements for this study were highly consistent with older meta-analyses, except for the higher effectiveness found for the water filters in this survey. 


\section{Chapter 7}

\section{Conclusion}

The analysis presented in this report gives us a better understanding of the water and sanitation situation in rural Uganda and what particular investments in water and sanitation infrastructure make a real difference in peoples' lives.

Data from the water usage survey indicated that people use a fixed amount of water regardless of the reported distance to the water source or the time needed to collect it. Furthermore, there was no difference in water usage between the service levels defined by Howard and Bartram. Although many collection times exceeded one hour, rural Ugandans place a high emphasis on cleanliness and hygiene both of their bodies

and of their clothes and dishes. It is therefore not surprising that they take more time and energy to collect extra water that likely goes towards those purposes. It is also true that, although water collection can be very difficult and time-consuming, Uganda is blessed with a moderate climate, ample rainfall and abundant natural resources. These factors may also be the reason why there was no correlation between per capita water usage, collection times or distances and diarrhea rates as was discussed 
in Section 6.1.1. A similar survey in a drier climate, i.e., one in which people did not have access to sufficient water for bathing and laundering clothes, might have yielded different results. It is not apparent from this data what that minimum amount of water might be.

Despite the lack of correlation between water usage and distance to sources, there does appear to be some relationship between water usage and socioeconomic status. This is likely due to the fact that higher socioeconomic status (as measured by household type and highest educational level obtained) is associated with a higher level of knowledge about, and adherence to, sound hygiene and sanitation practices. Hygiene and sanitation lessons are taught in Ugandan schools and is discussed periodically from primary school onwards. A second correlation between household size and per capita usage was probably due to an economy-of-scale argument.

One important failing of the analytical work presented in this report is the lack of data regarding the socioeconomic impacts of moving a water source closer to a given household. There is little doubt that water collection does place an undue burden on women and children. In fact, only $14 \%$ of households in the water usage survey reported that men sometimes help collect water, and even this is probably a gross exaggeration since the author never saw a man collecting water. This time and energy could be much better spent studying, working on agricultural production or other socioeconomic actives. Furthermore, young women collecting water are at a heightened risk of rape (and therefore HIV/AIDS) and other sexual harassment by young men who prey on women on their way to collect water. These factors cannot be underemphasized when interpreting the results presented in this report. Finally, it is hard to imagine a downside to easier access to more water. 
The conclusion of the What Works Best Survey indicate that point-of-use treatments do the most to prevent diarrheal diseases. This is not surprising and is consistent with the results of the baseline survey (Section 6.1.1). It is also not surprising that the filters are still being highly utilized and are very effective. They are not only a highly-coveted status symbol, but are also a household appliance with obvious direct benefits, i.e. purifying the taste of the water and reducing particulate matter.

Further comparison with the other methods of diarrhea prevention is difficult given the statistical uncertainty. However, the simple fact that most Ugandans use dirty jerrycans to transport their water from clean sources is consistent with lower rates of decrease seen for the shallow well improvements.

It is not clear how the latrine improvement campaign done for this report would compare with new latrine construction. Furthermore, latrine prevalence would likely lead to larger reductions in urban or peri-urban environments compared with the relatively dispersed settlements of rural Uganda.

The lack of accurate data regarding the effectiveness in increasing rates of handwashing makes that intervention difficult to assess. However, although very few households had hand-washing stations before intervention, Ugandans are sanitary people who regard hand-washing highly albeit not always during the critical times advocated for during the campaign. Future studies should conduct a similar campaign, but with more robust measures of before and after hand-washing rates.

The multiple intervention community also fared well, but since project funds did not allow household water filters to be installed in that community the reductions seen there could have probably been much higher.

Therefore, it is the conclusion of this report that the emphasis of water and sanita- 
tion improvements should be placed on the maintenance of the safe water chain to assure that water collected either from safe or contaminated sources should be purified either by boiling or, preferably, through the use of filters. Every effort should be made to teach community members about the importance of purifying their water. However, the other interventions including the provision of safe water sources as close as possible to homes should not be neglected both because they are highly effective at reducing diarrheal disease, and also because of the improved quality of life that they provide. 


\section{Bibliography}

[1] Aziz, K., B. Hoque, K. Hasan, M. Patwary, S. Huttly, M. Rahaman, and R. Feachem. (1990). Reduction in Diarrhoeal Diseases in Children in Rural Bangladesh by Environmental and Behavioral Modifications. Transactions of the Royal Society of Tropical Medicine and Hygiene 84(3):433 38.

[2] Cairncross, S., Cliff, J.L. (1987). Water Use and Health in Mueda Mozambique. Transactions of the Royal Society of Tropical Medicine and Hygiene 81(1):51-4.

[3] Cairncross, S., Feachem, R.G. (1983). Environmental Health Engineering in the Tropics: An Introductory Text. John Wiley and Sons. Chichester, no. 36166, pp. 283.

[4] Curtis, V., and S. Cairncross. (2003). Effect of Washing Hands with Soap on Diarrhea Risk: A Systematic Review. Lancet Infectious Disease 3(5):275 81.

[5] Curtis, V., S. Cairncross, and R. Yonli. (2000). Domestic Hygiene and Diarrhea: Pinpointing the Problem. Tropical Medicine and International Health 5(1):22 32.

[6] Cutler, D., and G. Miller. (2005). The Role of Public Health Improvements in Health Advances: The 20th Century United States. Demography 42(1):1 22. 
[7] Esrey S.A., Feachem R.G. and Hughes J.M., 1985, Interventions for the control of diarrhoeal diseases among young children: improving water supplies and excreta disposal facilities, Bulletin of the World Health Organization, 63(4): 757-772.

[8] Esrey, S.A. (1996). Waste, Water, and Well-Being: A Multicountry Study. American Journal of Epidemiology 143(6):608 22.

[9] Esrey, S. A., J. B. Potash, L. Roberts, and C. Shiff. (1991). Effects of Improved Water Supply and Sanitation on Ascariasis, Diarrhea, Dracunculiasis, Hookworm Infection, Schistosomiasis, and Trachoma. Bulletin of the World Health Organization 69(5):609 21.

[10] Esrey, S. A., and J.-P. Habicht. (1986). Epidemiologic Evidence for Health Benefits from Improved Water and Sanitation in Developing Countries. Epidemiology Review 8:117 28.

[11] Fewtrell, L., R. B. Kaufmann, D. Kay, W. Enanoria, L. Haller, and J. M. Colford. (2005). Water, Sanitation, and Hygiene Interventions to Reduce Diarrhoea in Less Developed Countries: A Systematic Review and Meta-Analysis. Lancet Infectious Diseases 5(1):42 52 .

[12] Gleick P H, 1996, Basic water requirements for human activities: meeting basic needs, Water International, 21: 83-92.

[13] Government of Uganda - Directorate of Water Development - Rural Water Supply Division. Supported by SNV Netherlands Development Organization. (2004). A National Framework for Operation and Maintenance of Rural Water Supplies, Kampala, Uganda.

[14] Government of Uganda - Ministry of Water, Lands and Environment. (2000). 
Rural Water and Sanitation Strategic Investment Plan 2000-2015, Kampala, Uganda.

[15] Howard G, Bartram J (2003). Domestic Water Quantity, Service Level and Health. New York: World Health Organization.

[16] World Vision International, Kooki Rakai Area Development Programme. (2006). Ten Year Strategic Water Development Plan for Kooki County.

[17] Huttly, S. R., A. D. Blum, B. R. Kirkwood, R. N. Emeh, and R. G. Feachem. (1987). The Epidemiology of Acute Diarrhea in a Rural Community in Imo State, Nigeria. Transactions of the Royal Society of Tropical Medicine and Hygiene $81: 86570$.

[18] Blum, D., R. Emeh, S. R. A. Huttly, O. Dosunmu-Oganbe, N. Okeke, M. Ajala, J. I. Okora, C. Akeijobi, B. R. KirkwoodR. G. Feachem. (1990). The Imo State (Nigeria) Drinking Water Supply and Sanitation Project 2: Impact on Dracunculiasis, Diarrhoea, and Nutritional Status. Transactions of the Royal Society of Tropical Medicine and Hygiene 84(2):316 21.

[19] Kennedy, P.,(2006). An Analysis of the Relationship Between Water Accessibility, Use and Health in Muthara, Kenya. Michigan Technological University.

[20] Kremer, M., J. Leino, E. Miguel, and A. Zwane. (2006). Spring Cleaning: Results from a Randomized Impact Evaluation of a Source Water Quality Improvement. Berkeley: University of California.

[21] Luby, S., M. Agboatwalla, J. Painter, A. Altaf, W. Billhimer, B. Keswick, and R. Hoekstra. (2006). Combining Drinking Water Treatment and Hand Washing for 
Diarrhea Prevention: A Cluster Randomized Control Trial. Tropical Medicine and International Health 11(4):479 89.

[22] Ofcansky, Thomas P. (1995). Uganda: Tarnished Pearl Of Africa (Nations of the Modern World: Africa), Westview Press.

[23] Rakai District Local Government. (2006). Rakai District HIV/AIDS Strategic Plan 2006/7-2010/11, Uganda.

[24] Rugumayo, A.I., N. Kiiza and J. Shima. (2003). Rainfall Reliability for Crop Production: A Case Study in Uganda. Diffuse Pollution Conference Dublin 2003.

[25] UNICEF. Uganda Statistics (2009).

http://www .unicef.org/infobycountry/uganda_statistics.html

Last Accessed August 6, 2009.

[26] USAID Uganda (2008). Moving from Subsistence to Commercial Farming in Uganda: Agricultural Productivity Enhancement Program Final Report.

[27] WELL 1998, Guidance manual on water supply and sanitation programmes, WEDC, Loughborough, UK.

[28] Zwane, A.P., and M. Kremer. (2007). What Works in Fighting Diarrheal Diseases in Developing Countries? A Critical Review, The World Bank Research Observer Advance Access. 
Appendix A

\title{
Rainwater-Harvesting Baseline
}

\author{
Survey
}




\section{QUESTIONNAIR FOR BASELINE FOR RAINWATER HARVESTING PROJECT JANUARY 2008}

\section{Introduction}

My names are .......... I am working with ........ NGO. I am collecting data on water and sanitation status in the community. The findings will b used by the subcounty, districts and donors in planning for water and sanitation in this community.

I request to ask you a few questions regarding water and sanitation in your household and the community in general. Your responses will be treated with confidentiality and in making the report, names will not be mentioned. You are free not to answer any question. Thank you in advance. You may ask any questions or clarifications before we start.

\section{SECTION 1: SOCIO-ECONOMIC BACKGROUND OF THE RESPONDENT}

1.1 Name of the household head ..........

1.2 Sex of the head of household?

1.3 Age?

1.4 Level of education?

1. Primary

2. Secondary

3. Post secondary

4. Never went to school

1.5 Occupation of the head of household?

1.6 Occupation of the head of household?

1. Farmer

2. Business person

3. Civil Servant

4. Others (specify)

1.7 Number of persons who live in the household? Men .Women .......Girls.... Boys...... Disabled ...

1.8 Type of main dwelling house?

1. Hut

2. Semi- permanent (iron roofed mud and wattle)

3. Permanent (brick house with iron roof)

4. Others (specify) 
1.9 For iron roofed houses, estimate the number of iron sheets used?................

1.10 If the house is iron roofed, measure the length ..........and width ............(in feet)

\section{SECTION 2: WATER USE IN THE HOUSEHOLD?}

2.1 From which water sources do you fetch water for domestic use?

1. Borehole

2. Rainwater harvesting tank

3. Spring

4. Tap

5. Unprotected water sources

2.2 From which source do you normally fetch water for drinking?

1. Borehole

2. Rainwater harvesting tank

3. Spring

4. Tap

5. Unprotected water sources

2.3 If you have a rainwater harvesting tank, how many jerrycans of water does it hold?........

2.4 How far is the water source from your household ..... km

2.5 How much time does it take you to go and come back from fetching water?..........

2.6 How many jerrycans of water does your household use in a day?.

2.7 Who fetches the water in the household?

1. Man

2. Woman

3. Girls

4. Boys

5. All the above

6. Others (specify)

2.8 What do you use the water for in the household?

2.9 Does the water source dry up during the dry season?

1. Yes

2. No

2.10 If yes, what distance do you travel to collect water during the dry season? ........km 
2.11 How much time do you take to fetch water during the dry season?

2.12 It you have a rainwater harvesting facility, how did you acquire it?

2.13 If you have a rainwater harvesting facility;

(i) Who pays for its maintenance?

(ii) Where do you get spare parts?

2.14 If there was a project to provide rainwater harvesting tanks; Would you be willing to contribute?

Yes

No

2.15 If yes what will you be willing to contribute? (i) Money (ii) Sand (iii) Aggregate (iv) transport (v) Others (specify)

2.16 If no why?

2.17 What is the average length of dry season in this area? Months

\section{SECTION 3 SAFE WATER CHAIN}

3.1 Check whether the water collection containers are clean?

Yes

No

3.2 Ask and if possible check whether drinking water is stored in a separate container? Yes

No

3.3 If the household has a rainwater harvesting tank, check if it is clean? Yes

No 


\section{SECTION 4: SANITATION AND HYGIENE}

4.1 Go and Observe the presence of the following sanitation and hygiene facilities;

\begin{tabular}{|l|l|}
\hline Facilities & Tick or cross \\
\hline No latrine? & \\
\hline Has Latrine? & \\
\hline Latrine has pit only? & \\
\hline $\begin{array}{l}\text { Latrine has pit, superstructure } \\
\text { only? }\end{array}$ & \\
\hline $\begin{array}{l}\text { Latrine has superstructure and } \\
\text { roof? }\end{array}$ & \\
\hline Is the latrine floor firm? & \\
\hline \begin{tabular}{l} 
Latrine has slab/sanplat? \\
\hline Is the latrine maintained clean?
\end{tabular} & \\
\hline $\begin{array}{l}\text { Latrine has hand washing } \\
\text { facilities next to it? }\end{array}$ & \\
\hline $\begin{array}{l}\text { Hand washing facility has water } \\
\text { and it is used? }\end{array}$ & \\
\hline $\begin{array}{l}\text { There is soap or hand washing } \\
\text { after latrine use? }\end{array}$ & \\
\hline Household has dish drying rack? & \\
\hline Household has garbage pit? & \\
\hline Household has bath shelter? & \\
\hline Household has kitchen? & \\
\hline Separate shelter for animals? & \\
\hline
\end{tabular}

4.2 Do members of the households wash their hands after latrine use?

4.3 Do you use soap to wash hands after latrine use? Yes No 


\section{SECTION 5: PREVALENCE OF WATER AND SANITATION RELATED DISEASES}

5.1 Did any member of you household suffer from diarrheal diseases in the last 3 months?

6.2 If yes, how many members suffered?

What do you thank caused Diarrhoeal?

In the last one year, have you lost any member of the household due to diarrhoeal related disease?.

THANK 
Appendix B

What Works Best Survey 


\section{Part I Diarrhoea Questions (Goal 2)}

Household head name: RHSP Reference Num:

Number of household members: Number of children under 5 yrs:

In the past 3 months how many of the under-5 children have fallen sick?

What symptoms/sickness did those children have?

What do you think caused that sickness?

Did you go for treatment?

If so, where and what was the treatment?

In the past 3 months how many times have your under-5 year old children had diarrhoea?

What do you think caused that diarrhoea?

Part II Additional Questions to be asked about water and sanitation situation. (Goal 1)

IIa. Shallow Wells (Objective 1a)

From what source do you most often get your water?

How far is it in metres? How long does it take to fetch water?

Why from that source?

How many 20L jerry-cans do you use everyday?

IIb. Latrines (Objective 1b)

Do you have a latrine? yes no

Floor Covering: not covered wood cement other

Superstructure: none temporary mud/waddle and iron roof brick and iron roof

Cleanliness (1-8 scale):

Is the latrine hole covered? yes no

IIc. Water Filters (Objective 1d) 
Do you treat your water? If so, how?

If not, why not?

How do you store/serve your water?

IId. Hand Washing (Objective 1c)

Do you have a hand-washing facility? yes no

Do you use soap for washing hands? yes no

Do you wash your hands:

\begin{tabular}{|l|l|l|}
\hline & Yes/No & With Soap? \\
\hline Before feeding your babies? & & \\
\hline After defecating? & & \\
\hline Before eating? & & \\
\hline After cleaning babies bottom? & & \\
\hline
\end{tabular}

IIe. Health Education (Objective 1f)

What can cause diarrhoea?

How can you prevent your babies from getting diarrhoea?

Does your house have a(n):

\begin{tabular}{|l|l|l|l|l|l|}
\hline Rubbish Pit & Bathroom & Drying Rack & $\begin{array}{l}\text { Clean } \\
\text { Water } \\
\text { Container }\end{array}$ & $\begin{array}{l}\text { Compound } \\
\text { Cleanliness } \\
(1-6 \text { Scale })\end{array}$ & $\begin{array}{l}\text { Covered and } \\
\text { sanitary } \\
\text { drinking } \\
\text { water } \\
\text { container } \\
\text { with cup? }\end{array}$ \\
& & & & & \\
\hline & & & & & \\
\hline
\end{tabular}

* Note that Objective 1f will be measured by IIa-IIe. 
Appendix C

Community Contract 


\section{Contract for Latrine Slab Construction}

\section{Open Palm COWESER/Rakai Health Sciences Program/Michigan Technological University}

\section{"What Works Best in Diarrheal Disease Prevention?"}

This agreement, signed on is between the community of herein referred to as the 'community' and Mr. Jonathan Mellor an employee of Open Palm COWESER and project manager for the project entitled "What Works Best in Diarrheal Disease Prevention?"

Mr. Mellor agrees to assist the community with the fabrication of latrine slabs for households with children under five. The number of slabs available will depend on funding and community willingness to participate, but will likely be around

\section{Roles and Responsibilities}

Mr. Mellor and his Representatives

- Will train 3-5 masons in latrine slab construction.

- Will provide all non-locally available materials for construction.

- Periodically visit households to assure they all have covers and are well cared for.

- Coordinate fabrication activities along with the latrine committee.

The Community

- Will form a 6 to 8 member Sanitation Committee whose composition will have gender, age and socio-economically balance.

- Making a list of the recipient households.

- Assure that poor households or households without young men are not left behind because they can't dig their holes.

- Find a suitable place for slab construction and a dry place to keep materials (i.e. cement).

- Provide lunch for the masons during training.

- Help coordinate slab construction activities and materials.

- Keep a list of households needing latrines, those ready for a latrine slab and the mason who completed each one.

- Inform masons when holes are ready to receive their slabs.

- Help account for materials.

- Encourage households to construct well-built superstructures.

- Assure that all households keep their latrines clean.

- Be primary contact persons between COWESER and the latrine users. 
- Will assist COWESER team finding and transporting any locally available materials.

- The well recipients:

a. Shall have dug their holes by November $15^{\text {th }}$

b. Commit to keeping their latrine slab clean, free of flies, covered and have wiping materials nearby.

- Provide a solidly-built superstructure.

Acceptance and Seal by Signature

Project Manager: Mr. Jonathan Mellor

Mr. Mellor's Signature:

Date:

LC1 Chairperson:

LC1 Chairperson's Signature:

Date:

Sanitation Committee Chairperson:

Sanitation Chairperson's Signature:

Date: 
Appendix D

Copyright 
ELSEVIER LICENSE

TERMS AND CONDITIONS

Jul 28, 2009

This is a License Agreement between Jonathan E Mellor ("You") and Elsevier ("Elsevier") provided by Copyright Clearance Center ("CCC"). The license consists of your order details, the terms and conditions provided by Elsevier, and the payment terms and conditions.

All payments must be made in full to CCC. For payment instructions, please see information listed at the bottom of this form.

Supplier

Registered Company Number

Customer name

Customer address

Elsevier Limited

The Boulevard, Langford

Lane

Kidlington,Oxford, OX5

1GB,UK

1982084

Jonathan E Mellor

2501 Brighton Ct.

Vienna, VA 22903

License Number

2237990779399

License date

Jul 28, 2009

Licensed content publisher

Elsevier

Licensed content publication

The Lancet Infectious

Diseases

Licensed content title

Water, sanitation, and

hygiene interventions to

reduce diarrhoea in less

developed countries: a

systematic review and

meta-analysis

Licensed content author

Lorna Fewtrell, Rachel B

Kaufmann, David Kay,

Wayne Enanoria, Laurence Haller and John M Colford Jr

Licensed content date

January 2005

Volume number

5

Issue number

1

Pages

11

Type of Use

Thesis / Dissertation 
Rightslink Printable License

Portion

Portion Quantity

Format

You are an author of the Elsevier article

Are you translating?

Number of languages

Languages

Order Reference Number

Expected publication date

Elsevier VAT number

Permissions price

Value added tax $0.0 \%$

Total

Terms and Conditions
https://s100.copyright.com/App/PrintableLicenseFrame.jsp?pub...

Figures/table/illustration
/abstracts
2
Both print and electronic
No
Yes
1
Aug 2009
GB 494627212
0.00 USD
0.00 USD
0.00 USD
/abstracts

Both print and electronic

No

Yes

\section{INTRODUCTION}

1. The publisher for this copyrighted material is Elsevier. By clicking "accept" in connection with completing this licensing transaction, you agree that the following terms and conditions apply to this transaction (along with the Billing and Payment terms and conditions established by Copyright Clearance Center, Inc. ("CCC"), at the time that you opened your Rightslink account and that are available at any time at http://myaccount.copyright.com).

\section{GENERAL TERMS}

2. Elsevier hereby grants you permission to reproduce the aforementioned material subject to the terms and conditions indicated.

3. Acknowledgement: If any part of the material to be used (for example, figures) has appeared in our publication with credit or acknowledgement to another source, permission must also be sought from that source. If such permission is not obtained then that material may not be included in your publication/copies. Suitable acknowledgement to the source must be made, either as a footnote or in a reference list at the end of your publication, as follows:

"Reprinted from Publication title, Vol /edition number, Author(s), Title of article / title of chapter, Pages No., Copyright (Year), with permission from Elsevier [OR APPLICABLE SOCIETY COPYRIGHT OWNER]." Also Lancet special credit - "Reprinted from The Lancet, Vol. number, Author(s), Title of article, Pages No., Copyright (Year), with permission from Elsevier."

4. Reproduction of this material is confined to the purpose and/or media for which 
permission is hereby given.

5. Altering/Modifying Material: Not Permitted. However figures and illustrations may be altered/adapted minimally to serve your work. Any other abbreviations, additions, deletions and/or any other alterations shall be made only with prior written authorization of Elsevier Ltd. (Please contact Elsevier at permissions@elsevier.com)

6. If the permission fee for the requested use of our material is waived in this instance, please be advised that your future requests for Elsevier materials may attract a fee.

7. Reservation of Rights: Publisher reserves all rights not specifically granted in the combination of (i) the license details provided by you and accepted in the course of this licensing transaction, (ii) these terms and conditions and (iii) CCC's Billing and Payment terms and conditions.

8. License Contingent Upon Payment: While you may exercise the rights licensed immediately upon issuance of the license at the end of the licensing process for the transaction, provided that you have disclosed complete and accurate details of your proposed use, no license is finally effective unless and until full payment is received from you (either by publisher or by CCC) as provided in CCC's Billing and Payment terms and conditions. If full payment is not received on a timely basis, then any license preliminarily granted shall be deemed automatically revoked and shall be void as if never granted. Further, in the event that you breach any of these terms and conditions or any of CCC's Billing and Payment terms and conditions, the license is automatically revoked and shall be void as if never granted. Use of materials as described in a revoked license, as well as any use of the materials beyond the scope of an unrevoked license, may constitute copyright infringement and publisher reserves the right to take any and all action to protect its copyright in the materials.

9. Warranties: Publisher makes no representations or warranties with respect to the licensed material.

10. Indemnity: You hereby indemnify and agree to hold harmless publisher and CCC, and their respective officers, directors, employees and agents, from and against any and all claims arising out of your use of the licensed material other than as specifically authorized pursuant to this license.

11. No Transfer of License: This license is personal to you and may not be sublicensed, assigned, or transferred by you to any other person without publisher's written permission.

12. No Amendment Except in Writing: This license may not be amended except in a writing signed by both parties (or, in the case of publisher, by CCC on publisher's behalf).

13. Objection to Contrary Terms: Publisher hereby objects to any terms contained in any purchase order, acknowledgment, check endorsement or other writing prepared by you, which terms are inconsistent with these terms and conditions or CCC's Billing and Payment terms and conditions. These terms and conditions, together with CCC's Billing and

Payment terms and conditions (which are incorporated herein), comprise the entire agreement between you and publisher (and CCC) concerning this licensing transaction. In the event of any conflict between your obligations established by these terms and conditions and those established by CCC's Billing and Payment terms and conditions, these 
terms and conditions shall control.

14. Revocation: Elsevier or Copyright Clearance Center may deny the permissions described in this License at their sole discretion, for any reason or no reason, with a full refund payable to you. Notice of such denial will be made using the contact information provided by you. Failure to receive such notice will not alter or invalidate the denial. In no event will Elsevier or Copyright Clearance Center be responsible or liable for any costs, expenses or damage incurred by you as a result of a denial of your permission request, other than a refund of the amount(s) paid by you to Elsevier and/or Copyright Clearance Center for denied permissions.

\section{LIMITED LICENSE}

The following terms and conditions apply to specific license types:

15. Translation: This permission is granted for non-exclusive world English rights only unless your license was granted for translation rights. If you licensed translation rights you may only translate this content into the languages you requested. A professional translator must perform all translations and reproduce the content word for word preserving the integrity of the article. If this license is to re-use 1 or 2 figures then permission is granted for non-exclusive world rights in all languages.

16. Website: The following terms and conditions apply to electronic reserve and author websites:

Electronic reserve: If licensed material is to be posted to website, the web site is to be password-protected and made available only to bona fide students registered on a relevant course if:

This license was made in connection with a course,

This permission is granted for 1 year only. You may obtain a license for future website posting,

All content posted to the web site must maintain the copyright information line on the bottom of each image,

A hyper-text must be included to the Homepage of the journal from which you are licensing at http://www.sciencedirect.com/science/journal/xxxxx or, for books, to the Elsevier homepage at http://www.elsevier.com

Central Storage: This license does not include permission for a scanned version of the material to be stored in a central repository such as that provided by Heron/XanEdu.

17. Author website for journals with the following additional clauses:

All content posted to the web site must maintain the copyright information line on the bottom of each image, and

The permission granted is limited to the personal version of your paper. You are not allowed to download and post the published electronic version of your article (whether PDF or HTML, proof or final version), nor may you scan the printed edition to create an electronic version

A hyper-text must be included to the Homepage of the journal from which you are licensing at http://www.sciencedirect.com/science/journal/xxxxx,

Central Storage: This license does not include permission for a scanned version of the material to be stored in a central repository such as that provided by Heron/XanEdu.

18. Author website for books with the following additional clauses: 
Authors are permitted to place a brief summary of their work online only.

A hyper-text must be included to the Elsevier homepage at http://www.elsevier.com.

All content posted to the web site must maintain the copyright information line on the bottom of each image

You are not allowed to download and post the published electronic version of your chapter, nor may you scan the printed edition to create an electronic version.

Central Storage: This license does not include permission for a scanned version of the material to be stored in a central repository such as that provided by Heron/XanEdu.

19. Website (regular and for author): A hyper-text must be included to the Homepage of the journal from which you are licensing at http://www.sciencedirect.com/science/journal Lxxxx or, for books, to the Elsevier homepage at http://www.elsevier.com.

20. Thesis/Dissertation: If your license is for use in a thesis/dissertation your thesis may be submitted to your institution in either print or electronic form. Should your thesis be published commercially, please reapply for permission. These requirements include permission for the Library and Archives of Canada to supply single copies, on demand, of the complete thesis and include permission for UMI to supply single copies, on demand, of the complete thesis. Should your thesis be published commercially, please reapply for permission.

21. Other conditions: None

v1.5

Gratis licenses (referencing $\$ 0$ in the Total field) are free. Please retain this printable license for your reference. No payment is required.

If you would like to pay for this license now, please remit this license along with your payment made payable to "COPYRIGHT CLEARANCE CENTER" otherwise you will be invoiced within $\mathbf{3 0}$ days of the license date. Payment should be in the form of a check or money order referencing your account number and this license number 2237990779399.

If you would prefer to pay for this license by credit card, please go to http://www.copyright.com/creditcard to download our credit card payment authorization form.

Make Payment To:

Copyright Clearance Center

Dept 001

P.O. Box 843006

Boston, MA 02284-3006

If you find copyrighted material related to this license will not be used and wish to cancel, please contact us referencing this license number 2237990779399 and noting the reason for cancellation.

Questions? customercare@copyright.com or +1-877-622-5543 (toll free in the US) or +1-978-646-2777. 